\title{
6 Stimmen der Gegenwart: Existentialistische Literatur
}

\author{
Laßt uns die \\ unbeantworteten Briefe an das Gestern vergessen! \\ Die Zeit tut Wunder. Kommt sie uns aber unrecht, \\ mit dem Pochen der Schuld: wir sind nicht zu \\ Hause. \\ Ingeborg Bachmann, „Herbstmanöver“. \\ Aus meinem Schulheft \\ Jahrgang neunzehnhunderteinundfünfzig \\ zweite Klasse Volksschule \\ Diktat: \\ Der Krieg hat vieles zerstört \\ was uns hoch und heilig war. \\ Unsere Ideale \\ und unsere Häuser \\ lagen in Trümmern. \\ Doch wir verzagten nicht. \\ Mit frohem Mut \\ und fleißigen Händen \\ machten wir uns \\ an den Wiederaufbau. \\ Heute sind wir wieder stolz \\ auf unser Heimatland. \\ Fehler: Null. \\ Äußere Form der Arbeit: Eins. \\ Peter Turrini, Ein paar Schritte zurück.
}

\subsection{Verflechtungen: Kafka und der neue Kanon}

Der Hybridität des Existentialismus gemäß stehen in seiner Ahnenreihe neben Philosophen (Descartes, Hegel, Husserl, Heidegger) und Philosophen mit ausgeprägt literarischen Qualitäten (Kierkegaard, Nietzsche) vor allem LiteratInnen, deren Werk über einen philosophischen oder philosophierbaren Gehalt verfügt, darunter etwa die amerikanischen ModernistInnen (cf. Kap. 5.2), Fjodor Dostojewski und Franz Kafka, der in Studienzeiten selbst mit der deutschsprachigen Phänomenologie in Berührung kommt und der nach $1945 \mathrm{zu}$ einem wichtigen Bindeglied bei der Existentialismus-Aufnahme in Österreich wird. 
Vom Verlag Gallimard, durch die Mitarbeit Bernard Groethuysens auf den Import deutschsprachiger Moderne spezialisiert, wird Sartres erster Roman $L a$ Nausée (1938) als literarische Metaphysik („métaphysique littéraire“11) von Anfang an mit Verweis auf Kafka, den metaphysischen Schriftsteller schlechthin („romancier métaphysicien par excellence“²), vermarktet. Schon als Sartre im April 1937 mit dem Manuskript und drei Erzählungen in den Händen bei der Gallimard zugehörigen Literaturzeitschrift Nouvelle Revue Française vorstellig wird, macht ihn der später zum Redaktionsteam der Temps modernes gehörende Jean Paulhan auf die Ähnlichkeit aufmerksam: er könne Sartre, trotz aller Differenzen, in der modernen Literatur nur mit Kafka vergleichen (,[i]l me disait pendant ce temps-là: ,Connaissez-vous Kafka? Malgré les différences, je ne vois que Kafka à qui je puisse comparer cela dans la littérature moderne ““33). Die frühe Einschätzung gerät bald zum Standard-Vergleich. Noch vor Camus, der im Oktober 1938 in Alger républicain auf die Verwandtschaft Sartres mit Kafka („la parenté de M. Sartre avec un auteur qu'on n'a pas [sauf erreur] cité à propos de la Nausée, je veux dire Franz Kafka““4) hinweist, macht Paul Nizan in der Tageszeitung Ce soir aus seinem alten Schulfreund kraft dessen Fähigkeit, das Entsetzen bestimmter geistiger Situation auszudrücken („en vertu du don

1 Assouline: Gaston Gallimard, S. 258. Die Epoche habe aus ihnen allen „metaphysische Schriftsteller“ („des écrivains métaphysiciens“) gemacht, erläutert Sartre den Schreibstil seiner Generation, und mit Metaphysik sei „keine sterile Diskussion über abstrakte Begriffe, die der Erfahrung entgehen“ (,une discussion stérile sur des notions abstraites qui échappent à l'expérience“), gemeint, sondern „eine lebendige Bemühung, das Menschsein in seiner Totalität von innen zu umfassen“ (,un effort vivant pour embrasser du dedans la condition humaine dans sa totalité“). Sartre: Was ist Literatur?, S. 171. (Sartre: Qu'est-ce que la littérature?, S. 222.) 2 Bourdieu: Les Règles de l'art, S. 346. Cf. dazu den zuerst als Vorwort von Franz Kafkas Description d'un combat (Paris 1946) veröffentlichten Text „Phénoménologie de Kafka“ von Bernard Groethuysen. In: Groethuysen: Mythes et portraits. Avant-propos de Philippe Delpuech, préface de Jean Paulhan. Paris 1997 [1947], S. 119-129. Ungeachtet dessen, dass es einen fundamentalen Unterschied zwischen der Denkweise von PhilosophInnen und von RomanschriftstellerInen gibt („une différence fondamentale entre la façon de penser d'un philosophe et celle d'un romancier“), wie Milan Kundera einst im Hinblick auf Kafka formuliert (L’Art du roman [Paris 1986], S. 97), ist es laut Deiters (Literatur, S. 159) „umstritten und zweifelhaft“, inwieweit sich Kafkas „um die Themenkomplexe radikaler Vereinzelung und Schuld als principium individuationis kreisende Romane und Erzählungen [...] dem existenzialistischen Paradigma zurechnen lassen“. Cf. dazu auch Dorothea Lauterbach: „Unbewaffnet ins Gefecht“ - Kafka im Kontext der Existenzphilosophie. In: Engel und Lampig (Hg.): Franz Kafka und die Weltliteratur. Göttingen 2006, S. 305-325.

3 Sartre: Lettres au Castor, S. 114.

4 Camus: „La Nausée“ de Jean-Paul Sartre. In: Camus: Essais. Introduction par Roger Quilliot, édition établie et annotée par Roger Quilliot et Louis Faucon. Paris 1965, S. 1417-1419, hier S. 1418. [Zuerst in: Alger républicain, 20.10.1938.] 
qu'il a d'exprimer l'horreur de certaines situations intellectuelles“), bereits „un Kafka français“5. Grundlage für das Inbezugsetzen ist für Peter Zima die erstmalige Darstellung einer Wirklichkeit, „die alle gesellschaftlichen Sinngebungen und Wertsetzungen negiert, eine Wirklichkeit, in der auch die ,Innerlichkeit‘ und das Unbewußte gleichgültig sind“6. Hinzu kommt die Schlichtheit von Kafkas Stil, der, mit einem Wort Michael Hamburgers, frei „of all the paraphernalia of bourgeois decorum“7 etwa eines Thomas Mann ist. Schildern Sartre und Kafka mit Roquentin (La Nausée) und Josef K. (Der Process, 1925) Helden, denen ihr gewohntes Leben binnen kurzer Zeit entgleitet, geht Kafka im Moment der Entfremdung - in seiner auch in L'Être et le Néant aufgegriffenen „Beschreibung unseres Innerweltlich-seins-für-Andere“8 (,description de notre être-au-milieu-dumonde-pour-autrui “99) - über Sartre hinaus, so Beauvoir:

Die Erlebnisse K.s waren ganz anders - viel extremer und auswegloser - als die Antoine Roquantins [!]. In beiden Fällen jedoch schaffte der Held sich so viel Distanz zu seiner gewohnten Umwelt, daß für ihn die menschliche Ordnung zusammenbrach und er einsam in unheimlichem Dunkel dahinvegetierte. ${ }^{10}$

(L'aventure de $\mathrm{K}$... était très différente - beaucoup plus extrême et plus désespérée - que celle d'Antoine Roquantin [!]; mais, dans les deux cas, le héros prenait, par rapport à ses entours familiers, une distance telle que pour lui l'ordre humain s'effondrait et qu'il sombrait solitairement dans d'étranges ténèbres. $)^{11}$

Le Procès, dem die französische Kritik bei Erscheinen 1933 wenig Aufmerksamkeit schenkt und beispielsweise klar Hans Fallada vorzieht, sei für sie und Sar-

5 Paul Nizan: La Nausée, un roman de M. Jean-Paul Sartre. In: Ce soir, 15.05.1938. Allerdings sieht er Sartres Werk im Gegensatz zu jenem Kafkas als „moralischen Fragen vollkommen fremd. Kafka hat sich immer über den Sinn des Lebens Gedanken gemacht, Herr Sartre nur über die Tatsache der Existenz, welche eine viel unmittelbarere Art von Realität ist als die menschliche und soziale Ausgestaltung des Lebens, welche unterhalb des Lebens liegt.“ [Übers. d. Verf.] (,[...] entièrement étrangère aux problèmes moraux. Kafka s’est toujours interrogé sur le sens de la vie, $M$. Sartre ne s'interroge que sur le fait de l'existence, qui est un ordre de réalité beaucoup plus immédiat que les élaborations humaines et sociales de la vie, qui est en deça de la vie.“)

6 Peter V. Zima: Der gleichgültige Held. Textsoziologische Untersuchungen zu Sartre, Moravia und Camus. Trier 2004, S. 187.

7 Michael Hamburger: From Prophecy to Exorcism. The Premisses of Modern German Literature. London 1965, S. 94.

8 Sartre: Das Sein und das Nichts, S. 479.

9 Sartre: L'Être et le Néant, S. 305.

10 Simone de Beauvoir: In den besten Jahren. Deutsch von Rolf Soellner. Reinbek 1987 [1969], S. 160 .

11 Beauvoir: La Force de l'âge, S. 214. 
tre eine ganz besondere Leseerfahrung gewesen (,un des livres les plus rares, les plus beaux que nous ayons lus depuis longtemps““12), erinnert sich Beauvoir, ihre Bewunderung Kafkas sei sofort radikal ausgefallen. Die erwähnte inhaltliche und formale Nähe von Sartres früher Prosa zu jener Kafkas lässt sich darüber hinaus nur bedingt auf direkte Wirkungen zurückführen: Sartres Beschäftigung mit dem Prager Autor intensiviert sich nach Erscheinen von La Nausée und Le Mur mit einer systematischen Lektüre im September 1939, zu Beginn seines Kriegsdienstes. In seinen Carnets de la drôle de guerre bezeichnet er den für ihn hauptsächlich aus Ausharren bestehenden Krieg als kafkaesk (,guerre à la Kafka“13) und seine drei Kollegen als Gehilfen, in Anlehung an Kafkas zweifelhafte Schloss-Gehilfen (,par référence aux Aides ambigus de K.“14). Hier deutet sich an, was Kafka von anderen prägenden AutorInnen wie William Faulkner abhebt, die Sartre und Beauvoir ferne Geschichten („de lointaines histoires“) erzählten; Kafkas Werk hingegen betreffe sie persönlich, spreche von ihnen und enthülle ihnen ihre Probleme in einer Welt ohne Gott („Kafka nous parlait de nous; il nous découvrait nos problèmes, en face d'un monde sans Dieu“"15). Auf dieser gemeinsamen Grundlage einer absurden conditio humana tragen die existentialistischen SchriftstellerInnen schließlich zur Verbreitung und zum Erfolg Kafkas bei („le succès que nous avons fait aux œuvres de Kafka“), wie Sartre in Qu'est-ce que la littérature? behauptet:

Über Kafka ist alles gesagt worden: daß er die Bürokratie, die Fortschritte der Krankheit, die Lage der osteuropäischen Juden, die Suche nach der unzugänglichen Transzendenz, die Welt der Gnade, wenn die Gnade fehlt, beschreiben wollte. All das ist wahr, ich würde sagen, daß er das Menschsein hat beschreiben wollen. Aber für uns war besonders spürbar, daß in diesem ständig ablaufenden Prozeß, der jäh und schlecht endet, dessen Richter unbekannt und unerreichbar sind, in den müßigen Anstrengungen der Angeklagten, die

12 Beauvoir: La Force de l'âge, S. 214. In Bezug auf das literarische Vorausweisen Kafkas (und des in dieser Hinsicht mit ihm verglichenen Thomas Bernhard) schreibt Ingeborg Bachmann: „Wie sehr diese Bücher die Zeit zeigen, was sie gar nicht beabsichtigen, wird eine spätre erkennen [...]. In diesen Büchern ist alles genau, von der schlimmsten Genauigkeit, wir kennen nur die Sache noch nicht, die hier so genau beschrieben wird, also uns selber nicht.“ Bachmann: [Thomas Bernhard:] Ein Versuch. Entwurf. In: Bachmann: Werke, Bd. 4: Essays, Reden, Vermischte Schriften, Anhang. Hg. von Christine Koschel, Inge von Weidenbaum und Clemens Münster. München, Zürich 1978, S. 361-362, hier S. 361f. Zahlreich sind in der Folgegeneration die AutorInnen, die wie Wolfgruber, Rosei oder Ransmayr „Trost“ in Kafkas „Erzählungen vollendeter Geschichten“ finden. Christoph Ransmayr: Die Erfindung der Welt. Fragen, Antworten. In: Ransmayr: Die Verbeugung des Riesen. Vom Erzählen. Frankfurt am Main 2003, S. 15-22, hier S. 20.

13 Sartre: Carnets de la drôle de guerre, S. 35.

14 Elkaïm-Sartre. In: Sartre: Carnets de la drôle de guerre, S. 35.

15 Beauvoir: La Force de l'âge, S. $214 \mathrm{f}$. 
Anklagepunkte zu erfahren, in dieser geduldig aufgebauten Verteidigung, die sich gegen den Verteidiger kehrt und zur Belastung wird, in jener absurden Gegenwart, die die Figuren mit Eifer erleben und deren Schlüssel woanders sind, wir die Geschichte und uns selbst in der Geschichte wiedererkannten. ${ }^{16}$

(De Kafka on a tout dit: qu'il voulait peindre la bureaucratie, les progrès de la maladie, la condition des Juifs en Europe orientale, la quête de l'inaccessible transcendance, le monde de la grâce quand la grâce fait défaut. Tout cela est vrai, je dirai qu'il a voulu décrire la condition humaine. Mais ce qui nous était particulièrement sensible, c'est que, dans ce procès perpétuellement en cours, qui finit brusquement et mal, dont les juges sont inconnus et hors d'atteinte, dans les efforts vains des accusés pour connaître les chefs d'accusation, dans cette défense patiemment échafaudée qui se retourne contre le défenseur et figure parmi les pièces à charge, dans ce présent absurde que les personnages vivent avec application et dont les clés sont ailleurs, nous reconnaissions l'Histoire et nous-mêmes dans l'Histoire.) $)^{17}$

Die Universalität von Kafkas Situationen - von Sartre einst dahingehend zugespitzt, dass man auch in Guinea das eigene Unbehagen in Kafka wiederfinden könnte (,[e]n Guinée je pourrais lire Kafka. Je retrouve en lui mon malaise“18) führt zu einer Vielzahl von Beanspruchungen; sie macht ihn zum „Auskunftsbüro"19 für alle Belange. Was an den diversen von Adorno angeführten Einreihungen Kafkas (unter „die Pessimisten“, „die Existentialisten der Verzweiflung“, „die Heilslehrer“ ${ }^{\star 20}$ ) hervorsticht, ist die Vereinnahmung durch mehr oder minder entgegengesetzte Interessensgruppen. Diese Tendenz ist in Österreich klar erkennbar,

16 Sartre: Was ist Literatur?, S. 175.

17 Sartre: Qu'est-ce que la littérature?, S. $226 \mathrm{f}$.

18 Sartre: Je ne suis pas désespéré et ne renie pas mon œuvre antérieure. In: Le Monde, 18.04.1964.

19 Theodor W. Adorno: Aufzeichnungen zu Kafka. In: Adorno: Kulturkritik und Gesellschaft 1. Hg. von Rolf Tiedemann. (Gesammelte Schriften 10.1.) Frankfurt am Main ${ }^{2} 1996$, S. 254-287, hier S. 254: „Die Beliebtheit Kafkas, das Behagen am Unbehaglichen, das ihn zum Auskunftsbüro der je nachdem ewigen oder heutigen Situation des Menschen erniedrigt und mit quickem Bescheidwissen eben den Skandal wegräumt, auf den das Werk angelegt ist, weckt Widerwillen dagegen, mitzutun und den kurrenten Meinungen eine sei's auch abweichende anzureihen. [...] Weniges von dem, was über ihn geschrieben ward, zählt; das meiste ist Existentialismus. Er wird eingeordnet in eine etablierte Denkrichtung, anstatt daß man bei dem beharrte, was die Einordnung erschwert und eben darum die Deutung erheischt.“ Aus der Praxis meldet sich Wolfgang Hildesheimer, der sich „einmal mit dem Gedanken trug - wie schließlich jeder sensible Intellektuelle - ein Buch über Kafka zu schreiben“, ihn dann aber verwirft, womöglich aus dem genannten ,Widerwillen dagegen, mitzutun', allerdings auch, weil seine „sämtlichen Bekannten“ keinen Aspekt ununtersucht gelassen hätten. Wolfgang Hildesheimer: Ich schreibe kein Buch über Kafka. In: Hildesheimer: Lieblose Legenden. Frankfurt am Main 1987, S. 18.

20 Adorno: Aufzeichnungen zu Kafka, S. 284. 
wenn den Autor „die Surrealisten und auch die Existentialisten hundertprozentig für sich reklamieren (wenn Kafka das erlebt hätte!)“21, so der bildende Künstler Abu Nif (Arnulf Neuwirth) in der Kulturzeitschrift Plan, in der beide Strömungen Seite an Seite rezipiert werden (cf. Kap. 6.4). ${ }^{22}$ Die Interpretationsoffenheit seiner Literatur macht Kafka hier schnell zu einem passe partout-Autor, beobachtet 1948 der Germanist Peter Demetz:

Surrealisten und Existentialisten, Psychoanalytiker und moderne Theologen wärmen ihre Suppe gleich eifrig am Feuer des Dichters. Sie alle wollen plötzlich mit ihm zu tun haben, alle im rühmlichen Bezirk seines Schattens stehen, alle eine Zeile zur Unterstützung eigener Hypothesen zitieren. Kafkas Werk soll in ein Arsenal von Argumenten für und wider die moderne Intellektualität verwandelt werden: wo die einen das Symbol sehen, sind die zweiten von der Irrationalität geblendet, suchen die dritten nach Elementen eines archaischen Bewußtseins, fragen die vierten nach pathologischen Symptomen. ${ }^{23}$

\section{Gegen den Vorwurf einer simplifizierenden Kafka-Lesart wehren sich Beauvoir und Sartre früh:}

Wir erfaßten sofort, daß man es nicht zur Allegorie reduzieren noch es durch irgendwelche Symbole interpretieren dürfe, daß es vielmehr eine totalitäre Vision der Welt sei. Durch die Verdrehung der Bezüge zwischen Mittel und Zweck stellte Kafka nicht nur den Sinn der Instrumente, der Funktionen, der Rollen, der menschlichen Verhaltensweisen in Frage, sondern das gesamte Verhältnis des Menschen zur Welt. Er entwarf ein phantastisches und unerträgliches Bild, einfach indem er uns die ,Kehrseite‘ zeigte. ${ }^{24}$

(Nous comprîmes tout de suite qu'il ne fallait pas le réduire à une allégorie, ni chercher à travers quels symboles l'interpréter, mais qu'il exprimait une vision totalitaire du monde; pervertissant les relations entre les moyens et les fins, Kafka contestait non seulement le sens des ustensiles, des fonctions, des rôles, des conduites humaines, mais le rapport glo-

21 Abu Nif: Surrealistische Vorposten in Wien. In: Plan 1 (1946/47), Nr. 12, S. 968-969, hier S. 969.

22 Ein Nahverhältnis der französischen SurrealistInnen zu Kafka besteht schon am Beginn der Rezeptionsgeschichte, nachdem vor allem (pro)surrealistische Periodika wie die Cahiers du Sud oder Bifur in den dreißiger Jahren die Frühvermittlung des Autors nach Frankreich leisten.

23 Peter Demetz: Zur Interpretation Franz Kafkas. In: Plan 2 (1948), Nr. 6, S. 370-378, hier S. 370. Das Gewicht der Symbolik in Kafkas Werk betonen fast alle österreichischen Besprechungen, so jene des 1938 in die USA emigrierten Kafka-Experten Heinz Politzer (Der Dichter Franz Kafka. In: Silberboot 2 [1946], Nr. 1, S. 41-42, hier S. 42): „Handlung und Gleichnis, Fabel und Parabel sind in eins verschlungen, Sein und Bedeutung sind unlösbar ineinander verschränkt. Die Simultaneität von Existenz und Symbol - dies ist der Fortschritt, den Franz Kafkas Epik darstellt, zugleich eine Grenze, die nie mehr überschritten, kaum je noch erreicht werden wird.“

24 Beauvoir: In den besten Jahren, S. 160. 
bal de l'homme au monde; il en proposait une image fantastique et insupportable, simplement en nous le montrant à l'envers. $)^{25}$

Die genannten Verkehrungen, Widersprüchlich- und Zwiespältigkeiten in Kafkas Welten stehen ebenfalls für Albert Camus im Vordergrund, wie er anhand der Erzählung Die Verwandlung (1912) ausführt, in der sich der Handlungsreisende Gregor Samsa eines Morgens „,Zu einem ungeheueren Ungeziefer verwandelt“ ${ }^{\star 26}$ sieht:

Die Verwandlung dagegen ist gewiß die entsetzliche Bildfolge einer Ethik der Hellsichtigkeit. Sie ist aber auch das Produkt jenes unberechenbaren Staunens, das der Mensch empfindet, wenn er das Tier spürt, das er mühelos wird. In dieser grundlegenden Zweideutigkeit liegt Kafkas Geheimnis. Dieser ständige Wechsel zwischen Natürlichem und Außergewöhnlichem, zwischen Individuum und Allgemeinem, zwischen Tragik und Alltäglichem, zwischen Absurdem und Logischem geht durch sein ganzes Werk und gibt ihm seine Resonanz und seine Bedeutung. Diese Paradoxa müssen aufgezählt, diese Widersprüche müssen herausgestellt werden, um das absurde Werk zu verstehen. ${ }^{27}$

(La Métamorphose, à son tour, figure certainement l'horrible imagerie d'une éthique de la lucidité. Mais c'est aussi le produit de cet incalculable étonnement qu'éprouve l'homme à sentir la bête qu'il devient sans effort. C'est dans cette ambiguïté fondamentale que réside le secret de Kafka. Ces perpétuels balancements entre le naturel et l'extraordinaire, l'individu et l'universel, le tragique et le quotidien, l'absurde et le logique, se retrouvent à travers toute son œuvre et lui donnent à la fois sa résonance et sa signification. Ce sont ces paradoxes qu'il faut énumérer, ces contradictions qu'il faut renforcer, pour comprendre l'œuvre absurde. $)^{28}$

Camus hängt der zweiten Auflage seines Le Mythe de Sisyphe 1948 die Studie „L'espoir et l'absurde dans l'œuvre de Franz Kafka“ an, die in der Erstausgabe der deutschen Zensur zum Opfer gefallen ist, und zählt Kafka darin zu den ganz nach dem Absurden und seinen Konsequenzen ausgerichteten ExistenzialphilosophInnen und -romanschriftstellerInnen („romanciers et philosophes existentiels, tout entières tournées vers l'absurde et ses conséquences“²9). Stärker noch als Sartre wirkt Camus auf den weiteren Rezeptionsverlauf des Werks Kafkas außerhalb Frankreichs ein. „War es nicht so“, fragt beispielsweise Jean Améry, „daß Kafka erst über Paris und namentlich den ,mediterranen Kafka“,

25 Beauvoir: La Force de l'âge, S. 214 (Hervorhebung im Original).

26 Franz Kafka: Die Verwandlung. Nachwort von Egon Schwarz. Stuttgart 1999, S. 5.

27 Albert Camus: Der Mythos des Sisyphos. Deutsch und mit einem Nachwort von Vincent von Wroblewsky. Reinbek 2000, S. 167.

28 Camus: Le Mythe de Sisyphe, S. 174.

29 Camus: Le Mythe de Sisyphe, S. 183. 
Camus, verspätet und glanzvoll in Deutschland wieder eintraf?“30 Zum „Wortführer“ der „existentialistische[n] Kafka-Mode“ erhebt ihn auch Hans Mayer, der in der deutschen Nachkriegsprosa „ein drolliges Amalgam aus Franz Kafka und Albert Camus“31 erblickt. Ein solches Verschmelzen - „[e]xistentialistische Grenzsituationen frei nach Kafka“"32 - lässt sich in Österreich in dem Jahrbuch Stimmen der Gegenwart (1951-1956) finden, das junge Literatur fördert. In der Erzählung „Das Scheffelhaus“ (1951) des Schriftstellers und Psychologen Walter Toman reißt eine Familie, die aufgrund eines dritten Kindes ein weiteres Zimmer in ihrer Wohnung benötigt, kurzerhand eine Wand zu den benachbarten MieterInnen ein und überwältigt diese. Als weiteres Beispiel wäre Wilhelm Meissels schon im Titel auf Kafka Bezug nehmender Text „Das Urteil“ (1956) zu nennen: Hier sieht sich ein gewisser Herr Vorsicht ohne Bewusstsein von etwaigem Fehlverhalten zum Tode verurteilt, in einem Staat, dessen Einheitspartei die „Verurteilung ohne Anklage“ für den „Idealzustand“33 hält.

Insbesondere die unheimliche Erfahrung willkürlicher Herrschaft in Kafkas Urteilsnarrativen (mehr noch als in Das Urteil selbst in Der Process und in In der Strafkolonie), die in den nationalsozialistischen Konzentrationslagern zur täglich gelebten Wirklichkeit wird, ${ }^{34}$ behält im Kalten Krieg ihre Aussagekraft. ${ }^{35}$ Sie hallt auch bei den ExistentialistInnen nach, in Camus' La Peste zum Bei-

30 Améry: Unmeisterliche Wanderjahre, S. 115. Collins erwähnt als verwandte Entwicklung, dass erst das existentialistische Aufgreifen Kafkas diesen zu einem „publishing phenomenon in the anglophone world of the 1940s and 1950s“ macht. Collins: The Sociology of Philosophies, S. 770 .

31 Mayer: Die umerzogene Literatur, S. 73f. (Hervorhebung im Original).

32 Weber: Stimmen der Gegenwart, eine Anthologie, S. 27.

33 Wilhelm Meissel: Das Urteil. In: Stimmen der Gegenwart, 1956, S. 126-144, hier S. 144.

34 Cf. die Ausführungen von Bruno Bettelheim: Individual and Mass Behavior in Extreme Situations. In: Journal of Abnormal and Social Psychology 38 (1943), S. 417-452, hier S. 417: „The prisoners did not know exactly why they were imprisoned, and never knew for how long. This may explain why we shall speak of the prisoners as persons finding themselves in an ,extreme“ situation.“

35 In der Sowjetunion wird Kafka hartnäckig abgelehnt, trotz Verteidigungsversuchen von prokommunistischen Intellektuellen wie Ernst Fischer (Franz Kafka. In: Sinn und Form 14 [1962], Nr. 4, S. 497-553; sowie Fischer: Entfremdung, Dekadenz, Realismus. In: Sinn und Form 14 [1962], Nr. 5. und 6, S. 816-854) und auf französischer Seite Sartre (Die Abrüstung der Kultur. In: Sinn und Form 14 [1962], Nr. 5. und 6, S. 810-812). Und doch, so Hans Mayer: „Alles vergebens. Man erkannte sich selbst nur allzugut in Franz Kafkas Spiegel.“ Mayer: Gelebte Literatur. Frankfurter Vorlesungen. Frankfurt am Main 1987, S. 92. Cf. dazu auch Michael Rohrwasser: „In Sibirien verstehen wir Kafka besser“. Franz Kafka und der Kalte Krieg. In: Hansel und Rohrwasser (Hg.): Kalter Krieg in Österreich. Literatur - Kunst - Kultur. (Profile 17, 2010.) Wien 2010, S. 153-167. 
spiel, als der Figur Cottard die Lektüre über das Unrecht des Angeklagten Josef K., der bei sich „nicht die geringste Schuld auffinden kann“336, nahegeht:

,Aber ich las in diesem Roman. Da ist so ein armer Kerl, der wird eines Morgens einfach verhaftet. Man kümmerte sich um ihn, und er wußte nichts davon. Man sprach von ihm in den Amtsstuben, man schrieb seinen Namen auf Zettel. Finden Sie das gerecht? Finden Sie, daß man das Recht hat, einem Menschen so etwas anzutun? ${ }^{37}$

(,Mais je lisais ce roman. Voilà un malheureux qu'on arrête un matin, tout d'un coup. On s'occupait de lui et il n'en savait rien. On parlait de lui dans des bureaux, on inscrivait son nom sur des fiches. Vous trouvez que c'est juste? Vous trouvez qu'on a le droit de faire ça à un homme?‘) $)^{38}$

Die Frage erhält Gewicht auch angesichts der um sich greifenden Pest, durch die sich die EinwohnerInnen Orans „eines unbekannten Verbrechens wegen zu einer unvorstellbaren Gefangenschaft verurteilt““39 („,condamnés, pour un crime inconnu, à un emprisonnement inimaginable“40) fühlen.

Nicht wenige Erzählungen in Stimmen der Gegenwart zeugen von einem solchen Verschwinden verlässlicher Kausalitäten, „von der Fremdartigkeit des Lebens, von dem Labyrinth Welt“"41 als verbindende Linie zwischen den Autoren Camus, Sartre und Kafka, die sich teils auch durch direkte Nennung of-

36 Franz Kafka: Der Process. Hg. von Michael Müller. Stuttgart 2014, S. 16. Cf. zur Schuldthematik bei Kafka und Camus das Kapitel „Elders, Institutions and Existential Guilt in the Fiction of Franz Kafka and Albert Camus“ (S. 119-162) in David Tenenbaum: Issues of Shame and Guilt in the Modern Novel. Conrad, Ford, Greene, Kafka, Camus, Wilde, Proust, and Mann. With a Foreword by Adrian S. Wisnicki. Lewinston, Queenston, Lampeter 2009. Cf. auch Wolfgang Kraus (Hg.): Das Schuldproblem bei Franz Kafka. (Schriftenreihe der Franz-Kafka-Gesellschaft 6.) Wien et al. 1995.

37 Albert Camus: Die Pest. Deutsch von Guido G. Meister. Reinbek 1970 [1950], S. 46.

38 Camus: La Peste, S. 59. Eine ebenfalls „Unbehagen“ auslösende fiktive Kafka-Lektüre-Erfahrung bietet Marlen Haushofers Erzählung „Porträt eines alten Mannes“: „Seine Nichte hatte ihm vor einiger Zeit ein Buch geborgt, ein langweiliges, unlesbares Buch, aber ein paar Seiten davon waren ihm in Erinnerung geblieben. Irgendein Mensch verwandelt sich in einen riesen Mistkäfer oder dergleichen. Der Mann, der das Buch geschrieben hatte, mochte ein Narr sein, aber an dieser einen Geschichte war etwas dran. [...] Zwischen fünf und halb sechs Uhr morgens dachte er jetzt häufig an den Kerl, dem diese üble Verwandlung widerfahren war, voll Mitgefühl und Schadenfreude, immer aber wie an einen Schicksalsgefährten. Wurde denn er selber, auf dem Rücken liegend, das Federbett über den Bauch gewölbt, zur Decke starrend, jenem Käfer nicht von Tag zu Tag ähnlicher.“ Marlen Haushofer: Porträt eines alten Mannes. In: Haushofer: Schreckliche Treue [1968]. Hildesheim 1992, S. 176-182, hier S. 177.

39 Camus: Die Pest, S. 60.

40 Camus: La Peste, S. 96.

41 Basil: Stimme der Jugend. In: Plan 1 (1946), Nr. 4, S. 307. 
fenbart, so in Claus Packs „Besuch in Kafkanistan. Parabel in Form einer Parabel“ (1952), in dem das Ich, das eine „Hornbrille à la Sartre“ trägt, in dem wenig durchsichtigen narrativen Geschehen ein „Kontobuch des Josef K.“42 auf einer Parkbank findet. Die Präsenz des Seltsamen, des Fremden, des Abenteuerlichen in der zeitgenössischen Literatur soll laut Lilly von Sauter die LeserInnen aus ihrer Gefühlswelt lösen, diese „sollen das Nichts sehen lernen und die Absurdität, die hinter unserem nach scheinbar prosaischer Norm geführten Dasein steht. “43 Die sich primär auf Camus’ La Peste beziehende Einschätzung steht im Einklang mit der aufrüttelnden Absicht, die Kafka am 27. Jänner 1904 in einem Brief an seinen früheren Mitschüler und Freund Oskar Pollak in Worte fasst:

Wenn das Buch, das wir lesen, uns nicht mit einem Faustschlag auf den Schädel weckt, wozu lesen wir dann das Buch? [...] Wir brauchen aber die Bücher, die auf uns wirken wie ein Unglück, das uns sehr schmerzt, wie der Tod eines, den wir lieber hatten als uns, wie wenn wir in Wälder verstoßen würden, von allen Menschen weg, wie ein Selbstmord, ein Buch muß die Axt sein für das gefrorene Meer in uns. ${ }^{44}$

Ebenso unvergnüglich sollen existentialistische Werke auf ihr Publikum wirken, man wünsche es „,an der Gurgel zu packen“ ${ }^{45}$ („nous souhaitions le prendre à la gorge ${ }^{\text {“46 }}$ ), auf dass es die Dinge neu sehe, fordert Sartre in Qu'est-ce que la litté-

42 Claus Pack: Besuch in Kafkanistan. Parabel in Form einer Parabel. In: Stimmen der Gegenwart, 1952, S. 120-124, hier S. 120, 124. Über diesen Text hinaus finden sich, abweichend von Webers Angabe, in der Anthologie werde aus dem Bereich des Existentialismus „nur einmal ein Name genannt“ (Weber: Stimmen der Gegenwart, eine Anthologie, S. 16), noch mehrere Fälle. Weber führt Andreas Okopenkos Text „Konversation“ an (in: Stimmen der Gegenwart, 1951, S. 18-19), in dem sich das Thema Sartre für das „seit dem letzten Bakterienkrieg“ hustende Ich für ein sich anbahnendes Gespräch anbietet: „Sie gehen heute ins Theater? / Sind Sie nicht auch, gnädige Frau, der Ansicht, daß Jean Paul Sartre einige Schuld am letzten Kriege zuzumessen ist? Sie würden sich gerne mit mir unterhalten darüber? Heute abend, wenn Sie allein sind, sagen Sie?“ Weitere Verweise verschiedenen Umfangs erfolgen unter anderem in Gerhard Fritschs „Der Augenblick der Bedienerin“ (in: Stimmen der Gegenwart, 1952, S. 78-82 [cf. Kap. 6.2]), und in Ingomar Hartners „Die Rechenmaschine“ (in: Stimmen der Gegenwart, 1954, S. 217-220, hier S. 219), in dem es über die seinerzeitige Situation heißt: „Wir bauen alles um: Volk wird Staat, Heimat Aufenthalt, Glaube Existentialismus, Kunst Virtuosität und so fort“.

43 L. v. S.: Porträt unseres Helden. In: Europäische Rundschau 3 (1948), Nr. 17, S. 806-808, hier S. 807.

44 Franz Kafka: An Oskar Pollak [27. Januar 1904]. In: Kafka: Briefe 1902-1924. (Gesammelte Werke, hg. von Max Brod.) Frankfurt am Main 1966, S. 27 f.

45 Sartre: Was ist Literatur?, S. 174.

46 Sartre: Qu'est-ce que la littérature?, S. 226. 
rature? Der geteilte Hang zum Entsetzen bleibt nicht unbemerkt, schon die früheste österreichische Berichterstattung zum „existenziellen Pessimismus“47 Sartres, Ende 1945, setzt ihn mit Kafka in Bezug: „In Sartre und Camus kommt der französische ,Existenzialismus‘ zu vollem Ausdruck, eine Theorie des Pessimismus, die weitläufig von Jaspers, Heidegger, Dostojewsky und Franz Kafka stammt." ${ }^{48}$ Im Wiener Kurier wird der Existentialismus gar als ein Wiederaufleben eines von Kafka geprägten (ergo „österreichischen“) Denkens dargestellt:

Man hat schon von der ,Mode“ der Existenzphilosophie gehört, die sich in Frankreich um den Namen Jean Paul Sartre drängt. Aber nur die Mode ist neu und sensationell. Die Sache spricht sich bereits seit Jahren herum. So erleben wir das Merkwürdige, daß in der geistigen Welt Frankreichs, Englands und Amerikas die Ideen des Österreichers Kafka, der ein dichtender Philosoph war, und des Deutschen Heidegger, der neben Scheler und Jaspers der Hauptvertreter der neuen Existenzphilosophie ist, mit einer Energie debattiert werden, die über das Theoretische weit hinausgeht. ${ }^{49}$

Es ist Sartres „vielleicht nur mit Kafka zu vergleichende mehr-als-realistische [...] Eindringlichkeit“ ${ }^{50}$, die ihm einen Platz in den Nachkriegsperiodika sichert, nicht selten mit dem literarischen Idol in einem Heft. Es überwiegt allerdings in der österreichischen Kafka-Aufnahme bisweilen das phantastisch-groteske Moment, das „im Zeichen einer neuen Beziehung zur Wirklichkeit“ steht, die der Stimmen der Gegenwart-Herausgeber Hans Weigel wie folgt beschreibt:

So wie wir allmählich zu erkennen hatten, daß die „fortschrittliche“ Partei „ganz links“ in Wahrheit die reaktionärste ist, müssen wir auch die als solche bezeichnete „Wirklichkeitsnähe“, die „naturalistische“ Schule, die „realistische“ Darstellungsweise mit Argwohn als äußerste Form der Stabilisierung erkennen lernen. Der Traum, die Utopie, die blutige Satire, der Alpdruck sind heute echter, authentischer, wirklicher als Reportagen und Stenogramme. Die Wochenschau lügt, der unartikulierte Aufschrei stimmt. ${ }^{51}$

47 [P. A. Stephano:] Der Ruf von draußen. I. Die Wiederkehr Franz Kafkas. In: Der Turm 1 (1946), Nr. 6, S. 149-151, hier S. 151.

48 -r.: Frankreich: Die neue Situation. In: Der Turm 1 (1945), Nr. 4/5, S. 111. Auch eine Engführung des Werks Kafkas mit jenem Heideggers ist gelegentlich zu beobachten. Darauf angesprochen, ob er „Kafka, dessen Romane von seiner Philosophie durchdrungen sind“, lese, entgegnet Heidegger 1949 in einem Kulturelles-Interview (Luce-Michèle: Heidegger weigert sich Sartre zu lesen, 21.11.1949): „,Kafka? Nein, von ihm habe ich auch nichts gelesen. Ich warte ständig, dass man mir seine Werke zukommen lässt, um die behauptete Ähnlichkeit unserer Gedanken zu überprüfen ... ‘. ،

49 -n: Zwei Bücher aus Österreich. Zur weltanschaulichen Situation unserer Zeit. In: Wiener Kurier, 28.03.1946.

50 Améry: In die Welt geworfen, S. 193.

51 Hans Weigel: Die gefundene Generation. In: Kontinente 7 (1953), Nr. 1, S. 13-14, hier S. 13. 
Abgesehen von einigen experimentellen Erzählungen (etwa der Autoren Walter Toman, Claus Pack, Anton Hegner und Erich Fried) fallen die von Weigel grundsätzlich „ohne alle politischen, weltanschaulichen und stilistischen Hintergedanken“ ${ }^{52}$ ausgewählten Texte der Anthologie jedoch eher konventionell aus, die jungen BeiträgerInnen (wie Herbert Eisenreich, Hermann Friedl, Marlen Haushofer, Herbert Zand, Karl Bednarik, Milo Dor und Reinhard Federmann) suchen zwar nach neuen Formen, halten aber meist ,an der traditionellen Erzählgrammatik“53 fest. Weber vermutet, dass die generelle „Avantgarde-Feindlichkeit“54 der Stimmen der Gegenwart ihren Grund im Einfluss des dem Surrealismus negativ gegenüberstehenden Existentialismus haben könnte (cf. Kap. 6.4). Die von Weigel erwähnten unartikulierten Aufschreie jedenfalls seien weniger „Bewältigung und Gestaltung der Wirklichkeit“ als Symptome von „Weltangst und Realitätsflucht“, die noch augenfälliger in dem „etwas dünneren Aufguß“ der zweiten Generation würden, so der Journalist Otto F. Beer über die sich ihm darbietende „Scheinwelt“: „Kafka spukt durch diese Seiten. “55 Für bedenklich hält in den Stimmen der Gegenwart selbst Hans Heinz Hahnl diesen Trend der auch von Sartre abgelehnten Kafka-Imitationen: ${ }^{56}$

So gibt es heute, wie es vor 150 Jahren eine Wertherkrankheit gab, eine Kafka- und Orwell-
seuche. Viele junge Autoren - auch sehr begabte und solche, die fähig sind, einen erlebten
Gedanken so auszusprechen, daß ihn ein anderer neu erleben kann - verfallen der Versu-
chung, ihre Skepsis, ihre Verlorenheit und Weltangst à la Kafka und Orwell auszusprechen,
in deren Werk, Kafkas vor allem, [...] sie sich wiederzuerkennen glauben. [...] In der Nach-
ahmung gewisser nihilistischer und pessimistischer Schilderungen eines Kafka oder Orwell
[...] entsteht wie bei jeder Nachahmung ein Automatismus. Angst um der Angst willen,

52 Hans Weigel: Vorbemerkung. In: Stimmen der Gegenwart, 1953, S. 5-6, hier S. 5.

53 Kriegleder: Die Literatur der fünfziger Jahre in Österreich, S. 39, 46. Dies gilt umso mehr für die älteren NachkriegsschriftstellerInnen, wie Ernst Waldingers Gedicht „Kafka in Kierling“ veranschaulicht, dessen erste Strophe lautet: „Es ergreift mich weh und sonderbar, / Wenn des neuen Hiobs ich gedenke, / Daß im Dorf in seinem Sterbejahr / Zwischen grünen Hügeln in der Senke / So er litt, wo ich einst glücklich war.“ Waldinger: Kafka in Kierling. In: Joseph Strelka (Hg.): Das zeitlose Wort. Eine Anthologie österreichischer Lyrik von Peter Altenberg bis zur Gegenwart. Mit einem Nachwort von Ernst Schönwiese. Graz, Wien 1964, S. 87.

54 Weber: Stimmen der Gegenwart, eine Anthologie, S. 25.

55 Otto F. Beer: Immer noch Kafka ... Bemerkungen zu einer Anthologie. In: Die Zeit, 13.08.1953.

56 „Kafka imitiert man nicht, schreibt man nicht neu: man mußte aus seinen Büchern eine kostbare Ermutigung schöpfen und woanders weitersuchen.“ („On n'imite pas Kafka, on ne le refait pas: il fallait puiser dans ses livres un encouragement précieux et chercher ailleurs.“) Sartre: Was ist Literatur?, S. 175. (Sartre: Qu'est-ce que la littérature?, S. 227.) 
Trauer um der Trauer willen, Tod des Effektes wegen. In dieser Gefahr befinden sich, das sei nicht geleugnet, auch Autoren, die in diesem Band vertreten sind. ${ }^{57}$

An anderer Stelle räumt Hahnl jedoch ein, dass nach 1945 kein Weg an Kafkas Übermacht vorbeiführt: „Das Vorbild war kaum abzuwerfen, unmöglich zu überwinden.“ 58 In seinem Kontinente-Artikel „Die gefundene Generation“ verteidigt Weigel die Anlehnung seiner Protégés an Kafka als einen Schritt, über den man froh sein sollte:

Die große optische Täuschung jeder Mitwelt besteht darin, Lebende unter allen Umständen für lebendig, Gestorbene für tot und Gleichalte für gleich alt zu halten. Noch ist das neunzehnte Jahrhundert unter uns, in Sechzig- und Siebzigjährigen, das zwanzigste aber steht vor uns in Trakl, Kafka und anderen großen Lebendigen. Einer neuen Generation vorzuwerfen, daß sie Trakl und Kafka imitiere und nachempfinde, heißt die Adresse verwechseln. Unsere Welt ist von Trakl und Kafka, wir schreiben nur mit; und immer noch besser, man ist „Epigone“ Trakls und Kafkas als Hofmannsthals oder Thomas Manns, immer noch besser kleingedruckt in einem späteren Kapitel der Literaturgeschichte als fettgedruckt in einem früheren! ${ }^{59}$

Der jungen Generation sei mit der Politik und Gesellschaftsordnung der Elterngeneration auch deren Literatur „fragwürdig geworden“60, bestätigt Hahnl. Sie gehe „lieber bei den Großvätern in die Schule“ und versuche, „ihre gegenwärtige Position in der Vergangenheit zu fundieren“, ergänzt Eisenreich: „Sie ist nicht konservativ, aber sie besinnt sich auf die Tradition. “61 Diese Herangehensweise betrifft nicht nur die Jungen, spitzt Eisenreich zu, sondern ein ganzes Land, das, „so ziemlich aller politischen und wirtschaftlichen Möglichkeiten beraubt, auf hysterische Art bei der Vergangenheit die Argumente für seine gegenwärtige Existenz suchte“62. An keiner Stelle tritt der Wille, sich am literarischen Gestern

57 Hans Heinz Hahnl: Zur Situation der Literatur. In: Stimmen der Gegenwart, 1951, S. 20-25, hier S. 22.

58 Hahnl: Von der Diskreditierung der Ideologien, S. 159. So ist der beste Rat, sich davor zu hüten, „zuviel Kafka zu lesen“, meint Elias Canetti, der anlässlich der Kafka-Preis-Verleihung darüber hinaus äußert, „daß es niemanden gibt, auf der ganzen Erde nicht und in keiner Sprache, der es wirklich verdienen würde, im Namen Kafkas ausgezeichnet zu werden“. Elias Canetti: Die tiefste Verehrung meines Lebens. In: Nachbaur und Scheichl (Hg.): Literatur über Literatur. Eine österreichische Anthologie. Innsbruck 1995, S. 95-96. [Zuerst in: Die Presse, 24.09.1981.]

59 Weigel: Die gefundene Generation, S. 13.

60 Hahnl: Zur Situation der Literatur, S. 23.

61 Eisenreich: Das schöpferische Mißtrauen, S. 83.

62 Eisenreich: Prominente von unten gesehen. In: Die Zeit, 26.02.1953. 
zu bedienen, überzeugter zutage als 1945 in Alexander Lernet-Holenias „Gruß des Dichters“ in der Zeitschrift Der Turm:

Um es vollkommen klar zu sagen: wir haben es nicht nötig, mit der Zukunft zu kokettieren und nebulose Projekte zu machen, wir sind, im besten und wertvollsten Verstande, unsere Vergangenheit, wir haben uns nur zu besinnen, d a ß wir unsere Vergangenheit sind und sie wird unsere Zukunft werden. ${ }^{63}$

Die Konstruktion eines autonomen Österreich geht nach 1945 Hand in Hand mit der Konstruktion einer autonomen österreichischen Literatur. Über das altösterreichische Ideal der großen Vergangenheit von vor 1914 („du grand passé d'avant $1914^{\text {“64 }}$ ) zeitlich hinausgehend berücksichtigen die französischen Kulturverantwortlichen durchaus ZwischenkriegsautorInnen und kommen damit dem Wunsch nach Neuartigem nach (bzw. Neuem, denn: „Wer kannte vor 1945 Kafka?“65), der entgegen dem Gemeinplatz, dass „,das Neue‘ grundsätzlich nur geringen Eindruck ${ }^{\text {‘66 }}$ auf die ÖsterreicherInnen mache, besonders bei jüngeren und schriftstellerisch tätigen LeserInnen nach Kriegsende vorhanden ist. Diese bräuchten sich bald nicht mehr um internationale Moden zu kümmern, sondern nur um die „weltoffene Tradition, die unsere Kultur seit langem auszeichnet“"67, empfiehlt Weigel. Mit Werken aus dem ,übernationalen Raum, den der alte Völkerstaat der Donaumonarchie als großes Erbe hinterlassen hat“68, erübrigt sich alles In-dieFerne-Schweifen, man könne anknüpfen an „das Kontinuum einer organisch gewachsenen Kultur“,

an die große Generation vorher: an den geheimnisvollen Humor Kafkas und an die intellektuelle Skepsis Musils, an die von der Sprache erhellte Untergangsstimmung Trakls und an die Sprach- und Sachkritik von Karl Kraus, an die Vivisektion der Gesellschaft durch Broch, an den Weltblick Hofmannsthals. ${ }^{69}$

Kafka, der mit Sartre, Camus und anderen Literatur-Novitäten nach 1945 in kaum einem Periodikum fehlt, regt dort anhaltend den Geist eines überwiegend progressiven Publikums an: Noch 1954, zum 30. Todestag Kafkas, gibt es „kaum einen zweiten Autor, der leidenschaftlicher diskutiert und vielfältiger in-

63 Lernet-Holenia: Gruß des Dichters, S. 109 (Hervorhebung im Original).

64 Cullin: L’Action culturelle française en Autriche après 1945, S. 323.

65 Hahnl: Von der Diskreditierung der Ideologien, S. 159.

66 Eisenreich: Worin besteht der Unterschied?, S. 35.

67 Weigel: Das verhängte Fenster, S. 397.

68 Buchebner: Lektüre-Ratschläge für die junge österreichische Generation, S. 48.

69 Eisenreich: Worin besteht der Unterschied?, S. 35. 
terpretiert wird.“70 Für den akademischen Bereich hingegen gilt dies bis Mitte der fünfziger Jahre nicht. Nachdem es schon der kritischen Arbeit fast dreier Jahrzehnte bedurft habe, „diesen einzigartigen Dichter gegen Apathie und Widerstand der offiziellen Literaturbonzen“71 durchzusetzen, so der Plan-Herausgeber und frühe Kafka-Propagator Otto Basil 1946, braucht es eine bekannte französische Mittlerpersönlichkeit, um ihn schließlich an der Universität zu etablieren. Der Wiener Germanist Helmut Birkhan erinnert sich, wie Kafka zuvor von allen „geschnitten“ wurde: „Erst ein Gastprofessor, den uns das französische Kulturinstitut zur Verfügung gestellt hat, Professor Susini, hat eine vielbesuchte Kafka-Vorlesung gehalten.“72

\subsection{Kontinuität als / statt Neuanfang}

Wird das Vorbild Kafkas, Musils oder Brochs „für die meisten nach 1945 Schreibenden verbindlich“73, wie Wendelin Schmidt-Dengler anmerkt, so sind damit vorrangig junge AutorInnen gemeint, die erst in den sechziger Jahren bei Publikum und Kritik wirklich Gehör finden. Bis dahin erleben weite Teile der literarischen Landschaft eine „Restauration katholischen Geisteslebens“74. Forciert

70 tbg. [Friedrich Torberg]: Zur 30. Wiederkehr des Todestages von Franz Kafka. In: FORVM 1 (1954), Nr. 6, S. 19. Cf. Sabina Reiter: Die Wiederentdeckung Kafkas. In: Hay (Hg.): Zur literarischen Situation 1945-1949, S. 252-269; sowie Reinhard Urbach: Aspekte literarischer KafkaRezeption in Österreich. In: Schmidt-Dengler (Hg.), unter Mitwirkung von Kranner: Was bleibt von Franz Kafka? Positionsbestimmung. Kafka-Symposion, Wien 1983. (Schriftenreihe der Franz-Kafka-Gesellschaft 1.) Wien ${ }^{2} 1985$, S. 199-210.

71 Otto Basil: Franz Kafka. In: Plan 1 (1946), Nr. 4, S. 310-312, hier S. 310.

72 Irene Ranzmaier: Germanistik an der Universität Wien zur Zeit des Nationalsozialismus. Karrieren, Konflikte und die Wissenschaft. (Literaturgeschichte in Studien und Quellen 10.) Wien, Köln, Weimar 2005, S. 190 f.

73 Wendelin Schmidt-Dengler: Vorwort. In: Nachbaur und Scheichl (Hg.): Literatur über Literatur, S. 11-24, hier S. 15.

74 Friedrich Stadler: Kontinuität und / oder Bruch? Anmerkungen zur österreichischen Wissenschaftsgeschichte 1938 bis 1955. In: Stadler (Hg.): Kontinuität und Bruch, S. 9-23, hier S. 11. Durch das Anknüpfen an Vorkriegstraditionen ist das Kriegsende „weniger für die österreichische Literatur als für die österreichische Literaturgeschichte ein Jahr Null“ (Hahnl: Von der Diskreditierung der Ideologien, S. 159), wobei ohnehin ,Stunde Null‘, ,tabula rasa“ und „Stichwörter dieser Art meist bewußt vermieden“ würden. Joseph McVeigh: Kontinuität und Vergangenheitsbewältigung in der österreichischen Literatur nach 1945. (Untersuchungen zur österreichischen Literatur des 20. Jahrhunderts 10.) Wien 1988, S. 53. Cf. auch Bizeul und Wodianka (Hg.): Mythos und Tabula rasa. Narrationen und Denkformen der totalen Auslöschung und des absoluten Neuanfangs. Bielefeld 2018, vor allem die Beiträge „1940 - Die Niederlage als Ursprungsort politischer Mythen in Frankreich“ von Matthias Waechter (S. 111-124) und 
durch die harmlose(re)n Repräsentanten der Vorkriegsliteratur, die, so Kriegleder, ein Interesse daran hatten, ,ihre ehemaligen Positionen im literarischen Feld zu reaktivieren“"75, erfolgt parallel zum sukzessiven Rückzug der Alliierten aus dem Literaturbetrieb eine „partielle Wiederaufnahme und Fortführung der Kulturpolitik des Ständestaates“76. Mit der Rekonstruktion jener Kultur, „die nicht unbeträchtlich Anteil an den Siegen der beiden Faschismen gehabt hatte“777, treten viele vorübergehend aus dem literarischen Verkehr Gezogene wieder in Erscheinung: Von der 1946 vom Bundesministerium für Unterricht ausgegebenen Liste der gesperrten Autoren und Bücher mit circa 1600 verbotenen AutorInnen (darunter Gertrud Fussenegger, Friedrich Schreyvogl, Josef Weinheber, Bruno Brehm und Maria Grengg) konnten einige „fast bruchlos“ an ihre Erfolge anknüpfen, so dass sich in diesem Zusammenhang von einer gescheiterten Entnazifizierung, wenn nicht einer „Renazifizierung““78 der Literatur sprechen lässt. Die sogenannte Ostmark-Literatur bildet in den fünfziger Jahren die Basis „der meisten approbierten Lesebücher, Anthologien und Sammelbände“"79. Der für die französischen Alliierten tätige Hermann Schreiber, Sohn eines Buchhändlers, weist diesen Umstand 1947 im Österreichischen Tagebuch als strukturell getragen aus, durch höhere Papierzuteilungen für Verlage von ,Ostmark‘-SchriftstellerInnen oder die direkte „Förderung von Naziautoren“ durch prestigeträchtige Literaturpreise, die zu dieser Zeit vornehmlich an jene vergeben würden, „die entweder bereits unter dem Austrofaschismus oder unter dem Nationalsozialismus oder unter beiden Systemen gefördert und ausgezeichnet worden waren.“ ${ }^{81}$

„,Stunde Null‘ und ,Achtundsechzig‘ als Gründungsmythen der deutschen Nachkriegsdemokratie“ (S. 125-140) von Wolfgang Bergem.

75 Kriegleder: Die Literatur der fünfziger Jahre in Österreich, S. 37.

76 Klaus Amann: Vorgeschichten. Kontinuitäten in der österreichischen Literatur von den dreißiger zu den fünfziger Jahren. In: Aspetsberger, Frei und Lengauer (Hg.): Literatur der Nachkriegszeit, S. 46-58, hier S. 47.

77 Dvořak: Thesen zur soziokulturellen Entwicklung in Österreich 1933 bis 1955, S. 31.

78 Bachleitner, Eybl und Fischer: Geschichte des Buchhandels in Österreich, S. 328. Cf. dazu in Meissls, Mulleys und Rathkolbs Band Verdrängte Schuld, verfehlte Sühne die Aufsätze von Gerhard Renner: „Entnazifizierung der Literatur“ (S. 203-229), und von Murray G. Hall: „Entnazifizierung in Buchhandel und Verlagen“ (S. 230-253). Cf. weiters Białek und Żyliński (Hg.): Die Quarantäne. Deutsche und österreichische Literatur der fünfziger Jahre zwischen Kontinuität und Neubeginn. Wrocław, Dresden ${ }^{2} 2006$.

79 McVeigh: Kontinuität und Vergangenheitsbewältigung in der österreichischen Literatur nach 1945, S. 78.

80 Hermann Schreiber: Das Buch. Papierpolitik. In: Österreichisches Tagebuch, 19.09.1947.

81 Amann: Vorgeschichten, S. 47. Cf. auch Sigurd Paul Scheichl: Vergessene. Träger des Großen Österreichischen Staatspreises in den 50er Jahren. In: Walter Buchebner Gesellschaft 
Die Literaturförderungspolitik bringt allgemein „die Hypothek einer einseitigen Traditions- und Kanonbildung“82 auf Kosten der AutorInnen, die das Land verlassen mussten. Unter den raren Fällen offenen Widerspruchs gegen diese Entwicklung bittet Rudolf Geist Ende 1945 in der Zeitschrift Plan „die jüdische Intelligenz“ zurück „zur Mitarbeit an allen österreichischen Verlagen“83. Die Republik zeigt sich derweil „desinteressiert und indolent“84 gegenüber den Vertriebenen. Jean Améry etwa kehrt, wie auch Manès Sperber, nach Kriegsende nicht in die verlorene „Heimat“85 zurück, „die Kränkung war zu groß“86. Améry beginnt 1945 „die geistige Landkarte des französischen Existentialismus zu entziffern“ ${ }^{87}$, seine mehr als drei Jahrzehnte währende Beschäftigung mit Sartre - für ihn „die imponierendste literarisch-philosophische Figur des Jahrhunderts“88 - ist einzigartig unter den deutschsprachigen Intellektuellen, sein Gewicht als Mittler im Existentialismus-Transfer nach Österreich hingegen vernachlässigbar. Vom frankophonen Kulturraum aus publiziert er in deutschen, kaum jedoch in österreichischen Periodika, so dass ihn 1961 die prokommunistisch ausgerichtete Zeitschrift Tagebuch im Zuge einer Besprechung seiner Studie Geburt der Gegenwart („eine brillante Zustandsschilderung der westlichen Zivilisation seit dem Kriegsende“) vorstellen muss als „vorurteilslose[n] Belgier“89.

Unter den Exil-SchriftstellerInnen, deren Initiation sich in Wien vollzogen hat, gelangen einige in unmittelbare Nähe Sartres, allerdings ohne geistiges

(Hg.): Literatur in Österreich von 1950 bis 1965. (Walter Buchebner Tagung, 1984, 7.-9. Dez. 1984 in Neuberg an der Mürz.) Mürzzuschlag 1984, S. 75-91.

82 Amann: Vorgeschichten, S. 56.

83 Rudolf Geist: Österreichische Verpflichtung. In: Plan 1 (1945), Nr. 3, S. 232-235, hier S. 234.

84 Schmid: Kulturpolitische Tendenzen der fünfziger Jahre, S. 19.

85 Cf. zu Amérys Heimatbegriff das Kapitel „Wieviel Heimat braucht der Mensch?“ in Améry: Jenseits von Schuld und Sühne (S. 71-100).

86 Sperber: Bis man mir Scherben auf die Augen legt, S. 160.

87 Améry: Über das Altern, S. 109. Mit Feindt lässt sich Amérys beispiellose Auseinandersetzung mit Sartre unter den deutschsprachigen SchriftstellerInnen unterstreichen: „[E]r hatte nicht nur die Schriften und Werke Sartres bis in die 1950er Jahre analysiert, sondern (und hier kann man wirklich von Empathie sprechen) weiterhin jede öffentliche Äußerung von Sartre verfolgt.“ [Übers. d. Verf.] (,[I]l n’avait pas uniquement analysé les écrits et les œuvres de Sartre jusque dans les années 50, mais [et on peut ici parler véritablement d'empathie] continuait à observer chaque manifestation publique de Sartre.“) Feindt: Engagement, empathie, distanciation, S. 77.

88 Jean Améry: Ein neuer Verrat der Intellektuellen? (1977) In: Améry: Werke, Bd. 6: Aufsätze zur Philosophie. Hg. von Gerhard Scheit. Stuttgart 2004, S. 157-179, hier S. 174 [Zuerst in: Schatz (Hg.): Abschied von Utopia? Anspruch und Auftrag der Intellektuellen (1977).]

89 B. F.: Neu und wichtig. In: Tagebuch 16 (1961), Nr. 12, S. 15. 
Nahverhältnis, so der 1948 von der Europäischen Rundschau präsentierte „erfolgreiche englische Schriftsteller“90 Arthur Koestler. Koestler parodiert in seinem Roman The Age of Longing (1951) Sartre und Beauvoir als Professor und Madame Pontieux auf eine Weise, die wenig Zweifel daran lässt, dass ihm Boris Vians L'Écume des jours bekannt war (cf. Kap. 5.2):

Pontieux had begun to expound the principles of neo-nihilism, a philosophy which he had launched in his famous work ,Negation and Position', and which had been the fashionable craze after the second world war. There had been neo-nihilistic plays, neo-nihilistic night clubs and neo-nihilistic crimes - among them the famous case of Duval, a colour-blind upholsterer in Menilmontant who had cut the throats of his wife and three children and had countered the question why he had committed the crime with the classic answer: ,Why not? This led to the splitting off of a radical wing of neo-nihilists who called themselves the ,Whynot-ists' and founded a rival night club which, mainly thanks to a trio of attractive singers called the ,Why-not-Sisters, ' captured the lion's share of the intellectually minded American tourists. Professor Pontieux was horrified by these developments; for he was a sincere moralist, a dialectician and a believer in the revolutionary mission of the Proletariat - all of which, as he did not tire of explaining in a stream of books and pamphlets, was the true essence of neo-nihilistic philosophy. ${ }^{91}$

Simone de Beauvoir wiederum lässt Koestler in Les Mandarins auftreten, als Scriassine, „ein schleimig verlogener, von Schuld- und Angstgefühlen getriebener Trinker, den der Menschenhaß nicht einmal in seinem Liebensleben losläßt“92, wie Doris Brehm die Figur 1956 im Tagebuch charakterisiert. Die verstörende Affäre der Heldin mit Scriassine bleibt dem österreichischen Lesepublikum durch mehrere Besprechungen nicht verborgen, die Tageszeitung Neues Österreich beruhigt (fälschlicherweise), es handle sich hierbei um eine „freie Erfindung“93 der Autorin. Beauvoir lässt Scriassine in ihrem Roman auf einen anderen Exil-Wiener, Manès Goldman, treffen, eine Manès Sperber nachempfundene Figur (auch in Koestlers The Age of Longing findet Sperber als „Professor Vardi“ Erwähnung):

„Victor Scriassine, nicht wahr?“

Ein kleiner, kahlköpfiger Greis mit sehr sanften Augen hatte sich unserem Tisch genähert.

„Ja.“ In Scriassines Augen entdeckte ich Mißtrauen, aber auch so etwas wie eine Hoffnung.

90 Artur [!] Koestler: Die Zukunft des Romans. In: Europäische Rundschau 3 (1948), Nr. 17, S. 805-806, hier S. 805.

91 Arthur Koestler: The Age of Longing. London 1951, S. $104 \mathrm{f}$.

92 Doris Brehm: Der Kreis um Sartre. In: Tagebuch, 24.03.1956.

93 o.f.b.: La Grande Sartreuse. In: Neues Österreich, 26.02.1956. 
„Sie erkennen mich nicht? Ich bin sehr alt geworden seit den Zeiten in Wien. Manes Goldman. Ich hatte mir vorgenommen, Ihnen - falls ich Sie jemals treffen sollte - meinen Dank auszusprechen: Dank für Ihr Buch.“

„Manes Goldman! Natürlich!“ sagte Scriassine herzlich. „Leben Sie jetzt in Frankreich?“ „Seit 1935. Ich war ein Jahr lang im Lager von Gurs, aber ich bin gerade noch rechtzeitig herausgekommen ... “

Seine Stimme war noch sanfter als sein Blick, so sanft, daß sie wie tot erschien.

„Ich will Sie nicht stören. Ich bin froh, daß ich dem Mann, der Das braune Wien geschrieben hat, die Hand geben konnte.“

„Und ich bin froh, daß ich Sie wiedergesehen habe“, sagte Scriassine.

Der kleine Österreicher hatte sich mit lautlosen Schritten entfernt; er verschwand durch die Glastür hinter einem amerikanischen Offizier. ${ }^{94}$

(„Victor Scriassine, n’est-ce pas?“ Un petit vieillard chauve aux yeux très doux s'était approché de notre table.

„Oui.“ Dans les yeux de Scriassine je lisais de la méfiance, mais aussi une sorte d'espoir.

„Vous ne me reconnaissez pas? J'ai beaucoup vieilli depuis Vienne. Manès Goldman; je m'étais promis si jamais je vous rencontrais de vous dire merci: merci pour votre livre.“

„Manès Goldman! bien sûr!“ dit Scriassine avec chaleur. „Vous vivez en France, maintenant?“

„Depuis 35. J’ai passé une année au camp de Gurs, mais j’en suis sorti juste à temps ... “ Il parlait d'une voix plus douce encore que son regard, si douce qu'elle semblait morte. „Je ne veux pas vous déranger; je suis content d'avoir serré la main de l'homme qui a écrit $V i$ enne la brune."

„Je suis content de vous avoir revu“, dit Scriassine.

Le petit Autrichien s'était déjà éloigné à pas feutrés; il disparut par la porte vitrée, derrière un officier américain. $)^{95}$

Wie sein Freund Koestler Ex-Kommunist und daher in der Pariser intellektuellen Szene nach 1945 zunächst eher Außenseiter, versteht sich Sperber zwischen 1946 und 1950 sehr gut mit Sartre, der, wie er sagt, in dieser Phase „ein entschiedener Gegner jeder Diktatur, auch der stalinschen, ein Feind all dessen,

94 Simone de Beauvoir: Die Mandarins von Paris. Deutsch von Ruth Ücker-Lutz und Fritz Montfort. Reinbek 1993 [1965], S. 92.

95 Beauvoir: Les Mandarins, S. 69. In Beauvoirs Lebensrückblick heißt es diesbezüglich: „Durch Koestler lernten wir Manès Sperber kennen, der sich als seinen Lehrmeister und den fähigsten Psychologen des Jahrhunderts betrachtete. Er hatte viel Charme, aber als unversöhnlicher Adlerianer und wilder Antikommunist stieß er uns durch seinen Dogmatismus ab.“ („Par Kœstler nous avons connu Manès Sperber, qu’il considérait comme son maître et le psychologue le plus compétent du siècle. Il avait un charme feutré; mais, adlérien intransigeant, anticommuniste farouche, son dogmatisme nous rebuta.") Beauvoir: Der Lauf der Dinge, S. 112. (Beauvoir: La Force des choses, Bd. 1, S. 156.) 
was die Freiheit der Person einengen oder gar gefährden konnte“, war: „Nichts ließ damals die Vermutung aufkommen, daß er über die Weltlage und besonders über den Stalinismus anders dachte als ich oder als Arthur Koestler, mit dem er sich besonders gut $\mathrm{zu}$ verstehen schien, oder mit seinem jüngeren Freund Albert Camus. “96 Anders als Koestler und André Gorz schreibt Sperber überwiegend in deutscher Sprache, wirkt allerdings nur im Rahmen kritischer Stellungnahmen in seinen journalistischen und autobiographischen Texten nach Ende der Erstrezeption als Existentialismus-Vermittler nach Österreich.

Als Reaktion auf den „Verlust des gesamten geistigen, fortschrittlich demokratischen Potentials“97 im Nachkriegskulturbetrieb besetzt die teils belastete ältere AutorInnen-Generation jene Leerstellen, die zunächst kurz mit internationaler Literatur befüllt waren. Um die jungen SchriftstellerInnen ist es unterdessen still, sie machen eine „schöpferische Pause“ und holen Versäumtes nach, erste Versuche werden als „unzulänglich und unfertig“98 empfunden. Als sie sich bereit fühlen, ist alle „Aufbaueuphorie“99 ${ }^{\text {“9 }}$ passé und ihnen stehen kaum Publikationsplattformen zur Verfügung. Wider den Vorkriegserzählstil, der sich in den fünfziger Jahren in Heimito von Doderers Monumentalprosa vollenden wird, verfassen die Jungen, wie Michael Scharang es später umreißt, vielfach „eine Literatur, die klein daherkommt“"100, was nicht in das nach 1945 propagierte Selbstbild als Kulturnation passt: „Und so spielte man Mozart gegen Alban Berg aus, ,volksnahe“ Kunst gegen die Moderne und die im ,Dritten Reich“ kompromittierten Schriftsteller gegen die junge Generation. “101 Bei manchen nicht etablierten AutorInnen setzt die staatliche Förderung konservativen Schreibens eine Selbstzensur in Gang, doch auch ihr Werk, das „häufig eine unbewusste Kontinuität“102 zur Literatur der Ersten Republik aufweist, bleibt ohne positive Resonanz. Nichts als

96 Sperber: Nur eine Brücke zwischen Gestern und Morgen, S. 40, 39; cf. S. 39f.: „Wenn wir allein waren, erwogen wir vornehmlich Fragen, die die wissenschaftlichen Ansprüche des Marxismus betrafen und noch öfter das psychische Phänomen der Entfremdung und Selbstentfremdung, das ich bereits im Jahre 1934 recht ausführlich in einem Buch behandelt hatte. Der Lektor, der es ein Jahrzehnt vorher angenommen hatte, hatte Sartre über meine Bemühungen um eine marxistische Individualpsychologie informiert. Überdies hatte ihm Koestler, der damals häufig nach Paris kam, wohl ausführlich von mir erzählt.“

97 Stadler: Kontinuität und / oder Bruch?, S. 11.

98 Zlabinger: Literarische Zeitschriften in Österreich 1945-1964, S. 79.

99 Hahnl: Von der Diskreditierung der Ideologien, S. 157.

100 Michael Scharang: Die proletarisierte Literatur. In: Scharang: Die List der Kunst. Essays. Darmstadt und Neuwied 1986, S. 14-24, hier S. 15. [Zuerst in: Literatur Konkret 1983/1984, Nr. 8.]

101 Kriegleder: Die Literatur der fünfziger Jahre in Österreich, S. 34.

102 Kriegleder: Die Literatur der fünfziger Jahre in Österreich, S. 38. 
ein „müdes ,Fortwursteln““ erkennt in diesem Sinne Ernst Fischer in den Nachkriegspublikationen, deren qualitative Dürftigkeit er im Dreiparteienblatt Neues Österreich bemängelt, der ersten Zeitung, die nach 1945 von den Alliierten eine Lizenz erhält und deren erster Chefredakteur er ist:

Wenn wir uns nun vor Augen halten, was die österreichischen Verleger bisher an Büchern herausgebracht haben, muß man als Österreicher wahrhaft Scham empfinden. Wir haben wenig Papier - aber dieses Papier wird zu einem wesentlichen Teil für die Herausgabe belangloser, abgeschmackter und in jeder Hinsicht überflüssiger Romane verschwendet. Daß heute jedes Buch gekauft wird, ist keinerlei Entschuldigung für den Triumph der Banalität und Mittelmäßigkeit, den die meisten Neuerscheinungen darstellen. Wenn man augenblicklich keinen Autor findet, der das neue Österreich repräsentiert, dann möge man dem österreichischen Leser, der jahrelang von der Kulturwelt abgeschnitten war, englische, russische, amerikanische, französische Literatur in guten Übersetzungen vermitteln, Werke von Dichtern und von Kämpfern, die uns Ernsteres, Packenderes zu berichten haben als irgend welche lächerlichen Ehekonflikte und faden erotischen Verwicklungen. ${ }^{103}$

Die Behauptung, es gebe einfach nicht genug gute AutorInnen, zeugt für deren Fürsprecher Hans Weigel von „Böswilligkeit und Nichtwissen“104. Die Jungen dichten ins Leere, sofern sie „keine klangvollen Namen“ haben, bestätigt aus Erfahrung Thomas Bernhard 1952 im Salzburger Demokratischen Volksblatt: „Es ist nicht wahr, wenn man von einer Schwäche, Ausdrucksnot und Oberflächlichkeit des Nachwuchses spricht, aber es könnte sein, daß man es versäumt, diesen am Glauben an die Zukunft Gebrochenen hilfreich unter die Arme zu greifen?“105 Lohnend wäre es, so Weigel, zwar würde nicht aus jedem „ein neuer Trakl und ein neuer Kafka“: „Aber mindestens ein Trakl und ein Kafka ist zweifellos unter ihnen.“106

Nachdem von VerlegerInnen-Seite noch in den fünfziger Jahren das Veröffentlichen unbekannter AutorInnen ein zu großes finanzielles Wagnis darstellt, sind diese mehrheitlich „zum Schweigen verurteilt“"107. Auf Interesse stoßen sie zunächst beim „undogmatischen Sozialisten“108 Otto Basil in der Zeitschrift Plan (1945-1948) - die Informationsquelle und „zugleich ein forum für die ersten

103 Ernst Fischer: Um ein geistiges Österreich! In: Fischer: Das Jahr der Befreiung, S. 98-100, hier S. 98, 99. [Zuerst in: Neues Österreich, 04.01.1946.]

104 Hans Weigel: Autoren, die uns nicht erreichen. Zur tragischen Situation der jungen österreichischen Literatur. In: Arbeiter-Zeitung, 24.09.1950.

105 Bernhard: Junge Dichter in Österreich, S. 15.

106 Weigel: Autoren, die uns nicht erreichen. In: Arbeiter-Zeitung, 24.09.1950.

107 Hahnl: Zur Situation der Literatur, S. 24. Cf. Lunzer: Der literarische Markt 1945-1955, S. 32, 34.

108 Sommer: Basil - Doderer - Gütersloh, S. 37. 
tastenden versuche der jüngeren und jüngsten“109 ist - und in der Zeitschrift Lynkeus (1948-1951) des „halblinken“ (,als Dichter konservativ, als Prosaiker interessant, als Herausgeber durchaus fortschrittlich“110) P.E.N-Club-Vorstandsmitglieds Hermann Hakel. Schließlich wird - die Verschärfung des Kalten Kriegs im Literaturbetrieb spiegelnd - der „stark antikommunistisch orientiert[e]“ Hans Weigel zum „bedeutenden Jugendförderer“111 mit seinem Jahrbuch Stimmen der Gegenwart. Die zwischen 1951 und 1956 erscheinenden fünf Bände lancieren „fast alle Autorinnen und Autoren, die in der Folge eine wichtige Rolle in der österreichischen Literatur spielen“"112. Mit Gedichten und Erzählungen (in geringerem Maß auch mit Literatur-, Kunst- und Kulturkritiken sowie Illustrationen) vertreten sind Ingeborg Bachmann, Marlen Haushofer, Andreas Okopenko, Paul Celan, Christine Lavant, Michael Guttenbrunner, Gerhard Fritsch, Erich Fried, Ernst Jandl, Christine Busta, Humbert Fink, Herbert Zand, Thomas Bernhard, Jeannie Ebner und H. C. Artmann. ${ }^{113}$ Die Anthologie steckt sich das Ziel, so Richard Schmitz vom herausgebenden Wiener Albrecht Dürer Verlag, „den Anspruch der neuen österreichischen Literatur im gesamteuropäischen Kulturleben

109 Rühm: das phänomen „wiener gruppe“, S. 17.

110 Max Blaeulich: Zirkel, Kreise, Treffpunkte der österreichischen Literatur nach 1945. In: Polt-Heinzl und Strigl (Hg.): Im Keller. Der Untergrund des literarischen Aufbruchs nach 1945. Wien 2006, S. 151-162, hier S. 160.

111 Okopenko: Die schwierigen Anfänge österreichischer Progressivliteratur nach 1945, S. 1. Allerdings weisen sich Reinhard Federmann und Milo Dor zu Beginn als die treibenden Kräfte aus, sie hätten „diese Anthologie erfunden“, „das Ganze zusammengestellt und redigiert“ und „nur den Weigel vorgeschoben“. Milo Dor: Gemeinsam mit dem geschenkten Leben fertig werden. Andreas Weber im Gespräch mit Milo Dor. In: Weber (Hg.): Dear Fritz, S. 123-141, hier S. 130. Cf. zu deren und Jeannie Ebners HerausgeberInnenschaft: Wolfgang Straub: Die Netzwerke des Hans Weigel. Wien 2016, S. 240-252. Weigel gibt weiters in der Reihe „Junge österreichische Autoren“ im Wiener Jungbrunnen-Verlag die Werke vieler zwischen 1918 und 1931 geborener SchriftstellerInnen heraus, unter anderem Walter Tomans Die eigenwillige Kamera (1951), Gerhard Fritschs Zwischen Kirkenes und Bari (1952), Reinhard Federmanns Es kann nicht ganz gelogen sein (1951), Jeannie Ebners Gesang an das Heute: Gedichte, Gesichte, Geschichten (1952), Herbert Eisenreichs Einladung deutlich zu leben (1952), Marlen Haushofers Das fünfte Jahr (1951), Hans Heinz Hahnls Die verbotenen Türen (1952) und Ilse Aichingers Rede unter dem Galgen (1952).

112 Kriegleder: Die Literatur der fünfziger Jahre in Österreich, S. 39.

113 Eisenreich: Prominente von unten gesehen. In: Die Zeit, 26.02.1953; der Kreis trifft sich im Café Raimund im 1. Wiener Bezirk: „Niemand würde dieses sehr ruhige Caféhaus gegenüber dem Volkstheater für ein Literatencafé halten, denn mit Bohême hat das alles überhaupt nichts zu tun: was dort getan wird, geschieht in bester österreichischer Tradition, und das 
anzumelden“"114. In Weigels Vorbemerkung zum ersten Jahrgang heißt es bezüglich dieses Vorhabens vorwurfsvoll:

Hier wird der Versuch unternommen, in Worten und Bildern die Gegenwart sprechen zu lassen und darzustellen. [...] Angesichts des Vakuums innerhalb unseres geistigen Lebens wird jedoch die Verschwörung des Schweigens zur tragischen Schuld. Verkannt, mißverstanden, verfolgt, in äußerster physischer und psychischer Notlage, von inkompetenten Wichtigtuern des offiziellen Betriebs ignoriert oder bestenfalls leutselig auf die Schultern geklopft, lebt diese Generation auf Grund eines erstaunlichen, fast wundersamen Potentials an Haltung und Disziplin aus sich selbst, denkt, arbeitet, reift und gibt durch ihre bloße Existenz die einzige Garantie für das Weiterbestehen von Kunst und Gesittung in Österreich. ${ }^{115}$

1952 ist der zweiten Vorbemerkung zufolge die Situation noch desolater als im ersten Jahr: „Unbeschreiblich und erschütternd ist ihre materielle Not, ärger noch die Hoffnungslosigkeit und Isoliertheit der von der lebendigen Wirkung in der Öffentlichkeit durch Presse, Bühnen, Verlage, Redaktionen und Sender fast völlig Ausgeschlossenen."116 1953 erreicht die Publikation durch Spenden und staatliche Förderung zu Weigels Überraschung ihren dritten Jahrgang, in diesen Zeiten „fast schon ein biblisches Alter“117. Immer noch ist er jedoch geneigt,

nicht Form und Inhalt des Geschriebenen, sondern die Lebensform der Schreibenden darzustellen: ... lebt von der Arbeitslosenunterstützung, ... hat keine Schreibmaschine, ... hat außer dem Brotberuf einen Haushalt und zwei Kinder zu betreuen, ... ist schwer krank und hat keine Mittel, um sich auszukurieren, ... kommt kaum zum Schreiben, ... kommt kaum zum Schreiben, ... kommt kaum zum Schreiben ... ${ }^{118}$

Eine der Beteiligten, Ingeborg Bachmann, bestätigt den Eindruck aus eigenem Erleben:

Wir waren alle Mitte zwanzig, notorisch geldlos, notorisch hoffnungslos, zukunftslos, kleine Angestellte oder Hilfsarbeiter, einige schon freie Schriftsteller, das hieß soviel wie abenteuerliche Existenzen, von denen niemand recht wußte, wovon sie lebten, von Gängen aufs Versatzamt jedenfalls am öftesten. ${ }^{119}$

heißt: es geschieht diskret, und man läßt sich nicht anmerken, daß die Muße und die Arbeit gar nicht sosehr entfernt voneinander wohnen.“

114 Richard Schmitz: Zum Geleit. In: Stimmen der Gegenwart, 1953, S. 3.

115 Weigel: Vorbemerkung. In: Stimmen der Gegenwart, 1951, S. 5.

116 Weigel: Vorbemerkung. In: Stimmen der Gegenwart, 1952, S. 6.

117 Weigel: Vorbemerkung. In: Stimmen der Gegenwart, 1953, S. 5.

118 Weigel: Die gefundene Generation, S. 13.

119 Ingeborg Bachmann: [Gruppe 47] Entwurf. In: Bachmann: Werke, Bd. 4, S. 323-330, hier S. 324 . 
Thomas Bernhard, vertreten in den Jahrbüchern 1954 und 1956 mit seinen Erzählungen „Großer, unbegreiflicher Hunger“ und „Der Schweinehüter“, diagnostiziert in seinem Artikel „Junge Dichter in Österreich“ (zu denen kriegsbedingt „auch noch die 40jährigen zu zählen sind“120), dass die Stimmen der GegenwartTexte „durch einen tiefen Pessimismus gekennzeichnet sind“, wenig überraschend bei DichterInnen, die mit „Wassersuppe und trockenem Brot, mit geflickten Hemden und durchlöcherten Schuhen “121 vorlieb nehmen müssen. Von mangelndem Einfühlungsvermögen zeugt es auch für Weigel, „die Greisenhaftigkeit und die Untergangsstimmung“ zu beanstanden: „Ehe man Depression und Nihilismus verurteilt, sehe man einmal diesen Jungen $\mathrm{zu}$, wie sie leben. “122 $\mathrm{Zu}$ den betrüblichen privaten Lebensumständen tritt laut Okopenko der lähmende zeitgeschichtliche Zustand, in dem sich auch die Auseinandersetzung mit der Existenzphilosophie vollzieht:

Durchdringung mit angelesenem Gedankengut und eigenes Durchdenken der Situation führten zu Resignationserlebnissen: Die politische Lage Österreichs und der Welt schien für Jahrtausende festgefroren und von Menschen, die keine Atombombe besaßen, nicht beeinflußbar; andererseits war die erste Unmittelbarkeit von Schreck und Not vorbei; die Parteien - des kalten Krieges und der Innenpolitik - reizten alle nicht zur Hingabe; durch Zustimmung und Ablehnung hindurch spürte man manchmal unsere Isolation und die letztliche Wirkungslosigkeit unserer Mühen; in gemeinsamer Erfahrung von Kierkegaard, Sartre, Unamuno, Borchert wurden die unangenehmen Verhalte um Tod, Problematik des Lebenssinns und Grenzen der Liebe besonders sensibel wahrgenommen; quasi existentialistische Materie verdrängte die aktivistische, zeitkritische; echter Pessimismus zuweilen den vermeintlichen, den nur Dummköpfe in Polemik und Realismus erblickt hatten. ${ }^{123}$

Die Sartres als optimistisch ausgegebenem Denken (,un optimisme“124) widersprechenden, aber gemeinhin verknüpften negativen Assoziationen (cf. Kap. 7.3) sorgen dafür, dass die junge österreichische Literatur - die „eine erschütternde Ratlosigkeit, eine bedrückende Primitivität des Denkens, eine ungeheure Resignation“125 auszeichne, mehr noch: „ein Chaos von Desillusionierung, Zynismus, Fanatismus, Gleichgültigkeit, Nihilismus, Schwermut, persönlicher und kollektiver Angst, das durch die soziale und weltpolitische Situation gegenwärtig noch

120 Thomas Bernhard [Th. B.]: Bücher warten auf Dich! In: Bernhard: Werke, Bd. 22/1, S. 88-90, hier S. 89. [Zuerst in: Demokratisches Volksblatt, 29.11.1952.]

121 Bernhard: Junge Dichter in Österreich, S. 13.

122 Weigel: Autoren, die uns nicht erreichen. In: Arbeiter-Zeitung, 24.09.1950.

123 Okopenko: Die schwierigen Anfänge österreichischer Progressivliteratur nach 1945, S. 10.

124 Sartre: L'Existentialisme est un humanisme, S. 78.

125 Basil: Stimme der Jugend. In: Plan 1 (1946), Nr. 4, S. 307. 
verschärft wird“'126 - oft in den unmittelbaren Wirkungskreis des Existentialismus gerückt wird. Die von den französischen Alliierten gegründete Zeitung Welt am Montag versucht schließlich die Wogen zu glätten, indem sie Anfang 1950 die vorherrschende Schreib- und Denkhaltung als zeitbedingte Selbstverständlichkeit verteidigt: „Ist Sartres Diagnose pessimistisch oder nihilistisch? Ebenso pessimistisch oder nihilistisch ist ein Thermometer, das bei Frost Kältegrade zeigt. Wer Sartre schilt, der macht den Stenographen für eine beleidigende Rede haftbar." 127

\subsection{Literatur unter dem Galgen: Grenzsituationen}

Bei allen Bedenken, ob Kultur „handhabbare Hilfe im unsicheren Nachkriegsalltag“'128 leisten, ob Literatur bei der „geistigen Bewältigung des Lebens und aller damit verbundenen Probleme“ ${ }^{\text {“129 }}$ beistehen könne, hat das existentialistische „werkgewordene Unbehagen an der modernen Welt“ insofern einen kathartischen Effekt auf junge Schreibende und Lesende, als Sartres und Camus’ Texte als „Akte der Psychotherapie“ fungieren, „in denen Diagnose und Heilung zusammenfallen“"130, so Christian Lewalter 1950 in Die Zeit. Gerade für Kriegsrückkehrende bewährt sich der Existentialismus als „Artikulationsmedium erfahrener Ängste und Erschütterungen“131, allerdings bevorzugen diese in Österreich häufiger als innerhalb der bundesdeutschen Trümmerliteratur die allgemein als unengagiert geltende Gattung der Lyrik (cf. Kap. 6.4), um das Erlebte zu verarbeiten. Im Vorwort zum ersten Jahrgang der Anthologie Tür an Tür (1950) erklärt der Herausgeber (und Dichter) Rudolf Felmayer einzig das Gedicht als imstande, „wenigstens einigermaßen die seelischen Probleme unserer Gegebenheiten zu bewältigen“132. Lyrik, so McVeigh, bietet „die Möglichkeit einer direkten Aus-

126 Hahnl: Zur Situation der Literatur, S. 21.

127 o. V.: Die Jungen. In: Welt am Montag, 23.01.1950.

128 Englerth, Gausterer und Kaukoreit: Österreichs Literaturzeitschriften 1945-1990 im Überblick, S. 16.

129 Buchebner: Lektüre-Ratschläge für die junge österreichische Generation, S. 48.

130 Christian E. Lewalter: Die entsetzliche Freiheit. Zu Jean-Paul Sartres „Aufschub“. In: Die Zeit, 22.06.1950.

131 Große Kracht: Jean-Paul Sartre und die deutsche Zusammenbruchgesellschaft, S. 90. Cf. Evelyne Polt-Heinzl: Trümmerliteratur aus Österreich. In: treibhaus 10 (2014), S. 50-66.

132 Rudolf Felmayer: [Vorwort]. In: Tür an Tür. Gedichte vierzehn junger Autoren. Wien 1950, o. S. 
sage, ohne den Anschein der Objektivität zu beanspruchen“133, wobei Letzteres laut Kriegleder dennoch des Öfteren vorkommt: „Das schwer Sagbare wurde in dichterischem Geraune überhöht, Sonette wucherten und eine erlesene Metaphorik suchte individuelle Beschädigungen ins Allgemeingültige zu erhöhen. “134

Das breite Lesepublikum hingegen suche statt existentieller Krisen-Dichtung „schlicht Erholung und Erbauung, die Flucht in eine weniger anstrengende Welt““135: Karl Müller weist darauf hin, wie „Bilder der Einheit, der Ruhe, Geborgenheit und Stabilität“ in der etablierten Literatur der fünfziger Jahre „Chaos und Unordnung“ bannen und „,alles Bedrohliche und Fremde“136 ausgrenzen. Die teils religiöse Heimkehrer- und Heimat-Literatur wartet mit konstanten Motive auf („Natur, Liebe, Tradition“), die die politische Katastrophe unverändert überstanden haben: „Hier wirkt das Gefühl am stärksten, daß Faschismus und Krieg, an diesen Konstanten gemessen, vergängliche Phänomene repräsentieren“137. Die schon vor 1938 vorherrschende ,insistierende Beschwörung von Heimat und Heimkehr“'138 durch AutorInnen wie Karl Heinrich Waggerl, Franz Tumler und Erna Blaas verklingt nach 1945 nicht, vielmehr belegen beispielsweise Waggerls volkstümliche Gedichte zwischen 1951 und 1956 dreimal das Bestseller-Spitzenfeld. Die darin entworfenen Geborgenheitsidyllen stabilisieren in Karl Müllers Augen das beschädigte Ich der Kriegsrückkehrer, mildern Schuldgefühle, heilen ein „,angeknackstes Selbstwertgefühl“139.

Die Lyrik der die junge Literatur repräsentierenden Stimmen der GegenwartAutorInnen (cf. Kap. 6.2), die selbst auf Lebensläufe aus „Kriegsdienst, Verwundung, manchmal Emigration, dann Beendigung des Studiums, Brotberuf “140

133 McVeigh: Kontinuität und Vergangenheitsbewältigung in der österreichischen Literatur nach 1945, S. 196.

134 Kriegleder: Die Literatur der fünfziger Jahre in Österreich, S. 41.

135 Englerth, Gausterer und Kaukoreit: Österreichs Literaturzeitschriften 1945-1990 im Überblick, S. 10 .

136 Karl Müller: Die Bannung der Unordnung. Zur Kontinuität österreichischer Literatur seit den dreißiger Jahren. In: Stadler (Hg.): Kontinuität und Bruch, S. 181-215, hier S. 187.

137 McVeigh: Kontinuität und Vergangenheitsbewältigung in der österreichischen Literatur nach 1945, S. 197.

138 Müller: Die Bannung der Unordnung, S. 187. Cf. auch Karl Müller: Zur (Dis-)Kontinuität österreichischer Literatur seit den 30er Jahren: Karl Heinrich Waggerl (1897-1973). Ein Erfolgsautor der 50er Jahre. In: Walter Buchebner Gesellschaft (Hg.): Literatur in Österreich von 1950 bis 1965, S. 52-74.

139 Müller: Die Bannung der Unordnung, S. 188.

140 Beer: Immer noch Kafka ... In: Die Zeit, 13.08.1953. 
zurückblicken, enthüllt hingegen überwiegend Traumata und Anti-Idyllen. So heißt es in Michael Guttenbrunners „Schlachtfelder“: „Der Welt, die noch nicht weiß, will ich es sagen / wie die Soldaten sterben. Sie soll hören / die Stimmen der Gewehre, Tag und Nacht“141. Gerhard Fritschs Soldat „atmete die Welt“ im Gedicht „Paris / Mai 1943“ im glänzenden Paris, dessen „Feind“142 er ist. Zweieinhalb Jahre später in „Wien / November 1945“ muss er Fragen beantworten:

Die Leute fragen mich, wo ich denn war.

Ich bin daheim. Das andre ist vorbei.

Ich war im Krieg und habe mitgemacht, wie alle neben, vor und hinter mir.

Ein paar Millionen wurden umgebracht ...

Und viel zu spät, mein Freund, erzähl ich dir. ${ }^{143}$

Den Weg der ,beschädigten‘ HeldInnen schlägt 1951 schon das erste Stimmen der Gegenwart-Gedicht ein: Bertrand Alfred Eggers „Unser Gesicht“ spricht vom Krieg in den „Gesichtern von Millionen“, vom „zerschoss'nen Niemandsland“ und von „Toten, die verwesen“144. Mit der im Folgejahr in seiner eigenen Sammlung Mohn und Gedächtnis erscheinenden „Todesfuge“ ist auch Paul Celan - nur wenigen bekannt als das „bedeutendste surrealistische Talent der jungen österreichischen Generation“"145 - Teil dieses ersten Bandes. Im nächsten Band halten Krieg und Tod Einzug in die Metaphorik von Landlyrik wie Traude Maria Seidelmanns „Mohn“: „Wie verkohlte Sparren aus den Feuergarben / rechen sich, entblättert, schwarze Narben. "146 Auch die Naturerscheinungen in Christine Bustas „Nebliger Tag“ wirken durch Begriffe wie „Todeshauch“, „trüber Rost“, „hoffnungslos“, „sturmzerfetzt“ oder „grauem Schweiß der Ängste“ ${ }^{147}$ kaum idyllisch.

141 Michael Guttenbrunner: Schlachtfelder. In: Stimmen der Gegenwart, 1953, S. 12-14, hier S. 12.

142 Gerhard Fritsch: Paris / Mai 1943. In: Stimmen der Gegenwart, 1951, S. 40.

143 Gerhard Fritsch: Wien / November 1945. In: Stimmen der Gegenwart, 1951, S. 49.

144 Bertrand Alfred Egger: Unser Gesicht. In: Stimmen der Gegenwart, 1951, S. 7.

145 Zlabinger: Literarische Zeitschriften in Österreich 1945-1964, S. 83. Cf. Christine Ivanović: Paul Celans Umweg über den Wiener Surrealismus. In: Goßens und Patka (Hg.): „Displaced“: Paul Celan in Wien, 1947-1948. Frankfurt am Main 2001, S. 62-70. Celans Lyrik verfehlt Anfang der fünfziger Jahre die österreichische LeserInnenschaft, die „wenig übrig für derartige Verse“ hat (Dor: Auf dem falschen Dampfer, S. 210), ebenso wie die Avantgarde, so Rühm: „was allerdings, etwa durch paul celan, als ,postsurrealismus‘ eben in mode kam, lehnten wir als symbolistisch verpanschten aufguss ab - das schien uns auf eine neue mythisierung hinauszulaufen, und alles mythische war durch den nationalsozialismus für uns endgültig diskreditiert.“ Rühm: das phänomen „wiener gruppe“, S. 19.

146 T. Maria Seidelmann: Mohn. In: Stimmen der Gegenwart, 1952, S. 37.

147 Christine Busta: Nebliger Tag. In: Stimmen der Gegenwart, 1951, S. 27. 
In zahlreichen Stimmen der Gegenwart-Texten erscheint die Welt ,welk und grau“148, „zartgrau“149 im günstigsten Fall. Aus der „Sinnlosigkeit“ blicken Figuren „mit leeren Augen“: „Sie hatten sich mit allem abgefunden, so wie man mit zu Boden gesenktem Gesicht hinter einem Leichenzug dahintrottet und die Erdklumpen, die andere schon zertreten haben, verträumt mit dem Fuß beiseite schiebt. “150 Die Symbolik verrät: Der Krieg hat nicht nur Millionen Tote gefordert, sondern auch unter den Lebenden „viele tote Gesichter“151 hinterlassen.

Die unter anderem 1953 von Herbert Zand skizzierte Haltlosigkeit von Figuren, ,ausgesetzt zwischen einer Welt, von der [sie] bereits Abschied genommen hatte[n], und einer anderen Welt, zu der es noch keine Brücke gab“152, entspricht der existentialistischen Grundstimmung des délaissement, die Sartre definiert als des Menschen Einsicht, dass er auf Erden verlassen und hilflos und voll verantwortlich auf sich selbst gestellt ist („qu'il est seul délaissé sur la terre au milieu de ses responsabilités infinies, sans aide ni secours, sans autre but que celui qu'il se donnera à lui-même, sans autre destin que celui qu'il se forgera sur cette terre“153). In Humbert Finks „Gegen den Strom“ wohnt der Verlassenheit ganz in diesem Sinne auch „der Mut der Verzweiflung, die nichts mehr zu verlieren hat“ ${ }^{154}$, inne. Unter Verzweiflung, der zweiten Grundstimmung der Trias Angst, Verzweiflung und Verlassenheit (angoisse, désespoir, délaissement), versteht Sartre das Handeln(müssen) ohne Hoffnung (,agir sans espoir“155) und Sicherheiten („conjecturer sans preuves, entreprendre dans l'incertitude et persévérer sans espoir“'156). Noch im letzten Jahrgang der Anthologie Stimmen der Gegenwart 1956 dominieren „dumpfe Verzweiflung“, aber auch „messerscharfe Angst“"157 viele Texte: „Es geht viel Angst um / in diesen Stunden. / Angst / in den beschriebenen Zeiten / der Städte und Gräber. “158 In der Angst schließlich wird das Individuum seiner Freiheit und Verantwortung gewahr, doch unterstreicht Sartre, Pascal paraphrasierend, dass sie dennoch nicht hemmt: „Die Angst ist keineswegs ein Hindernis für das Handeln, sondern

148 Michael Guttenbrunner: Zu Nebel ward die Welt. In: Stimmen der Gegenwart, 1952, S. 13.

149 Herbert Zand: Niemandszeit. In: Stimmen der Gegenwart, 1953, S. 32-36, hier S. 33.

150 Hermann Stöger: Die Verlobung. In: Stimmen der Gegenwart, 1953, S. 28-30, hier S. 30.

151 Humbert Fink: Gegen den Strom. In: Stimmen der Gegenwart, 1953, S. 72-75, hier S. 74.

152 Zand: Niemandszeit, S. 32.

153 Sartre: À Propos de l'existentialisme, S. 656.

154 Fink: Gegen den Strom, S. 74.

155 Sartre: L’Existentialisme est un humanisme, S. 48.

156 Sartre: Qu'est-ce que la littérature?, S. 225.

157 Paul Blaha: Der Vorabend. In: Stimmen der Gegenwart, 1956, S. 7-20, hier S. 10.

158 Alois Hergouth: Wort aus der Zeit. In: Stimmen der Gegenwart, 1952, S. 125. 
vielmehr dessen Voraussetzung, und sie ist eins mit dem Sinn jener erdrückenden Verantwortlichkeit aller gegenüber allen, die unsere Pein und unsere Größe ausmacht.“159 („[L]'angoisse, loin d'être un obstacle à l'action, en est la condition même et qu'elle ne fait qu'un avec le sens de cette écrasante responsabilité de tous devant tous qui fait notre tourment et notre grandeur. “160)

Wenig menschliche Größe, dafür umso mehr Pein spricht aus der existentialistischen Literatur, die die philosophischen Ideale ex negativo veranschaulicht, um die LeserInnen mit Fragen und Qualen („questions et tourments“161) aus ihrem unbeteiligten Zuschauen herauszulösen. Negative Erfahrungswerte wie Ekel, Fremdheit, Hass und Scham ergänzen dabei die Grundstimmung aus Angst, Hoffnungslosigkeit und Verlassenheit. Eine Ballung solcher Emotionen ist in der jungen österreichischen Nachkriegsliteratur leicht zu finden, etwa in Gerhard Fritschs Gedicht „Einem Soldaten“ (1945):

\author{
Schrei hinaus deine Qual \\ auf die triebgejagte Gasse, \\ wirf deine bangende Frage \\ den Hastenden ins Gesicht: \\ Warum, warum das alles? \\ Warum die Not, die Angst, \\ der Kampf und der Tod? \\ Wo ist unseres Lebensjammers \\ versöhnende Rechtfertigung? \\ Du kannst nicht mehr glauben \\ an die Fassaden und Masken \\ verhüllender Täuschungen, \\ weil du voll Ekel gesehen hast \\ jegliches Ding in seiner Nacktheit, \\ wenn alles abfällt von ihm \\ wie schlechter Bewurf. \\ Lüge ist alles, was sie sagen \\ vom dunklen Sinn der Welt,
}

159 Jean-Paul Sartre: Zum Existentialismus. Eine Klarstellung. Deutsch von Traugott König und Vincent von Wroblewsky. In: Sartre: Der Existentialismus ist ein Humanismus und andere philosophische Essays 1943-1948. S. 113-121, hier S. 117.

160 Sartre: À Propos de l'existentialisme, S. 656. „[I]n der Angst gewinnt der Mensch Bewußtsein von seiner Freiheit, oder, wenn man lieber will, die Angst ist der Seinsmodus der Freiheit als Seinsbewußtsein, in der Angst steht die Freiheit für sich selbst in ihrem Sein in Frage.“ (,[C]'est dans l'angoisse que l'homme prend conscience de sa liberté ou, si l'on préfère, l'angoisse est le mode d'être de la liberté comme conscience d'être, c'est dans l'angoisse que la liberté est dans son être en question pour elle-même.“) Sartre: Das Sein und das Nichts, S. 91. (Sartre: L'Être et le Néant, S. 64.)

161 Sartre: Qu'est-ce que la littérature?, S. 235. 


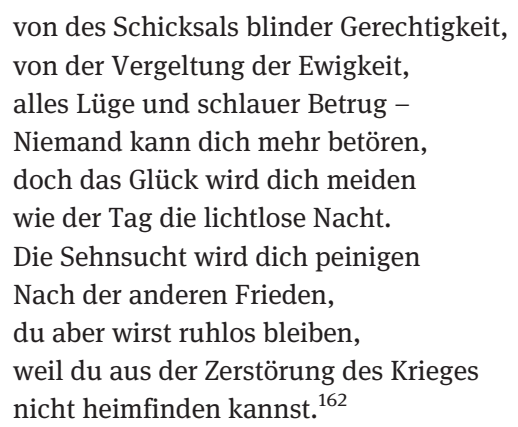

Ein Vergleich von Fritschs Gedicht mit Hans Humers Kurzprosa „Der Ungeborgene“ zeigt, wie sich der Hoffnungslosigkeit eines Menschen, der nicht ankommen kann, gattungsübergreifend Ausdruck verleihen lässt:

\begin{abstract}
Als Georg gerade auf die Straße getreten war, um sie zu überqueren, kreischten Bremsen und das Auto hielt mit einem Ruck an. Wie unter einem unsichtbaren Griff sprang Georg auf den Gehsteig zurück. Vor seinen Augen tanzte die Straße in gleißender Helle. Er fühlte sein Herz so heftig schlagen, daß Übelkeit ihm den Hals zuschnürte. [...] Er fühlte, wie die Angst in ihm hochkam, wie sie unbarmherzig an ihm zerrte. Noch nie hatte er die Straße so fremd und so verhaßt empfunden. [...] Die Zigarette, die er anzündete, zitterte in seiner Hand. Georg schämte sich. [...] Hätte er nicht unter dieses Auto kommen sollen? Wäre das nicht eine Möglichkeit gewesen, endlich einmal aus diesem Leben zu treten, das mit seinen Alltäglichkeiten seine ganze Kraft lahmlegte? Was nützte es denn überhaupt und was nützte vor allem er darin? ${ }^{163}$
\end{abstract}

Die historische Situation, die die jungen SchriftstellerInnen in Österreich wie in Frankreich in eine Verlassenheit geworfen hat, von der aus sie bis zum Äußersten, bis zum Absurden sehen können (,dans ce délaissement d'où l'on peut voir jusqu'aux extrêmes, jusqu'à l'absurde“164), lässt sie laut Lilly von Sauter von der Sentimentalität vorangegangenen Schreibens abweichen und „aus Protest gegen die übertriebene Gefühlsduselei recht häufig einer wilden Grausamkeit“"165 verfallen. Sie erschaffen damit genau jene Literatur der extremen Situationen (,littérature des situations extrêmes“166), die den Existentialismus als literarische Strömung kennzeichnet und deren Themen und Motive nach Kriegsende aufgrund des kol-

162 Gerhard Fritsch: Einem Soldaten. In: Susanne Zobl: „... weil du aus der Zerstörung des Krieges nicht heimfinden kannst“. Zu Leben und Werk von Gerhard Fritsch (28.03.192422.03.1969). In: Der literarische Zaunkönig 2004, Nr. 1, S. 38-41, hier S. 38.

163 Hans Humer: Der Ungeborgene. In: Stimmen der Gegenwart, 1954, S. 7-17, hier S. 7.

164 Sartre: Qu'est-ce que la littérature?, S. 222.

165 L. v. S.: Porträt unseres Helden, S. 807.

166 Sartre: Qu'est-ce que la littérature?, S. 222. 
lektiven Erlebens dieser Epoche das Werk zahlreicher europäischer AutorInnen durchziehen (,les gens d'une même époque et d'une même collectivité, qui ont vécu les mêmes événements, qui se posent ou qui éludent les mêmes questions, ont un même goût dans la bouche“167). Was sie eint, ist direkt aus ihrem Not, Krieg und Folter entwundenen Leben gegriffen:

Was schreiben Camus, Malraux, Koestler, Rousset usw. andres als eine Literatur extremer Situationen? Ihre Geschöpfe sind entweder am Gipfel der Macht oder in Verliesen, kurz davor, zu sterben oder gefoltert zu werden oder zu töten; Kriege, Staatsstreiche, revolutionäre Aktionen, Bombardements und Massaker, das ist ihr Alltag. Auf jeder Seite, auf jeder Zeile ist es immer der ganze Mensch, der in Frage steht. ${ }^{168}$

Que font Camus, Malraux, Koestler, Rousset, etc., sinon une littérature de situations extrêmes? Leurs créatures sont au sommet du pouvoir ou dans des cachots, à la veille de mourir, ou d'être torturés, ou de tuer; guerres, coups d'État, action révolutionnaire, bombardements et massacres, voilà pour le quotidien. A chaque page, à chaque ligne, c'est toujours l'homme tout entier qui est en question. ${ }^{169}$

Die geschilderten Szenen lassen sich als Grenzsituationen im Jaspersschen Sinne verstehen, als „eine Wand, an die wir stoßen, an der wir scheitern“170, als Lebensversuche gegen eine Mauer („,contre un mur“6171), so ähnlich Camus, als Fluchtversuche gestoppt durch eine Mauer (,arrêtées par un Mur“172), so

167 Sartre: Qu'est-ce que la littérature?, S. 76.

168 Sartre: Was ist Literatur?, S. 172.

169 Sartre: Qu'est-ce que la littérature?, S. 305. Die „tiefere und größere Bedeutung“ des Grenzerlebens kommentiert Hans Werner Richter: Der junge Mensch habe „an der äußersten Grenze der menschlichen Existenz gelebt, dort, wo das Pendel des Lebens nicht in der Mitte ruht, sondern wohin es ausschlägt, wenn es in fortwährender Bewegung ist, in der Nähe des Hasses, in der Nähe brausender Begeisterung, in der Nähe des Todes.“ Richter: Warum schweigt die junge Generation? In: Neunzig (Hg.): Der Ruf. Unabhängige Blätter für die junge Generation. Eine Auswahl; Vorwort von Hans Werner Richter. München 1976, S. 60-65, hier S. 61 [Zuerst in: Der Ruf 1 (1946), Nr. 2.]

170 Karl Jaspers: Philosophie, Bd. 2: Existenzerhellung. Berlin 1932, S. 203. Das in diesem Werk ausführlich betrachtete Konzept der Grenzsituation findet als „unüberschreitbare Daseinsgrenze“ (Tod, Zufall, Leiden, Schuld), an der die Existenz („eine Wirklichkeit des Selbstseins“) erwachen kann, bereits 1913 Erwähnung in Jaspers' Allgemeine Psychopathologie (Berlin, Heidelberg ${ }^{9} 1973$, S. 11), an deren Übersetzung ins Französische Sartre 1927 mitgearbeitet hat. Cf. hierzu auch Jürgen Link: Denormalisierung als Grenzsituation. Oder über den Anteil des Normalismus am Existentialismus. In: Frank und Lukas (Hg.), in Zusammenarbeit mit Landshuter: Norm - Grenze - Abweichung. Kultursemiotische Studien zu Literatur, Medien und Wirtschaft. (Michael Titzmann zum 60. Geburtstag.) Passau 2004, S. 265-282.

171 Albert Camus: Ni Victimes, ni bourreaux. In: Camus: Actuelles. Écrits politiques, Bd. 1: Chroniques 1944-1948. Paris 1950, S. 117-146, hier S. 117. [Zuerst in: Combat, 19.-30.11.1946.] 172 Jean-Paul Sartre: Prière d'insérer. In: Sartre: Euvres romanesques, S. 1807. 
Sartre. Ein wiederkehrender Topos in der um die Grenzsituationen Schuld, Kampf, Leid und Tod kreisenden existentialistischen Literatur ist etwa das Todesurteil, das Gegenstand von Prosa (Sartres „Le Mur“, Camus' L'Étranger, Koestlers Darkness at Noon) und philosophischen Abhandlungen ist, beispielsweise als Beitrag zur Debatte um den freien Willen und Determinismus (,débat entre les théories du libre arbitre et celles du déterminisme“"173) in Camus' und Koestlers Réflexions sur la peine capitale von 1957. Auch außerhalb Frankreichs bringt das Thema genügend Texte hervor. Todgeweihte, so Milo Dor, beschäftigen „dieselben Gedanken“, jene, die er in seiner Erzählung „Der vergessene Bahnhof“ in den Stimmen der Gegenwart von 1953 veranschaulicht:

Ich habe den Morgen gesehen, die anderen haben ihn nicht gesehen. Ihre Augen haben nicht denselben Morgen gesehen. Sie haben nicht gewußt, daß sie sterben werden, und konnten nicht alles sehen. Ich habe alles gesehen, klar, bis ins letzte Detail. Die Straße, auf der wir zum Hinrichtungsplatz gefahren sind, die Hügel, ein kleines, weißes Haus am Rande, mit einem kleinen Garten, die gebückte, alte Frau, einen Bauernwagen mit einem mageren Pferd, den struppigen Schnurrbart des Bauern und die erloschene Pfeife zwischen seinen gelben Zähnen. Und mein ganzes Leben lag da, auf dieser Straße. In dieser halben Stunde haben meine Augen alles ausgetrunken. Noch nie habe ich so gewünscht zu leben. Einfach leben. Ohne große Worte. In diesem Augenblick habe ich es gesehen, in dem Schauer des frühen Morgens, nach der durchwachten Nacht, meiner letzten Nacht. [...] [U]nd habe begriffen, daß es sich lohnt zu leben und für dieses Leben zu sterben, wenn es darauf ankommt. Aber das ist schon lange her. Für mich ist es schon aus. ${ }^{174}$

Die hier mit der herannahenden Hinrichtung in Gang gesetzten Gefühlsprozesse - Agitiertheit, gesteigerte Wahrnehmung der Umwelt, schließlich Beruhigung, Gleichgültigkeit und Akzeptanz des Schicksals - variieren die berühmte Schlussszene von Camus' L'Étranger (1941), in der der zum Tode verurteilte Held Meursault endlich zur Ruhe kommt:

Ich war erschöpft und warf mich auf meine Pritsche. Ich glaube, ich habe geschlafen, denn als ich wach wurde, schienen mir die Sterne ins Gesicht. Die Geräusche der Landschaft stiegen zu mir auf. Düfte aus Nacht, Erde und Salz kühlten meine Schläfen.Wie eine Flut drang der wunderbare Friede dieses schlafenden Sommers in mich ein. In diesem Augenblick und an der Grenze der Nacht heulten Sirenen. Sie kündeten den Aufbruch in eine Welt an, die mir nun für immer gleichgültig war. Zum erstenmal seit langer Zeit dachte ich an Mama. Jetzt begriff ich auch, warum sie am Ende eines Lebens einen „Bräutigam“ genommen, warum sie wieder „Anfang“ gespielt hatte. Auch dort drüben, dort im Altersheim, in dem die Leben erloschen, war der Abend wie ein melancholischer

173 Arthur Koestler: Réflexions sur la potence. In: Koestler und Albert Camus: Réflexions sur la peine capitale, introduction et étude de Jean Bloch-Michel. Paris 2002, S. 113.

174 Milo Dor: Der vergessene Bahnhof. In: Stimmen der Gegenwart, 1953, S. 107-116, hier S. $115 \mathrm{f}$. 
Waffenstillstand. Dem Tod so nahe, hatte Mama sich gewiß wie befreit gefühlt und bereit, alles noch einmal zu erleben. Als hätte dieser große Zorn mich von allem Übel gereinigt und mir alle Hoffnung genommen, wurde ich angesichts dieser Nacht voller Zeichen und Sterne zum erstenmal empfänglich für die zärtliche Gleichgültigkeit der Welt. ${ }^{175}$

(J'étais épuisé et je me suis jeté sur ma couchette. Je crois que j’ai dormi parce que je me suis réveillé avec des étoiles sur le visage. Des bruits de campagne montaient jusqu'à moi. Des odeurs de nuit, de terre et de sel rafraîchissaient mes tempes. La merveilleuse paix de cet été endormi entrait en moi comme une marée. À ce moment, et à la limite de la nuit, des sirènes ont hurlé. Elles annonçaient des départs pour un monde qui maintenant m'était à jamais indifférent. Pour la première fois depuis bien longtemps, j'ai pensé à maman. Il m'a semblé que je comprenais pourquoi à la fin d'une vie elle avait pris un „fiancé“ pourquoi elle avait joué à recommencer. Là-bas, là-bas aussi, autour de cet asile où des vies s'éteignaient, le soir était comme une trêve mélancolique. Si près de la mort, maman devait s'y sentir libérée et prête à tout revivre. Personne, personne n'avait le droit de pleurer sur elle. Et moi aussi, je me suis senti prêt à tout revivre. Comme si cette grande colère m'avait purgé du mal, vidé d'espoir, devant cette nuit chargée de signes et d'étoiles, je m'ouvrais pour la première fois à la tendre indifférence du monde.) $)^{176}$

Camus lässt Meursault vor der Vollstreckung der Todesstrafe wie befreit von der ihm nun indifferenten Welt erscheinen. Ihre „zärtliche Gleichgültigkeit“ („tendre indifférence“) zitieren mehrere österreichische AutorInnen teils wörtlich, wie Helmut Eisendle, in dessen essayistischer Prosa Jenseits der Vernunft oder Gespräche über den menschlichen Verstand sich zwei Freunde am Mittelmeer einem philosophischen Dialog hingeben, mit dem Resultat: „Man kann sich in der zärtlichen Gleichgültigkeit dieser Welt geborgen oder fremd fühlen. “177 Die Figur Rainer in Elfriede Jelineks Die Ausgesperrten nimmt den Gleichmut Meursaults als direktes Vorbild: „Dort schert den Helden nichts, genau wie mich. Er weiß, daß nichts wichtig ist, und er nur seines Todes, der ihn erwartet, sicher sein kann.“178 Gerade die „Stelle, wo für den Verurteilten eine Welt aufbricht, die ihm für immer gleichgültig geworden ist“, beschäftigt den Jugendlichen:

Rainer, der den Fremden von Camus liest, sagt, er möchte die Feindlichkeit der Welt zurücklassen. Wenn einem die Hoffnung auf Besseres genommen ist, dann hat man die Gegenwart endlich ganz in der Hand. Dann ist man selber die Wirklichkeit, und die übrigen

175 Albert Camus: Der Fremde. Deutsch von Georg Goyert und Hans Georg Brenner. Reinbek 1976 [1961], S. 121f.

176 Albert Camus: L’Étranger. Paris 1957, S. 185 f.

177 Helmut Eisendle: Jenseits der Vernunft oder Gespräche über den menschlichen Verstand. Salzburg 1976, S. 35.

178 Jelinek: Die Ausgesperrten, S. 116. 
sind Statisten. Wenn der Rainer einen Abend sieht, dann sagt er gleich, daß dieser Abend ein melancholischer Waffenstillstand ist, in dem das Leben erloschen ist. ${ }^{179}$

Er wiederholt, wie auswendig gelernt: „Wo das Leben erloschen ist, ist der Abend wie ein melancholischer Waffenstillstand, macht uns Camus glaubhaft“, und wählt zur Erreichung dieses „trêve mélancolique“ die eigenhändige Auslöschung seiner Familie:

Die Welt hat eine zärtliche Gleichgültigkeit, sagt Camus. Man muß ihre Feindseligkeit hinter sich lassen, sagt Camus. Wenn einem die Hoffnung weggenommen ist, dann hat man die Gegenwart ganz in der Hand, man ist selber die Wirklichkeit, und alle anderen sind Statisten. Das sind sie sowieso. ${ }^{180}$

Wer nichts mehr zu erhoffen hat - wie auch Sisyphos durch seine nutz- und hoffnungslose Tätigkeit (,travail inutile et sans espoir“"181) des ewigen Felsbrockenschiebens - , wird bei Sartre und Camus auf besondere Weise frei. Die Gewissheit der zum Tode Verurteilten, ihre göttliche Verantwortungslosigkeit (,,divine irresponsabilité‘ du condamné à mort“182), stellt zugleich einen Extremfall reiner Verzweiflung dar („où le désespoir soit pur“"183). Alle konventionellen Vorstellungen und Sinngebungen fallen von ihnen ab, alle traditionellen Werte verkehren sich, was die Menschen wirklich befreie, notiert Camus in seinen Carnets (,[l]'homme vraiment libre est celui qui, acceptant la mort comme telle, en accepte du même coup les conséquences - c'est-à-dire le renversement de toutes les valeurs traditionnelles de la vie“184). Diese sich im Angesicht des Todes realisierende Befreiung entspricht, insofern als keine (die Freiheit im Sartreschen Sinne konstituierenden) Entwürfe in die Zukunft mehr möglich sind, einer „Vergleichgültigung der Weltdinge und -tatsachen zu sinnentleerten Ansammlungen kontingenter Phänomene, die inert sind, träge und unbeteiligt, und namenlos die Augen des Klarsichtigen erfüllen.“"185 In Camus’ La Peste etwa sind diejenigen EinwohnerInnen der nach außen hin abgeschlossenen Stadt Oran, die die Pest überleben, bald von „einer eigenartigen Gleichgültig-

179 Jelinek: Die Ausgesperrten, S. 254, 54.

180 Jelinek: Die Ausgesperrten, S. 256; cf. S. 206.

181 Camus: Le Mythe de Sisyphe, S. 163.

182 Jean-Paul Sartre: Explication de „L'Étranger“ (1943). In: Sartre: Situations, I. Essais critiques. Paris 1947, S. 92-112, hier S. 96.

183 Albert Camus: Carnets I. Mai 1935 - février 1942. Paris 1962, S. 141.

184 Albert Camus: Carnets I. Mai 1935 - février 1942. Paris 1962, S. 118.

185 Manfred Geier: Das Glück der Gleichgültigen. Von der stoischen Seelenruhe zur postmodernen Indifferenz. Reinbek 1997, S. 190. 
keit“186 („une curieuse indifférence“187) erfüllt. Die sich unter den Vorzeichen der Unaufhebbarkeit des Todesurteils entwickelnde Befreiung sorgt für Schwierigkeiten im unwahrscheinlichen Szenario einer Aufhebung, wie Sartres Erzählung „Le Mur“ zeigt: Im Spanischen Bürgerkrieg wartet der Gefangene Pablo Ibbieta mit zwei anderen Verurteilten auf seine Hinrichtung, wird aber durch das Verraten des vermeintlichen Verstecks eines Gefährten im letzten Moment begnadigt, wobei sich die falschen Angaben, die er macht, unerwartet als tatsächlicher Aufenthaltsort des Gesuchten erweisen. Das die Geschichte beendende verzweifelte Gelächter Ibbietas über seine Freilassung lässt vermuten, das Todesurteil ist reversibel, die Gefühle, die es ausgelöst hat, sind es nicht:

Wenn man mir in dem Zustand, in dem ich war, mitgeteilt hätte, daß ich getrost nach Hause gehen könnte, daß man mich am Leben ließe, hätte mich das kaltgelassen: ein paar Stunden oder ein paar Jahre warten, das ist alles gleich, wenn man die Illusion, ewig zu sein, verloren hat. Mir lag an nichts mehr, in gewisser Weise war ich ruhig. ${ }^{188}$

(Dans l'état où j'étais, si l'on était venu m'annoncer que je pouvais rentrer tranquillement chez moi, qu'on me laissait la vie sauve, ça m'aurait laissé froid: quelques heures ou quelques années d'attente c'est tout pareil, quand on a perdu l'illusion d'être éternel. Je ne tenais plus à rien, en un sens, j'étais calme. $)^{189}$

Ähnlich entwickelt sich Ilse Aichingers Erzählung „Die geöffnete Order“, die 1951 in den Stimmen der Gegenwart erscheint: Soldaten in einem Stellungskrieg warten ungeduldig auf ihren Einsatz und planen bereits, auch ohne Befehl anzugreifen, als die Befehlshabenden einen von ihnen mit einer Meldung zum Kommando schicken. Nach einigem Fragen und Warten mit einer Order auf

186 Camus: Die Pest, S. 111.

187 Camus: La Peste, S. 173. Zu einer weiteren diesbezüglichen Romanidee von Camus cf. Albert Camus: Tagebücher 1935-1951. Deutsch von Guido G. Meister. Reinbek 1997 [1972], S. 427 (Hervorhebung im Original) (Camus: Carnets II. Janvier 1942 - mars 1951. Paris 1964, S. 281 [Hervorhebung im Original]): „Roman. Zum Tode verurteilt. Aber man schmuggelt ihm Zyankali zu ... Und dort, in der Einsamkeit seiner Zelle, begann er zu lachen. Ein unendliches Wohlbehagen erfüllte ihn. Er schritt nicht mehr der Mauer zu. Er hatte die ganze Nacht vor sich. Er würde wählen können ... Sich sagen ,Jetzt‘ und dann ,nein, noch einen Augenblick', und diesen Augenblick auskosten ... Welch eine Vergeltung! Welch eine Widerlegung!“ („Roman. Condamné à mort. Mais on lui fait passer le cyanure ... Et là, dans la solitude de sa cellule, il se mit à rire. Une aise immense l'emplissait. Ce n'était plus le mur contre lequel il marchait. Il avait toute la nuit. Il allait pouvoir choisir ... Se dire ,Allons‘ et puis ,Non, un moment encore‘ et savourer ce moment ... Quelle revanche! Quel démenti!“)

188 Jean-Paul Sartre: Die Wand. In: Sartre: Die Kindheit eines Chefs. Erzählungen. Deutsch von Uli Aumüller. (Gesammelte Werke in Einzelausgaben, Romane und Erzählungen 2.) Reinbek 1985, S. 24.

189 Jean-Paul Sartre: Le Mur. In: Sartre: Euvres romanesques, S. 211-233, hier S. 227. 
dem Rückweg, öffnet der verunsicherte Überbringer das versiegelte Dokument, das auf seine Erschießung lautet. Die Welt wird ihm ab diesem Moment fremd, die Umgebung erhält, wie bei Sartre, plötzlich einen komischen Anschein (,un drôle d'air“190): Die Erde trägt „den Abdruck eines fremden Gesichtes“, sein Reisebegleiter hat nun „eine Fraglosigkeit der Kontur, die ihm selbst versagt blieb“191. Der Bote schießt sich selbst an, um Schlimmerem zu entgehen, worauf sich jedoch aufklärt, dass die Order nur „eine merkwürdige Chiffre für den Beginn der Aktion“ war:

Während er dalag, wich seine Auflehnung einer verzweifelten Heiterkeit. Das Verbluten schien ihm dem Entweichen durch verschlossene Türen ähnlich, einem Übergehen aller Posten. Der Raum, der nur durch die Helle der gegenüberliegenden Mauer wie von Schneelicht ein wenig erleuchtet wurde, enthüllte sich als Zustand. Und war nicht der reinste aller Zustände Verlassenheit und das Strömen des Blutes Aktion? ${ }^{192}$

Aichingers „Die geöffnete Order“ findet später Eingang in den Band Rede unter dem Galgen, in dem sie von verschiedenen Grenzsituationen erzählt, von Tod, Angst und Ohnmacht, und fragt: „Und sind nicht alle Geschichten, die jemals erzählt wurden, von Grenzen bestimmt gewesen und von bedrohten Grenzen?“193 In ihren poetologischen Überlegungen „Das Erzählen in dieser Zeit“, die 1952 ebenfalls in den Stimmen der Gegenwart erscheinen, wird die Todesnähe zur Schreibhaltung:

So können alle, die in irgendeiner Form die Erfahrung des nahen Todes gemacht haben, diese Erfahrung nicht wegdenken, sie können, wenn sie ehrlich sein wollen, sich und die anderen nicht freundlich darüber hinwegtrösten. Aber sie können ihre Erfahrung zum Ausgangspunkt nehmen, um das Leben für sich und andere neu zu entdecken. ${ }^{194}$

Die Titelerzählung „Rede unter dem Galgen“ illustriert, wie unter dem Galgen Redende „vom Leben selbst“195 reden: Ein Verurteilter klärt in einem Monolog die ZuschauerInnen seines Unglücks über ihr grundsätzliches Zum-Tode-Sein auf, weiß allerdings, dass er selbst durch den „Strick um meinen Hals“ nicht mehr Teil des Ganzen ist: „Ich hab’s verlernt, dem Land die Furcht zu glauben,

190 Jean-Paul Sartre: Le Mur. In: Sartre: Euvres romanesques, S. 227.

191 Ilse Aichinger: Die geöffnete Order. In: Aichinger: Der Gefesselte. Erzählungen (19481952). Frankfurt am Main ${ }^{7} 2010$ [1991], S. 30-38, hier S. 34, 33.

192 Aichinger: Die geöffnete Order, S. 38, 37.

193 Ilse Aichinger: Das Erzählen in dieser Zeit. In: Aichinger: Der Gefesselte, S. 9-11, hier S. 9.

194 Aichinger: Das Erzählen in dieser Zeit, S. $10 \mathrm{f}$.

195 Aichinger: Das Erzählen in dieser Zeit, S. 10. 
dem Mond sein Licht, dem Frieden seine Ruh.“196 In dieser Situation wird nun, wie in Sartres „Le Mur“, die Hinrichtung abgebrochen:

Mein Henker ist gegangen, wie ein Dieb ist er gegangen und hat den Strick von meinem Hals gestohlen, ruft ihn zurück! Den Strick soll er mir wiedergeben, den roten Striemen darf er mir nicht nehmen, bevor ich ihn noch habe, die bloße Armut darf mir keiner aus den Händen winden! Bleibt, bleibt, schleicht euch nicht weg! Laßt mich jetzt nicht allein in der geschenkten Trauer, im Schein der Gnade, die kein Erbarmen hat. ${ }^{197}$

Es hebt hier „die Gnade nicht das Urteil auf“198, der Effekt der verhinderten Hinrichtung kommt dem einer Hinrichtung gleich. Verhandeln die genannten Texte von Sartre, Camus und Dor mit dem existenzphilosophischen Topos mehr oder minder konkrete menschliche Schuldgefühle des Verrats, des Unterlassens und des Davonkommens klingt bei Aichinger die Überlebensschuld an, die von Jean Améry später in aller Deutlichkeit aufgegriffen werden. Améry, Überlebender mehrerer Konzentrationslager, thematisiert in seinem Roman-Essay Lefeu oder der Abbruch (1974) die Schuldgefühle des titelgebenden Malers Lefeu, der sich weigert, seine verwahrloste Mansarde in einem im Abriss begriffenen Pariser Wohngebäude in der Rue Roquentin (!) ${ }^{199}$ zu räumen. Mit dem Widerstand gegen „den Abbruch meiner Person und meines Hauses“200 richtet er sich gegen das der allgemeinen Mentalität entsprechende Hinter-Sich-Lassen der

196 Ilse Aichinger: Rede unter dem Galgen. In: Aichinger: Der Gefesselte, S. 99-105, hier S. 101, 104.

197 Aichinger: Rede unter dem Galgen, S. 104.

198 Aichinger: Rede unter dem Galgen, S. 105. Eindrücklich illustriert dies Franz Kafka in seinem „Brief an den Vater“ (1919) im Hinblick auf eine ausbleibende körperliche Bestrafung: „Es ist, wie wenn einer gehenkt werden soll. Wird er wirklich gehenkt, dann ist er tot und es ist alles vorüber. Wenn er aber alle Vorbereitungen zum Gehenktwerden miterleben muß und erst wenn ihm die Schlinge vor dem Gesicht hängt, von seiner Begnadigung erfährt, so kann er sein Leben lang daran zu leiden haben. Überdies sammelte sich aus diesen vielen Malen, wo ich Deiner deutlich gezeigten Meinung nach Prügel verdient hätte, ihnen aber aus Deiner Gnade noch knapp entgangen war, wieder nur ein großes Schuldbewußtsein an.“ Franz Kafka: Brief an den Vater. In: Kafka: Nachgelassene Schriften und Fragmente II. In der Fassung der Handschriften. Hg. von Jost Schillermeit. Frankfurt am Main 1992, S. 168.

$199 \mathrm{Zu}$ den zahlreichen Sartre-Verweise im Roman cf. auch Ivonn Kappel: „In fremden Spiegeln sehen wir das eigene Bild“. Jean Amérys Lefeu oder Der Abbruch. Würzburg 2009.

200 Jean Améry: Lefeu oder Der Abbruch. Stuttgart 1982 [1974], S. 109. Giorgio Agamben spricht in Quel che resta di Auschwitz. L'archivio e il testimone (Homo sacer III. Torino 1998) von Amérys Unwillen, sich mit dem Erlittenen zu ,arrangieren', im Gegensatz zu dem ,vergebenden` Primo Levi, als einer Ethik des Ressentiments (etica del risentimento). 
Vergangenheit. Das in seinem Tod endende Nein ,ist rückführbar auf das Faktum, daß ich das Überstehen nicht überstehen kann“:

Es gab seither keine Jasage mehr: das Reich des Todes hatte sich aufgetan in der Welt. [...] Die Widersinnigkeit meiner Existenz stand in mir selbst vor mir. Warum spielte ich das längst verlorene Spiel noch mit? Warum korrespondierte ich mit Verlegern und Funkstationen, nahm läppische Tagessorgen blödsinnig ernst? Warum spielte ich den Schriftsteller, ich, der in irgendeinem längst durchpflügten Massengrab hätte seinen Platz finden sollen? ${ }^{201}$

Der Tod ist jenseits „der Logik des Lebens“, jenseits des Gewohnheitsdenkens; durch das Todesurteil - ob vom Ich selbst oder vom Anderen ausgesprochen wird das Individuum „frei, wenngleich auf eine ungeheuerliche Weise“, nichts gelte mehr, weshalb die „Fahrt zurück ins Unfreie“ für Améry „etwas Vernichtendes“202 hat. In seinem Essay Hand an sich legen: Diskurs über den Freitod (1976) diskutiert er die von Camus' als einziges wirklich ernstes philosophisches Problem („problème philosophique vraiment sérieux“203) bezeichnete Selbsttötung. Vor diesem Problem steht das Individuum laut Camus' Essai Le Mythe de Sisyphe nach der Konfrontation mit dem Absurden, bei dem es sich um die Vergeblichkeit des menschlichen Vernunftanspruchs gegenüber dem

201 Améry: Lefeu oder Der Abbruch, S. 130, 186f. Lefeus Geschichte kehrt (ohne direkten Verweis) zwei Jahrzehnte später sehr deutlich im Roman Levys neue Beschwerde (Graz 1989) des Grazer Autors Gabriel Loidolt wieder, in dem ein aus Europa stammender, in New York lebender jüdischer Schriftsteller sich ebenfalls mit tödlichem Ausgang der Räumung seiner ärmlichen Wohnung widersetzt und seine Hartnäckigkeit auf die „Lagerhaft im Dritten Reich“ (S. 15) zurückführt. Existentialistische Versatzstücke finden sich vereinzelt auch in Loidolts Prosa Leuchtturm (1988) oder Hurensohn (Berlin 1998), dessen erster Satz lautet: „Ich habe meine Mutter umgebracht, meine allerliebste Mutter!“ (S. 5), erinnernd an Camus’ Auftakt „Aujourd'hui, maman est morte“ (S. 9) in L'Étranger. Darauf angesprochen, antwortet Loidolt: „Also mir ist es nicht aufgefallen. Ich wollte so anfangen, dass man vom ersten Satz so gefesselt ist. Ich habe mir gedacht, das ist gut, vielleicht habe ich das unbewusst gewählt, dass es so ähnlich wie bei Camus klingt“. Werner Schandor: Der Underdog. In: Schreibkraft, Nr. 2/3 (1999). https://schreib kraft.adm.at/ausgaben/02-wiederkehr/der-underdog (einges. 03.01.2019).

202 Améry: Hand an sich legen, S. 24, 136, 147.

203 Camus: Le Mythe de Sisyphe, S. 15. Camus' Name fällt bisweilen ohne weiteren Zusammenhang in Verbindung mit dem Suizid-Topos, wie in Michael Köhlmeiers Trilogie der sexuellen Abhängigkeit (Innsbruck, Wien 1996, S. 27): „Warum ist diese Stadt so selbstmörderfeindlich? Praktisch keine Brücken, keine offenen Schienen ... Da sitzen die Grünen im Stadtrat, und nichts geschieht in dieser Richtung ... O Gott, wie gern hätte ich Camus persönlich kennengelernt!“ 
unvernünftigen Schweigen („silence déraisonnable“) der Welt handelt, um eine sich plötzlich in der Lebensmechanik auftuende Kluft:

Manchmal stürzen die Kulissen ein. Aufstehen, Straßenbahn, vier Stunden Büro oder Fabrik, Essen, Straßenbahn, vier Stunden Arbeit, Essen, Schlafen, Montag, Dienstag, Mittwoch, Donnerstag, Freitag, Samstag, immer derselbe Rhythmus - das ist meist ein bequemer Weg. Eines Tages aber erhebt sich das „Warum“, und mit diesem Überdruß, in den sich Erstaunen mischt, fängt alles an. „Fängt an“ - das ist wichtig. Der Überdruß steht am Ende der Handlungen eines mechanischen Lebens, gleichzeitig leitet er aber auch eine Bewußtseinsregung ein. Er weckt das Bewußtsein und fordert den nächsten Schritt heraus. Der nächste Schritt ist die unbewußte Rückkehr in die Kette oder das endgültige Erwachen. Schließlich führt dieses Erwachen mit der Zeit zur Entscheidung: Selbstmord oder Wiederherstellung. ${ }^{204}$

(Il arrive que les décors s'écroulent. Lever, tramway, quatre heures de bureau ou d'usine, repas, tramway, quatre heures de travail, repas, sommeil et lundi mardi mercredi jeudi vendredi et samedi sur le même rythme, cette route se suit aisément la plupart du temps. Un jour seulement, le „pourquoi“ s'élève et tout commence dans cette lassitude. „Commence“, ceci est important. La lassitude est à la fin des actes d'une vie machinale, mais elle inaugure en même temps le mouvement de la conscience. Elle l'éveille et elle provoque la suite. La suite, c'est le retour inconscient dans la chaîne, ou c'est l'éveil définitif. $\mathrm{Au}$ bout de l'éveil vient, avec le temps, la conséquence: suicide ou rétablissement.) ${ }^{205}$

\section{Im Verhältnis zu Camus ist das Absurde für Améry}

in Wahrheit zugleich alltäglicher und schrecklicher als der Sisyphos-Mythos, ein jeder von uns erlebt das Absurde, nur wenige nehmen das Erlebnis auf sich und führen es denkend und handelnd, ,denkhandelnd', würde ich schreiben, klänge das Wort nicht so gequält, zu Ende. On s'arrange: dies eine der meistgebrauchten Formeln der französischen Umgangssprache, die knapp die Tatsachen widerspiegelt. ${ }^{206}$

Für die beiden nach dem Einbruch des Absurden geschilderten Möglichkeiten, Lebensbeendigung oder Zurücksinken in den Alltag, finden sich in der österreichischen Prosa der fünfziger Jahre Beispiele: Marlen Haushofers Held in „Die Stechmücke" hat sich trotz innerer Widerstände ein bürgerliches Leben aufgebaut, in das sich jäh das Bewusstsein über einst überschrittene Grenzen bahnt: „Und wie ein Mensch, der aus der Narkose erwacht, fing er plötzlich an zu leiden. Er hatte Dinge gehört, gesehen und getan, die ihm erst jetzt ganz bewußt wurden, und er fand es widersinnig, daß er nach allem immer noch lebte.“207

204 Camus: Der Mythos des Sisyphos, S. 22 f.

205 Camus: Le Mythe de Sisyphe, S. 46, 29.

206 Améry: Hand an sich legen, S. $145 \mathrm{f}$.

207 Marlen Haushofer: Die Stechmücke. In: Haushofer: Schreckliche Treue, S. 158-166, hier S. 160 . 
Als es ihm nicht gelingt, die an seinem Fenster sterbende titelgebende Stechmücke zu retten, springt er in die Tiefe. Für die andere Option, die Wiederaufnahme des Lebens, entscheidet sich nach einem verunsichernden Blick gen Himmel die Heldin in Gerhard Fritschs Kurzgeschichte „Der Augenblick der Bedienerin“, mit Verweis auf den Existentialismus:

Der Himmel ist leer, und Frau K. ist traurig. Die Papierkörbe liegen zu ihren Füßen und außerdem ist es 7.33 Uhr geworden. Eine Bedienerin spürt zum erstenmal in ihrem Leben das elementare Unter-den-leeren-Himmel-Gehaltensein, das der Ausgangspunkt jeder wirklichen menschlichen Leistung ist und welches die Existentialisten, ebenso voreilig wie auf der anderen Seite die rosigen Katecheten, die Konfrontation mit dem Nichts betiteln. Aber es ist wirklich schwer, dafür etwas anderes als ganz großartige Worte zu finden, auch wenn es sich nur um den metaphysischen Augenblick einer Bedienerin handelt. [...] Sie wird bald ihre Körbe aufnehmen, hinauftragen und die nächsten herunterbringen. ${ }^{208}$

Wie die Uniformität des Alltags in Le Mythe de Sisyphe eine stets bedrohte Sicherheit darstellt, insistiert Fritschs Erzählerinstanz darauf, Dora K. habe ,es‘ wahrgenommen: „Keiner von uns ist sicher davor. Jeden trifft es in seinem Augenblick.“209 Camus empfiehlt als Reaktion eine Revolte genannte Lebenshaltung, die im Ertragen - bewusst und würdevoll - der Absurdität besteht, und greift als Modell den antiken Sisyphos-Stoff auf. Sisyphos, König von Korinth, ist dazu verdammt, im Hades einen schweren Stein hügelauf zu rollen, der sogleich wieder hinabrollt, wie Homer im XI. Gesang („Die Totenwelt“) der Odyssee berichtet:

Ja auch zu Sisyphus sah ich hinein, der leidend sich plagte;

Schob er ja doch einen riesigen Block mit beiden Händen.

Wahrlich, er stieß ihn hinauf bis zum Gipfel und stemmte dagegen,

Brauchte Füße und Hände; doch war es so weit, daß die Höhe

Endlich er hatte, da drängte die Überschwere ihn abwärts.

Wieder dann rollte der schamlose Stein in die Felder hinunter.

Er aber fing wieder an sich zu plagen und stieß, daß der Körper

Triefte vor Schweiß; um den Kopf aber kreiste von Staub eine Wolke. ${ }^{210}$

208 Fritsch: Der Augenblick der Bedienerin, S. 80. Zu einem direkten Verweis auf die Existentialisten kommt es auch in Fritschs Hörspiel Nachtfahrt (Baden 1983, S. 31), in dem ein bahnreisendes Ich unter Hervorhebung seiner Sartre-Kenntnisse mit einem zugestiegenen Pater über die „Verzweiflung an einer Welt ohne Sinn“ diskutiert.

209 Fritsch: Der Augenblick der Bedienerin, S. 82.

210 Homer: Odyssee, griechisch-deutsch; übertragen von Anton Weiher, mit Urtext, Anhang und Registern, Einführung von A. Heubeck. Berlin ${ }^{14} 2013$, S. 319. Zu Camus' Quellen und seinem Umgang mit dem antiken Mythos cf. Paul Archambault: Camus' Hellenic Sources. Chapel Hill/NC 1972; sowie Helmut Hühn: Revolte gegen das Absurde: Sisyphos nach Camus. In: Vöhler und Seidensticker, in Zusammenarbeit mit Emmerich (Hg.): Mythenkorrekturen. Zu einer 
Die kräftezehrende Tätigkeit verhindert laut Camus jede Bewusstwerdung, doch talwärts durchschaut Sisyphos sein Los, das er für sich annimmt, was ihn über die strafenden Götter erhebt. Während Sartre als Reaktion auf die Absurdität des menschlichen Seins (bei ihm Kontingenz - „la contingence universelle de l'être, qui est, mais qui n'est pas le fondement de son être“"211) die Sinngebung im freien Entwurf propagiert, rät Camus, für den jede Sinn-Sehnsucht unerfüllt bleiben muss, in die Breite zu leben, Erlebnisse zu maximieren. In der fiktionalen Welt optieren Sartres und Camus' Figuren bei Aussichtslosigkeit meist für das Weitermachen: Der sich gegen die in Oran wütende Pest auflehnende Dr. Rieux weiß, seine Aufgabe besteht darin, immer wieder von Neuem anzufangen (,consiste à recommencer“212), in Sartres Les Séquestrés d'Altona gilt für jeden dysfunktionalen Tag der Hamburger Familie: Alles ist von vorn zu beginnen (,[t]out est à recommencer“²13), und die drei Höllen-InsassInnen in Huis clos schließen den letzten Akt mit der (alternativlosen) Absicht, ihre Situation fortzusetzen (,[e]h bien, continuons“214).

Camus' 1950 auf Deutsch erschienener Essay Der Mythos von Sisyphos. Ein Versuch über das Absurde findet wenig Widerhall in der Presse, einige Resonanz jedoch bei österreichischen AutorInnen, von der einfachen Erwähnung des Mythos so wissen nach Jeannie Ebner alle KünstlerInnen, dass sie „den Stein anpacken“ müssen, „um ihn, wie Sisyphos, immer wieder zum Gipfel zu wälzen, auf daß er wieder zurückrolle“²15 - bis zur Ehrerbietung, so von Milo Dor: Er trifft, als er 1949 in Paris einige Wochen in Paul Celans Wohnung verbringt, nicht nur auf Manès Sperber, der in einem Rundfunkgebäude auf den Champs-Elysées arbeitet, sondern „drückte Albert Camus die Hand, dessen Mythos des Sisyphos, seit ich ihn gelesen hatte, eine Art Bibel für mich geworden war."216 Produktiv rezipieren Erich Fried und Rudolf Henz das Thema in Form von Gedichten:

paradoxalen Form der Mythenrezeption. (spectrum Literaturwissenschaft, Komparatistische Studien 3.) Berlin 2005, S. 345-368.

211 Sartre: Interview [mit Christian Grisoli], S. 1916.

212 Camus: La Peste, S. 149.

213 Sartre: Les Séquestrés d'Altona, S. 904.

214 Jean-Paul Sartre: Huis clos. In: Sartre: Théâtre complet, S. 89-128, hier S. 128.

215 Jeannie Ebner: Der Künstler und die Welt. In: Stimmen der Gegenwart, 1953, S. 145-151, hier S. 151.

216 Dor: Auf dem falschen Dampfer, S. 204f. Englerth sieht in Camus’ Essai die „zentrale Referenz für Dor in Tote auf Urlaub“, ein Text, dessen Held „auf der Sinnhaftigkeit von Revolte in einer ansonsten als sinnlos erkannten Welt“ bestehe. Holger Englerth: Literatur als Medium des Widerstands: Milo Dor. In: Sievers (Hg.): Grenzüberschreitungen. Ein literatursoziologischer Blick auf die lange Geschichte von Literatur und Migration. Wien, Köln, Weimar 2016, S. 85-126, hier S. 106. 


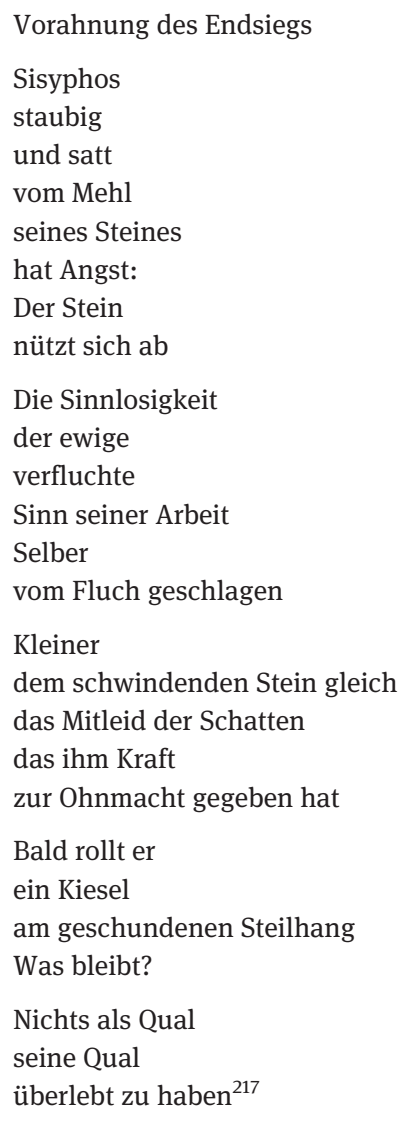

Während Fried dem antiken Mythos eine tragische Wendung verleiht, indem er Sisyphos mit dem sich abnützenden Felsen seinen Lebensinhalt nimmt, würdigt Rudolf Henz Camus' Text zu einem Teil des Existentialismus-Spektakels herab:

Sisyphos

Stemmt er den Stein auch bergan, wenn er sich allein weiß?

Vielleicht ruht er wie jede andere Weltattraktion, wenn die Schau geschlossen ist, die Kassiere schlafen, die Fremdenführer, kein Wächter am Geländer gähnt, Kein Psychiater mit Stoppuhr nicht ein einziger Reporter.

217 Erich Fried: Vorahnung des Endsiegs. In: Fried: Gedichte. Ausgewählt und hg. von Klaus Wagenbach, mit einem Nachwort des Herausgebers. München ${ }^{13}$ 2007, S. 17. 
Seit er sich in der großen Hades-Halle produziert mag ich ihn nicht mehr sehen.

Auch sie ist längst zu klein.

Wer heut auf sich hält, muß Sisyphos am Stein gesehen, sein Keuchen gehört haben -

Die Lautsprecheranlage funktioniert ausgezeichnet, wenn der Block von der Gipfelkante kippt, zurück, auf ihn, ihn überrollend in riesigen Sprüngen niederdonnert. Den Aufschrei der Tausend ertrüge ich nicht.

Als ich noch bei den Humanisten eingeschrieben war, vor fünfzig Jahren, vor vierzig, hatten wir jede Woche eine Führung durch die griechische Unterwelt.

Sisyphos stand nicht auf dem Programm.

Ganz weit hinten ein komisches Gepolter.

Sohn des Aiolos,

König von Korinth.

Seines ungebührlichen Benehmens wegen

in den Steinbruch verdammt.

Das genügte damals für Humanistenlehrlinge.

Als Vorbild wurde er uns nicht hingestellt.

Heut schlägt wo im Winkel

Orpheus die alte Leier,

singt Homer, vergnügt wie nur

ein Blinder noch sein kann, doch unbeachtet

wie seine Helden.

Die humanistischen Knaben von heute

entspringen dem Führer und stürzen

in die Monsterhalle hinüber und staunen

geifernd, wie der Stein zurückspringt und erzählen

daheim dann, strahlenden Auges:

Okay, ich habe die Verzweiflung gesehen! $!^{218}$

Dieses Anfang der sechziger Jahre verfasste Gedicht ist „deutlich gegen Camus und den Existentialismus gerichtet“, so Sigurd Paul Scheichl über Henz’ Kulturkonservatismus: „Die Oberflächlichkeit der Auseinandersetzung mit Camus wird man einem satirischen Gedicht nicht vorwerfen dürfen; problematisch - und zeittypisch - ist dagegen der Rückgriff aufs humanistische Gymnasium als Ort der bedrohten Werte“ ${ }^{\text {‘219 }}$.

218 Rudolf Henz: Sisyphos. In: Strelka (Hg.): Das zeitlose Wort, S. 105 f.

219 Scheichl: Vergessene. Träger des Großen Österreichischen Staatspreises in den 50er Jahren, S. 87. 
Es ist vor allem Albert Camus’ „offensives Ablehnen des Sprungs in den Glauben“220 in Le Mythe de Sisyphe, das einigen RezipientInnen Schwierigkeiten bereitet. Im Gegensatz zu den im weiteren existentialistischen Rahmen aufgenommenen Christen Emmanuel Mounier und Gabriel Marcel und zu Sartre, dem eigentlichen ,Gottsucher wider Willen' (cf. Kap. 7.3), erweist sich Camus als diesbezüglich schwer vereinnehmbar. Serge Doubrovsky spitzt diesen Kontrast 1960 in den Yale French Studies zu:

\begin{abstract}
Camus, indeed, is the farther away of the two from Christianity, since Sartre is merely anti-Christian, while Camus is un-Christian, pagan. Sartre and the Christians alike burden the individual with the weight of his original guilt and the sinfulness of his existence. Many Sartrean themes, such as responsibility, guilt, anguish, hatred of the flesh [...] seem to be inverted Christian themes. Camus, on the contrary, proclaims the value of sensuousness and the right to happiness, even in the midst of the plague ${ }^{221}$.
\end{abstract}

Dass mitten im Epidemiegeschehen des hier erwähnten Romans La Peste die Rebellion gegen Gott durchaus ihren Platz hat, verdeutlicht unter anderem eine Szene, in der der Arzt Rieux dem über den Dingen stehenden Pater Paneloux bitter die an der Pest verstorbenen Kinder vorhält: „Auch die grausamste Prüfung war für den Christen noch Gewinn.“222 („L'épreuve la plus cruelle était encore bénéfice pour le chrétien.“') ${ }^{223}$ Textstellen wie diese lassen das französische Besatzungsblatt Kulturelles den Roman sogar als das „antichristlichste seiner Bücher“2224 bezeichnen. Dass La Peste sich, getragen durch die Berichterstattung in Zeitschriften aller Ausrichtungen, in Österreich dennoch großer Beliebtheit (cf. Kap. 4.3) erfreut mehr als Camus' sonstige Prosa und weit mehr als seine Philosophie und seine Dramen - mag an dem Diskussionsraum liegen, den dieser antichristliche Diskurs eröffnet. Lilly von Sauter fasst in der Europäischen Rundschau mithilfe des „großartigen Buches“ exemplarisch die Erwartungen an den zeitgenössischen Roman zusammen: „Wir erwarten vom Roman nicht mehr, daß er uns eine Geschichte erzählt, eine Fabel, einen Bericht, wir verlangen, daß er uns dazu bringt, über uns selber nachzudenken, daß er zu einer inneren Offenbarung wird.“225

Dass es sich bei der positiven Aufnahme eines solchen Buches eher um einen glücklichen Einzelfall als um die Leserealität handelt, klingt bei Eva Priester im Österreichischen Tagebuch an: Diese Art von Literatur sei von der

220 Thomas Angerer: Versuch einer Zusammenschau. In: Angerer und Le Rider (Hg.): Französisch-österreichische Kulturtransfers seit 1945, S. 315-337, hier S. 320.

221 Serge Doubrovsky: Sartre and Camus: A Study in Incarceration. In: Yale French Studies 1960, Nr. 25, S. 85-92, hier S. 91.

222 Camus: Die Pest, S. 131.

223 Camus: La Peste, S. $202 \mathrm{f}$.

224 o. V.: Kurznachrichten. In: Kulturelles, 15.11.1948.

225 L. v. S.: Porträt unseres Helden, S. 806. 
„überwiegenden Mehrheit“‘226 einer die jüngere Vergangenheit verdrängenden Vergessenskultur unerwünscht. Claudia Frank (alias Bobbie Löcker) spricht in der unabhängigen Zeitschrift Plan ebenfalls von „der überwiegenden Mehrheit“, die „alles, was an vergangenen Kampf, an Angst, Elend, Schmerz, Leid und Verzweiflung gemahnt, an ihre, an aller Existenz gerührt hat" - und sei es auf symbolische Weise - , vergessen will, weil „,aus dem Hinschauen auf Unabänderliches nur eine neue Belastung des schon zur Genüge Bedrückten oder des bisher relativ Unbeschwerten erwachse.“227 Dieser Argumentation folgen Anfang der fünfziger auch einige junge SchriftstellerInnen wie Jeannie Ebner, die der zum Nachdenken anregenden Verarbeitungsliteratur 1953 klar überdrüssig ist:

So wie man den heimgekehrten Soldaten immer wieder vom Krieg erzählen hört, findet man in der Literatur unserer Zeit immer wieder den Kriegsroman und die Schilderung des Grauens. Sofern sie ehrlich sind, haben sie hohen chronistischen, letztlich also historischen Wert. Aber die immer wiederholte, reportagehafte Darstellung des Gräßlichen macht dieses nicht ungeschehen, sie verleiht ihm vielmehr deutlichere und stärkere Existenz, und läßt es als selbstverständlichen Bestandteil unserer Weltordnung erscheinen. ${ }^{228}$

Therapien für die von Traumata Geplagten zu liefern, sei das Gebiet von Fachleuten, meint Ebner, nicht das der Künstler. Thomas Bernhard pflichtet ihr bei:

Der Großteil setzt sich mit der jüngsten Vergangenheit auseinander, ist von Krieg und Bombardement, Mord, Flucht und Heimkehr durchsetzt. In sie haben die Autoren (nicht immer die ehrlichsten!) ihren Angstzustand verlagert, und wenn wir darin lesen, so empfinden wir nicht Zu-, sondern Abneigung. Wir selbst haben oft noch mehr von diesen ,Abenteuern` erlebt, als daß wir in diesen ,hoffnungslosen Resultaten des schrecklichsten Krieges‘ aufgehen könnten. ${ }^{229}$

226 Eva Priester: Die Aufgaben der österreichischen Literatur. In: Österreichisches Tagebuch, 16.11.1946. Cf. dazu Fritsch: Literatur, S. 7: „Daß der Schwung dieser austriakischen Renaissance bald erlosch, lag nicht nur an den Besatzungsmächten und an jenem nicht unwesentlichen Teil der österreichischen Bevölkerung, dessen Sentiment und Ressentiment zum Nationalsozialismus geführt hatte oder durch ihn bestimmt worden war. Selbstbesinnung, Bedenken und ,Bewältigen“ der Vergangenheit wurden auch durch Schematismus und opportunistisch betonte Phraseologie in weiten Kreisen kalmiert und erstickt. Im Gegensatz zum sogenannten Altreich [...] etablierte sich das öffentliche und private Bewußtsein so schnell wie bequem im geistigen Gestern, in ladenhütenden Klischees, die sich im übrigen für den bald ausbrechenden Kalten Krieg recht verwendbar erweisen sollten.“

227 Claudia Frank: Erinnern oder vergessen. In: Plan 1 (1945), Nr. 1, S. 133-134, hier S. 133.

228 Ebner: Der Künstler und die Welt, S. 146.

229 Bernhard: Bücher warten auf Dich!, S. 89. 
Das Beispiel Bernhard zeigt, dass auch manche, die ab den sechziger Jahren zu SchlüsselakteurInnen der literarischen Aufarbeitung werden, anfangs mit der „Dominanz apolitischer Literaturkonzepte und einer tendenziellen Abwendung von zeitgeschichtlichen Themen“230 konform gehen. Eine Reihe von Werken widerspricht dieser Tendenz jedoch schon, bevor die sechziger Jahre-Romane von Hans Lebert, Thomas Bernhard und Gerhard Fritsch schonungslos Verborgenes hervorholen und energisch „literarisches Niemandsland“231 beschreiten. Im Zusammenhang mit frühen Aufarbeitungsversuchen wie in Herbert Zands Letzte Ausfahrt (1953) fallen vielfach Namen von ExistentialistInnen, so in Wolfgang Kraus' Nachwort:

Camus, der frühe Sartre, Malraux, Gabriel Marcel und Wolfgang Borchert sind die eigentlichen Zeitgenossen Zands, obwohl nur Borchert derselben Generation angehörte. Wie sie alle erkannte Zand die Verurteilung zu einem Schicksal, das man nicht verändern, sondern in dem man nur sich selbst verändern kann. ${ }^{232}$

Fritz Habecks Prosa dreht sich laut Andreas Weber ebenfalls um die (existentialistisch beeinflusste) Suche nach Sinn und Werten im eigenen Leben:

Einerseits repräsentiert er das geistige Klima der sich an konservativen Werten orientierenden offiziellen Kulturpolitik des österreichischen Wiederaufbaus, andererseits ist in seinem Werk der Einfluß des französischen Existentialismus (Albert Camus, Jean-Paul Sartre) deutlich erkennbar. Habeck schrieb Geschichten vom Wandel, vom Zerfall und vom Weitermachen, um Haltung und den damit verbundenen Rest an Würde gegenüber dem Nihilismus zu bewahren. ${ }^{233}$

Gegen Ende seines Zeitromans Der Ritt auf dem Tiger (1958) spielt Habeck explizit mit der Opferthese (cf. Kap. 3.2), wenn er die mit einem Österreicher verheiratete Figur Helga, die nach 1945 nach Deutschland ausreist, darüber sinnieren lässt, dass Österreich ,ja bekanntlich unser erstes Opfer“ war:

Ich weiß durch meinen Mann, wie uns die Österreicher im Jahr 1938 empfangen haben. Ich weiß, wie sie sich den Juden gegenüber benommen haben und daß sie die wildesten

230 Günther Stocker: Der Kalte Krieg in der österreichischen Literatur. Ein Überblick. In: Hansel und Rohrwasser (Hg.): Kalter Krieg in Österreich, S. 59-80, hier S. 62 f.

231 McVeigh: Kontinuität und Vergangenheitsbewältigung in der österreichischen Literatur nach 1945, S. 217.

232 Wolfgang Kraus. In: Herbert Zand: Letzte Ausfahrt. Roman der Eingekesselten. Wien, Zürich 1992, S. 295-302, hier S. 299.

233 Weber: Über die Kluft zwischen Generationen, S. 16. Offenbar aus diesen Gründen halten Andreas Weber und Jutta Freund Habeck für einen der „wenigen ernsthaften Existenzialisten der österr. Literatur nach 1945“. Cf. Weber und Freund: Habeck, Fritz. In: Kühlmann (Hg.), in Verbindung mit Aurnhammer et al.: Killy Literaturlexikon. Autoren und Werke des deutschsprachigen Kulturraums. Bd. 4: Fri-Hap. Berlin 2009, S. 549-550, hier S. 549. 
Nationalsozialisten waren. Jetzt schieben sie alle Schuld auf uns. Sie sind ein charakterloses Volk und ich mag nichts mit ihnen zu tun haben. ${ }^{234}$

Als weitere Beispiele blicken Ernst Lothars Die Rückkehr (1949) und Reinhard Federmanns Das Himmelreich der Lügner (1959) nicht nur auf die jüngere Vergangenheit, sondern auch auf die mehr oder minder verborgene Kontinuität des Faschismus in der Gegenwart. Die zeitliche Differenzierung macht einen großen Unterschied angesichts der spezifischen Situation Österreichs, so McVeigh: Erübrige sich de facto durch den Opferstatus die Aufarbeitung der Phase 1938 bis 1945, sei der Fortbestand nationalsozialistischer Gesinnung umso problematischer, seine Sichtbarmachung durch die Literatur umso essentieller. ${ }^{235}$ Die Literatur leistet diese Aufgabe im Wesentlichen allein, bemerkt Ingeborg Bachmann in ihrem Vorreden-Entwurf zum Roman Der Fall Franza:

Die Massaker sind zwar vorbei, die Mörder noch unter uns, oft beschworen und manchmal festgestellt, nicht alle, aber einige, in Prozessen abgeurteilt. Die Existenz dieser Mörder ist uns allen bewußt gemacht worden, nicht durch mehr oder minder verschämte Berichterstattung, sondern eben auch durch die Literatur. ${ }^{236}$

Jenen „Mördern und Irren“, die auch in Bachmanns gleichnamiger Erzählung aus Das dreißigste Jahr (1961) nach dem Krieg „das Beste, was wir verloren haben“237, weiterjagen, lässt Michael Guttenbrunner schon 1953 sehr klare Worte zuteilwerden:

Die gegen euch erhobenen Klagen der ungezählten Tode, durch Gewalt und List bewirkt, sind vom Wind verweht, seit ihr wieder die ,Alten' seid: Bürger und Bürgen einer Ordnung, dem Leben vorgesetzt, wie der Galgen der ewigen Seligkeit. Vergessen ist, was der von Kopf zu Kopf einzeln und einsam arbeitende Henker mit Blut ins Licht gekeltert hat. Jedem unbarmherzigen Mitknecht, der seinen barmherzigen Richter schon gefunden und auch schon wieder vergessen hat, stehn eure Türen offen. [...] Ich aber sage: Die Mörder sind unter uns. ${ }^{238}$

234 Fritz Habeck: Der Ritt auf dem Tiger. Hamburg, Wien 1958, S. 545 f. Wenig später kritisiert die Erzählinstanz: „Auch die Atrappe [!] des österreichischen Menschen wurde wieder aus der Requisitenkammer geholt, und man entdeckte, daß man ja gar nicht deutsch, sondern österreichisch spreche, nannte das alte Deutsche Volkstheater nur mehr Volkstheater und verwendete das Wort Deutsch nur mehr als Kennzeichnung für minderwertige Charakterzüge.“ (S. 550).

235 Cf. McVeigh: Kontinuität und Vergangenheitsbewältigung in der österreichischen Literatur nach 1945, S. 198.

236 Ingeborg Bachmann: Der Fall Franza. Requiem für Fanny Goldmann. München ${ }^{5} 1986$, S. 9 f. 237 Ingeborg Bachmann: Unter Mördern und Irren. In: Bachmann: Sämtliche Erzählungen, S. 159.

238 Michael Guttenbrunner: Absage. In: Stimmen der Gegenwart, 1953, S. 118-121, hier S. 118 f. 
Der erste Roman, der sich der Abrechnung von Naziverbrechen, „der österreichischen Schuld und der nicht geleisteten Sühne“"239 verschreibt und insofern als bahnbrechend („un travail de mémoire pionnier“ ${ }^{240}$ ) gelten kann, ist Die Wolfshaut (1960), dessen Verfasser Hans Lebert zehn Jahre zuvor dichtend prophezeit:

Als hätte es nur auf dem Grunde

der Dinge unser geharrt,

strömt es nun breit aus dem Munde, aus des Landes verfilztem Bart. ${ }^{241}$

Der konkrete Ort, an dem sich dieses Szenario in Die Wolfshaut vollzieht, heißt Schweigen und summiert damit bereits das Hauptverhalten der in ihm angesiedelten Dorfgemeinschaft. Ein aus dem Krieg zurückgekehrter, aus dem Kollektiv ausgeschlossener Matrose spürt einem Verbrechen nach, das einem Fluch gleich über Schweigen liegt - versinnbildlicht nicht durch eine Fliegenplage wie in Sartres Les Mouches, sondern durch einen auf der Lauer liegenden Wolf. $^{242}$ Einige EinwohnerInnen, darunter auch der an den eigenen Schuldgefühlen zugrunde gegangene Vater des Matrosen, haben in den letzten Kriegstagen FremdarbeiterInnen hingerichtet und die Tat danach verdrängt. Ihre Gesichter erscheinen nun wie „Masken, durch deren Augenschlitze etwas anderes hervorsah, etwas, das gar nichts zu tun hatte mit dem Staatsbürgerblick jener Leute. Es drang von hinten durch die Mauer, durch Steine, Mörtel und Verputz, war im fotografischen Papier als unsichtbarer Moderfleck verspürbar.“243 Gerhard Fritsch rühmt hier den „Inhalt, der das vielzitierte Schlagwort von der ,Bewältigung‘ und ,Aufarbeitung‘ der Vergangenheit weitab der ge-

239 Kriegleder: Die Literatur der fünfziger Jahre in Österreich, S. 48.

240 Hélène Barrière: L'Hybridation narrative au service du débat sur le nazisme dans Die Wolfshaut (1960) de Hans Lebert. In: Germanica 2008, Nr. 42, S. 1-14, hier S. 1. https://jour nals.openedition.org/germanica/527 (einges. 09.01.2019).

241 Hans Lebert: Vergangenheit. In: Tür an Tür, 1950, S. 51.

242 Jürgen Egyptien: Kreuzfahrten durch den leeren Himmel. Hans Leberts „Wolfshaut“ als transzendentales Logbuch. In: Hans Lebert: Die Wolfshaut. Wien, Zürich 1991, S. 597-627, hier S. 614: Egyptien erkennt hier existentialistische Züge im „Gefühl der Verlassenheit, der Heimatlosigkeit und eines absoluten Ausgesetztseins“: „Unabweisbar spürt man hier die nicht nur zeitliche Nähe der ,Wolfshaut' zum Existenzialismus von Sartre oder Camus, deren berühmteste Romane ,Der Ekel', ,Der Fremde‘ oder ,Die Pest‘ schon alleine mit ihren Titeln in die Kernzonen der ,Wolfshaut" weisen.“

243 Hans Lebert: Die Wolfshaut. Hamburg 1960, S. 29. 
nannten Klischees zu erfüllen scheint.“244 Das „Pandämonium verbrecherischer Durchschnittlichkeit“245, das Lebert auffährt, nimmt Fritsch als Ausgangskonstellation für seinen eigenen Roman Fasching (1967): Auch hier trifft eine verschworene Dorfgemeinschaft auf einen Außenseiter, der sich weigert, den dringenden Rat „vergeben und vergessen“, „vergessen und vergeben“246 anzunehmen.

Auf einen von allen Seiten misstrauisch beäugten Einzelgänger konzentriert sich auch Thomas Bernhards Prosa Frost, die der Wolfshaut-Atmosphäre gleicht in ihrem „existenziellen Schrei““247, in der Animalität der dargestellten Menschen, der „Unmenschlichkeit“ der Natur („das Knochengerüst des Waldes“, ein „Chaos aus Schwärze und Schlamm“, „grau und ekelhaft“) und in der Brutalität des Klimas („ein naßkalter, wühlender, würgender Luftstrom“, „ein Frosthauch, ein eisiges Etwas“, „ein Unbehagen, ein ekelhaftes, frostiges Gefühl“248). Bevor mit dem Genre der Anti-Heimatliteratur in den siebziger Jahren eine „ansehnliche Liste der Nestbeschmutzer“ entsteht, stellt sich Bernhard radikal gegen die entlastende Neuinszenierung von Heimat mit ihren „Klischees der unschuldigen Natur“249:

Kinder entdeckten in Mulden hochexplosive Panzerfäuste, von denen sie zerrissen wurden. Fetzen von Kindern, wissen Sie, auf den Bäumen. Männer im besten Alter konnte man von Kanonenrädern erdrückt finden [...]. Und da und dort zerschossene Uniformen auf den Bäumen und aus dem Tümpel herausschauende steife Hände und Füße. ${ }^{250}$

244 Gerhard Fritsch: Dahintreibend in den Meeren des Herbstes. Zur Dichtung Hans Leberts. In: Wort in der Zeit 7 (1961), Nr. 3, S. 9-12, hier S. 9.

245 Fritsch: Dahintreibend in den Meeren des Herbstes, S. 12. Ein Jahr später, 1961, folgt mit Helmut Qualtingers und Carl Merz’ Der Herr Karl „eine einzige Abrechnung mit der österreichischen Spielart der Vergangenheitsbewältigung“, ein Angriff auch auf „den unpolitischen Österreicher, der durch Bauernschläue, Ideologieskepsis und Kompromißbereitschaft politische Übergriffe erfolgreich überstand“. Jutta Landa: Bürgerliches Schocktheater. Entwicklungen im österreichischen Drama der sechziger und siebziger Jahre. (Literatur in der Geschichte. Geschichte in der Literatur 15.) Frankfurt am Main 1988, S. 37. Zur Behandlung des Themas auf der Nachkriegsbühne cf. Peter Roessler: Studien zur Auseinandersetzung mit Faschismus und Krieg im österreichischen Drama der Nachkriegszeit und der 50er Jahre. Köln 1987.

246 Gerhard Fritsch: Fasching. Mit einem Nachwort von Robert Menasse. Frankfurt am Main 1995, S. 148.

247 Ronald Pohl: Der Untergang von Thomas Bernhards Welt. In: Der Standard, 12.02.2019.

248 Lebert: Die Wolfshaut, S. 23, 90, 87, 72, 57, 58, 7.

249 Ingeborg Rabenstein-Michel: Bewältigungsinstrument Anti-Heimatliteratur. In: Germanica 2008, Nr. 42, S. 1-11, hier S. 1, 2. https://journals.openedition.org/germanica/525 (einges. 09.01.2019).

250 Thomas Bernhard: Frost. Hg. von Martin Huber und Wendelin Schmidt-Dengler. (Werke, 1.) Frankfurt am Main 2018 [2003], S. 147. 
Kriegsnöte haben bei diesen in die literarhistorische Kontinuität einschneidenden VorreiterInnen eine von Skepsis durchdrungene „Anschauungskraft von der Welt“251 wachsen lassen: „Da gab es alle paar Jahre neue Götter und neue Verbrecher, neue Gesetze und neue Fahnen, neue Schwüre und neue Schulbücher lauter ,absolute“ Werte, die sich so gar nicht als beständig erwiesen“ ${ }^{\text {‘252 }}$, so Eisenreich. Wie in Leberts Die Wolfshaut erscheint Österreich bei Thomas Bernhard als „Lande der Anstreichermeister“, in dem „dauernd übertüncht und frisch gestrichen“253 wird. Kinder bezeugen, „mit welch taschenspielerischer Hurtigkeit“ man die „nazibraune Farbe mit altösterreichisch katholischem Tiefschwarz übermalte“254 ${ }^{25 o m m e n t i e r t ~ J e a n ~ A m e ́ r y ~ B e r n h a r d s ~ a u t o b i o g r a p h i s c h e s ~ W e r k ~ D i e ~ U r-~}$ sache. Eine Andeutung. Den plötzlichen Wandel der Erziehungsmethoden nach 1945 im Internat reflektieren darin die belassenen Wände: „Der ganze Raum war nicht einmal ausgemalt worden, dafür fehlte es offensichtlich an Geld, denn wo jetzt das Kreuz hing, war noch der auf der grauen Wandfläche auffallend weiß gebliebene Fleck zu sehen, auf welchem jahrelang das Hitlerbild hing. “255

Das Aufdecken ist teils unausgesprochene, teils ausdrückliche (cf. Kap. 6.4) Programmatik dieser AutorInnen, die mit ihren Porträts von Grenzsituationen der littérature engagée in deren Absicht des Enthüllens nahestehen. So kommt die Germanistin Daniela Strigl im Hinblick auf die Autoren Walter Buchebner, Hans Lebert und Andreas Okopenko zu dem Ergebnis: „Gerade die existentialistische Literatur der Nachkriegszeit zeigt jedenfalls, daß in Österreich keineswegs flächendeckend vergessen und verdrängt wurde.“256 Durch die Überschneidung dieser SchriftstellerInnen-Generation, die den Krieg in jungen Jahren miterlebt, und der existentialistischen Subkultur (als zugleich erste gegen den „Konsens des Schweigens über die politische Vergangenheit““257 opponierende Gruppe), werden auch Darstellungen von Verzweiflung, Hoffnungslosigkeit und Verlassenheit, die mehr der Zeit als dem Einfluss des Existentialismus geschuldet sind, oft mit dem Attribut ,existentialistisch` bedacht.

251 Bernhard: Die Kultur ist nicht stehen geblieben!, S. 142.

252 Eisenreich: Worin besteht der Unterschied?, S. 35.

253 Lebert: Die Wolfshaut, S. 387.

254 Jean Améry: Morbus Austriacus. Bemerkungen zu Thomas Bernhards „Die Ursache“ und „Korrektur“. In: Merkur 30 (1976), Nr. 1, S. 91-94, hier S. 94.

255 Thomas Bernhard: Die Ursache. Eine Andeutung. In: Bernhard: Die Autobiographie. St. Pölten, Salzburg 2011, S. 76.

256 Strigl: Marlen Haushofers Existentialismus, S. 133.

257 Krüger: Viel Lärm ums Nichts?, S. 268. 


\subsection{Littérature engagée zwischen Sprachskepsis und Engagement}

In Frankreich macht die mit dem Generationenwechsel nach Kriegsende einsetzende literarische Neuordnung das Engagement zur verpflichtenden Haltung. ${ }^{258}$ Demographische Faktoren, der Tod von Vorkriegsgrößen wie Jean Giraudoux und Romain Rolland und das Ausscheiden von SchriftstellerInnen der Kollaboration wie Louis-Ferdinand Céline ebnen den Weg für Résistance-AutorInnen wie Vercors, Sartre oder Camus, die mit einer gesteigerten Sensibilität für die Macht des Wortes die Literatur in ein Naheverhältnis zur Politik rücken. ${ }^{259}$ Bereits im ersten Heft der Zeitschrift Les Temps modernes, die sich mit engagierten Texten gegen die ,reine‘ Kunst der Zwischenkriegsära positioniert, kündigt Sartres Artikel „La Nationalisation de la littérature“ seine später in Qu'est-ce que la littérature? ausgeführte Poetik an:

Gewiß ist das geschriebene Werk eine Tatsache, die die Allgemeinheit angeht, und der Schriftsteller muß, noch ehe er zur Feder greift, sich dessen voll bewußt sein; er muß von seiner Verantwortlichkeit ganz durchdrungen sein. Er ist für alles verantwortlich: für verlorene und gewonnene Kriege, für Auflehnung und Unterdrückung; er unterstützt den Unterdrücker, wenn er nicht der natürliche Verbündete der Unterdrückten ist: Aber nicht nur

258 Cf. Dugast: La Situation culturelle de la France après 1945, S. 308.

259 Cf. Sapiro: La Guerre des écrivains, S. 561f. Es existieren diesbezüglich durchaus kritischere Einschätzungen: Trotz des Erfolges der Résistance-SchriftstellerInnen erkennt Wajsbrot eine literarische Kontinuität in Werken von Gide, Mauriac, Bernanos oder Claudel, die teils ohne die geringste Infragestellung auskämen. Selbiges gelte nach 1945 für die Surrealisten, die weiterhin eine vom Grauen des Krieges unbetroffene Traumwelt erforschten, ein Vorwurf, den auch Sartre in Qu'est-ce que la littérature? aussprechen wird. Wajsbrot stimmt Sartres literaturtheoretischen Forderungen zu, wirft aber auch ihm Heuchelei vor, da das Geschehen seiner Roman-Trilogie Les Chemins de la liberté im entscheidenden Moment ende, statt sich weiter mit dem Pétain-Regime auseinanderzusetzen (was Sartre allerdings in seinem 1946 uraufgeführten Theaterstück Morts sans sépulture nachholen wird; cf. Kap. 8.1). Wajsbrots Fazit zu der in der Literatur vorherrschenden Neigung, Vichy aus der Geschichte Frankreichs auszuklammern, weist Parallelen zur österreichische Situation dieser Jahre auf: „Die Literatur ähnelt der Gesellschaft, aus der sie stammt, und in den späten 1940er Jahren und am Anfang der 1950er Jahre hatten beide den gleichen offenkundigen Wunsch zu reparieren, oder eher zu kompensieren [...], und weigerten sich beide, den Dingen ins Auge zu sehen. Letzten Endes wurde trotz der Säuberung, die die Illusion erweckt, sich der Situation gestellt zu haben, alles in Eile erledigt, um danach besser zu vergessen.“ [Übers. d. Verf.] („La littérature ressemble à la société dont elle est issue, et, dans la fin des années 40, le début des années 50, on trouve dans l'une et l'autre le même désir apparent de réparer, plutôt de compenser [...], et le même refus de voir les choses en face. Au bout du compte, malgré l'épuration qui donne l'illusion d'avoir affronté la situation, tout s'est réglé à la hâte pour mieux oublier après.“) Wajsbrot: Littérature: le roman en fuite, S. 66, cf. S. 62-63, 65, 67. 
deshalb, weil er Schriftsteller ist, sondern vielmehr, weil er Mensch ist. Er muß diese Verantwortlichkeit leben und wollen [...]. Für ihn geht es nicht darum zu wissen, ob er einen neuen literarischen „-ismus“ ins Leben ruft, sondern darum, sich in der Gegenwart zu binden. Nicht eine ferne Zukunft vorauszusehen, von der aus er sich nachträglich beurteilen kann, sondern von einem Tag zum andern die unmittelbare Zukunft anzustreben. ${ }^{260}$

(Sans doute l'œuvre écrite est un fait social et l'écrivain avant même que de prendre la plume doit en être profondément convaincu. Il faut, en effet, qu'il se pénètre de sa responsabilité. Il est responsable de tout: des guerres perdues ou gagnées, des révoltes et des répressions; il est complice des oppresseurs s'il n'est pas l'allié naturel des opprimés. Mais non point seulement parce qu'il est écrivain: parce qu'il est homme. Cette responsabilité il doit la vivre et la vouloir [...]. Il ne s'agit pas pour lui de savoir s'il va déterminer un mouvement littéraire en „isme“, mais de s'engager dans le présent. Non de prévoir un avenir éloigné d'où il se puisse juger après coup, mais de vouloir au jour le jour l'avenir prochain.) ${ }^{261}$

Durch den Druck des Krieges plötzlich situiert („brusquement situé“), hätten die AutorInnen die eigene Geschichtlichkeit erfahren und könnten nur mehr aus der Subjektivität ihrer Gegenwart heraus Literatur verfassen; in allem, was sie schrieben, mache sich ein geschichtlicher Beigeschmack („un goût d'histoire“262) bemerkbar. Sich über den Zeitlauf zu erheben und Geschehnisse aus der Vogelperspektive zu beurteilen, jenes bei früheren SchriftstellerInnen so beliebte Überfliegen („survol“‘263), sei damit verunmöglicht. Vielmehr herrscht, so Gabriel Marcel in seinem Nachwort zu Paul-André Lesorts Roman Auf Herz und Nieren, der 1955 in Graz bei Styria erscheint, inzwischen

eine Abneigung gegen eine Technik, die beim Schriftsteller das unbegreifliche Vermögen voraussetzt, über seinen Geschöpfen zu schweben und uns von dem, was sie sind und was ihnen zustößt, eine Gesamtschau zu geben. Im wirklichen Leben ist sie keinem gegeben und kann keinem gegeben sein. ${ }^{264}$

Diese Abneigung ist auch bei österreichischen LiteratInnen und LiteraturkritikerInnen auszumachen, etwa bei Eva Priester, die 1946 in „Die Aufgaben der österreichischen Literatur“ (vor)gestrige Werke beanstandet, die unter dem politisch legitimierten Motto „Schnell vergessen!“ den Buchmarkt dominieren:

260 Sartre: Die Nationalisierung der Literatur, S. 180 f. (Hervorhebung im Original).

261 Sartre: La Nationalisation de la littérature, S. 51 (Hervorhebung im Original).

262 Sartre: Qu'est-ce que la littérature?, S. 213 (Hervorhebung im Original), 214.

263 Sartre: Qu'est-ce que la littérature?, S. 213.

264 Gabriel Marcel: Nachwort. In: Paul Andre Lesort: Auf Herz und Nieren. Graz 1955, S. 555561, hier S. 556. Die Übereinstimmung des katholischen Romanciers mit den ExistentialistInnen führt Marcel auf die historischen Umstände zurück, da Lesort „diese Gedanken in der Kriegsgefangenschaft ausarbeitete, also zu einer Zeit, da er von den Werken der Existentialisten noch keine Kenntnis haben konnte.“ 
Und am laufenden Band rollen die Bücher über Salzburger Idylle, Komtessen von Anno dazumal, das Wien der guten alten Zeit, gute und schlechte Liebesgeschichten (die auf dem Mond spielen könnten), gute und schlechte Kindheitserinnerungen (die sich bestenfalls an die „Aktualität“ des alten Oesterreich heranwagen und vergeblich - Josef Roth zu kopieren suchen), subtile Psychologie der „ewigen Dreiecke“, Vierecke und sonstiger Sexualgeometrie aus der Druckerpresse. ${ }^{265}$

Diese Negativbeispiele widersprechen dem Aktualitätsgebot der existentialistischen Literatur, die keinen Sprung ins Ewige (,saut dans l'éternel“) mehr dulde; die zeitliche Dimension, so Sartre in Qu'est-ce que la littérature?, habe realistisch zu sein, die Erzählzeit der erzählten zu entsprechen (wobei die beschränkten Möglichkeiten des zeitdeckenden Erzählens den Einsatz gewisser narrativer Tricks, „des trompe-l'œil“, rechtfertigen): „Wenn wir den Leser nämlich unvermittelt in ein Bewußtsein stürzen, wenn wir ihm alle Mittel verweigern, es zu überfliegen, dann muß man ihm ohne Abkürzungen die Zeit dieses Bewußtseins aufzwingen. Wenn ich sechs Monate auf einer Seite zusammenfasse, springt der Leser aus dem Buch heraus.“266 („Si nous plongeons en effet, sans médiation, le lecteur dans une conscience, si nous lui refusons tous les moyens de la survoler alors il faut lui imposer sans raccourcis le temps de cette conscience. Si je ramasse six mois en une page, le lecteur saute hors du livre.“267)

Einzutauchen in die eigene Epoche bedeutet in diesem Sinne auch, Ereignisse im Präsens zu schildern und nicht im sinnstiftenden Rückblick. Insgesamt werden der fiktionalen Welt die Versicherungen genommen, insbesondere die über das Figurengeschick waltende AutorInneninstanz: Machten frühere Werke - explizit oder allusiv - ständig auf die Existenz ihrer UrheberInnen aufmerksam, sollte nun nichts mehr auf diese zurückweisen (,nous voulions chasser la Providence de nos ouvrages comme nous l'avions chassée de notre monde“6268). Die existentialistischen Romane verzichten - „ohne innere Erzähler noch allwissende Zeugen“،269 (,sans narrateurs internes ni témoins tout-connaissants“) - auf alle Vermittlung zwischen LeserInnen und Figuren (,intermédiaires entre le lecteur et les subjectivités-points-de-vue de nos personnages“), um auf diese Weise einen rohen, nahen Realismus der Subjektivität (,réalisme brut de la subjectivité sans médiation ni distance ${ }^{\text {“270 }}$ zu erreichen. Ein System in voller Entwicklung (,en pleine évolution“)

265 Priester: Die Aufgaben der österreichischen Literatur, S. $3 \mathrm{f}$.

266 Sartre: Was ist Literatur?, S. 172.

267 Sartre: Qu'est-ce que la littérature?, S. $305 \mathrm{f}$.

268 Sartre: Qu'est-ce que la littérature?, S. 228.

269 Sartre: Was ist Literatur?, S. 173.

270 Sartre: Qu'est-ce que la littérature?, S. 224, 305. Ziel sei überdies, mehrere Subjektivitäten darzustellen, um der Pluridimensionalität von Ereignissen gerecht zu werden, nicht fern der Polyphonie und Dialogizität, die Michail Bachtin bei dem von den Existentialisten verehrten 
ersetzt somit das stimmige Kausalgefüge des bereits durchdachten Erlebten („du vécu déjà repensé‘ ${ }^{271}$ ), von dem sich auch Lilly von Sauter 1948 in der Europäischen Rundschau abwendet:

Was der Held des Romans erlebt, soll darum aus dem tiefsten Wesen des Menschen steigen, vor allem aber nicht mehr sich aus sozialen Bedingtheiten ergeben. Mit dem im Roman des 19. Jahrhunderts unerläßlichen sozialen Rahmen, der alle Reaktionen der einmal hineingestellten Personen bestimmte, ist es ein für allemal vorbei. Die Helden des wirklich modernen Romans sind Entwurzelte, ihrer gesellschaftlichen Kleider Beraubte, die sich nicht als Angehörige einer bestimmten Klasse oder Generation zu betragen haben, sondern einfach als Menschen. ${ }^{272}$

Mit dem stärkeren Außerachtlassen sozialer Implikationen (zu einer Zeit, als das naturalistische Schreiben im akademischen Bereich in Österreich besondere Aufmerksamkeit erfährt) ${ }^{273}$ geraten auf ihre Grundlosigkeit (gratuité) zu-

Dostojewski betrachtet: „[W]enn wir über unsere Epoche Aufschluß geben wollten, mußten wir die Romantechnik von der Newtonschen Mechanik zur allgemeinen Relativität übergehen lassen, unsere Bücher mit halb-klaren und halb-dunklen Bewußtsein bevölkern, [...] von denen aber keines gegenüber dem Ereignis noch gegenüber sich selbst einen privilegierten Standpunkt hätte, mußten wir Geschöpfe darbieten, [...] die niemals von innen entscheiden können, ob die Veränderung ihrer Schicksale von ihren Bemühungen, ihren Fehlern oder dem Lauf der Welt herrührten“. (,[I]l nous fallait, si nous voulions rendre compte de notre époque, faire passer la technique romanesque de la mécanique newtonienne à la relativité généralisée, peupler nos livres de consciences à demi lucides et à demi obscures, [...] dont aucune n'aurait sur l'événement ni sur soi de point de vue privilégié, présenter des créatures [...] qui ne pourraient jamais décider du dedans si les changements de leurs destins venaient de leurs efforts, de leurs fautes ou du cours de l'univers“.) Sartre: Was ist Literatur?, S. 173. (Sartre: Qu'est-ce que la littérature?, S. 224.) Zum ,Proto-Existentialisten' Bachtin cf. Tzvetan Todorov: Mikhaïl Bakhtine: le principe dialogique suivi de Écrits du Cercle de Bakhtine. Paris 1981. Am Beispiel des Helden aus Dostojewskis Aufzeichnungen aus dem Kellerloch (1864), einer Prosa, die bereits als „the best overture for existentialism ever written“ bezeichnet wurde (Walter Kaufmann: Existentialism from Dostoevsky to Sartre. New York ${ }^{12} 1960$, S. 14), expliziert Bachtin seine dem Sartreschen Denken nicht unverwandte Idee der Unabgeschlossenheit des Menschen: „He knows that he has the final word, and he seeks at whatever cost to retain for himself this final word about himself, the word of his self-consciousness in order to become in it that which he is not. His consciousness of self lives by its unfinalizability, by its unclosedness and its indeterminancy.“ Mikhail Bakhtin: Problems of Dostoevsky's Poetics. Hg. und Englisch von Caryl Emerson, Einleitung von Wayne C. Booth. (Theory and History of Literature 8.) London, Minneapolis 1999 [1984], S. 53.

271 Sartre: Qu'est-ce que la littérature?, S. 224, 226.

272 L. v. S.: Porträt unseres Helden, S. 806.

273 Abzulesen etwa am Lehrveranstaltungsangebot zu Gerhart Hauptmann am Institut für Germanistik (Deutsche und nordische Philologie) der Universität Wien (Vorlesungsverzeichnisse Sommersemester 1947, S. 37; Wintersemester 1947/48, S. 36; Sommersemester 1948, S. 38). Cf. auch Wendelin Schmidt-Dengler: Germanistik in Wien 1945 bis 1960. In: Grandner, Heiss, Rath- 
rückgeworfene ,Entwurzelte ${ }^{\text {in }}$ den narrativen Vordergrund. Aufgabe der SchriftstellerInnen ist es nun laut Herbert Eisenreich, genau zu beobachten, wie diese ,Entwurzelten“ auf Verengungen ihrer Freiheit reagieren, ob mit „Flucht aus der Verantwortlichkeit“ oder indem sie sich mit „Ausreden aus dem psychologischen Allgemeingut“ versorgen und ihr „schlechtes Verhalten“ ${ }^{274}$ noch im Moment des Erklärens für entschuldigt halten. Die SchriftstellerInnen müssen, so Eisenreich weiter, ihre Zeit kennen, deren Tendenzen aufspüren und Herkünfte erforschen, damit die Heldinnen „nicht im luftleeren Raum einer Fiktion agieren oder sich mit Problemen herumschlagen, die aus den Museen der Historie gestohlen sind.“275 Auf diese Bemerkung trifft am meisten Andreas Webers Urteil zu, Eisenreichs Stimmen der Gegenwart-Texte „muten wie bei Sartre bzw. Camus abgeschrieben an“ ${ }^{\text {¿276 }}$, was insofern bemerkenswert ist, als Eisenreich der existentialistischen Programmatik einige Jahre später mit unmissverständlicher Ablehnung begegnen wird. 1961 notiert er, es habe sich der von Frankreich ausgehende „Begriff der engagierten Literatur“

in etlichen Köpfen eingenistet, und dieser Vogel läßt seine Exkremente seither in die Spalten gewisser Zeitungen und Zeitschriften fallen, wo sie aber, zwischen heftiger Aversion gegen die Atombewaffnung des Westens und milder Sympathie für die des Ostens, nicht weiter stören. Wir verzichten daher auf jede naheliegende Polemik gegen diese Verwechslung von Politik und Literatur, von direkter und indirekter Wirksamkeit, und behaupten bloß, daß des Schriftstellers Humanität sich weitaus umfassender äußere als durch politisches Engagement, nämlich durch sein Ja zur vollen und ganzen Wirklichkeit. ${ }^{277}$

Für diesen literarischen Umgang mit der Wirklichkeit verwendet Eisenreich in einem anderen Aufsatz, „Literatur und Politik?“ (1959), durchaus den Begriff Politik:

Seit Grillparzer mühen sich nahezu alle Dichter um das Politische, das heißt um die überindividuellen, die allgemeinen Voraussetzungen menschlichen Daseins. Man wird uns nun aber daran erinnern, daß die großen österreichischen Dichter kaum je in das politische Geschehen ihrer Zeit eingegriffen haben, sehr im Gegensatz etwa zum ,Jungen Deutschland`

kolb (Hg.): Zukunft mit Altlasten. Die Universität Wien 1945 bis 1955. (Querschnitte 19.) Innsbruck et al. 2005, S. 212-222.

274 Herbert Eisenreich: Das Herz und die Drüsen. In: Stimmen der Gegenwart, 1952, S. 184191, hier S. 188.

275 Eisenreich: Das Herz und die Drüsen, S. 185.

276 Weber: Stimmen der Gegenwart, eine Anthologie, S. 24.

277 Herbert Eisenreich: Der Roman. Keine Rede von der Krise (1961). In: Eisenreich: Reaktionen, S. 43-56, hier S. 50. 
oder zu den modernen Franzosen vom Schlag eines Gide, eines Bernanos, eines Mauriac, eines Sartre, eines Camus. ${ }^{278}$

Anders als bei den ,modernen Franzosen' degradiere der politische Charakter der österreichischen Literatur die Kunst nicht „zu einem Mittel der politischen Agitation“, sondern äußere sich „in der Einbettung des individuellen Schicksals in das geschichtliche“‘279, erklärt Eisenreich, was keinen Widerspruch zu den existentialistischen SchriftstellerInnen darstellt, die Figuren ebenfalls als in die Geschichte integriert („réintégrés dans l'histoire“ ${ }^{280}$ ) präsentieren und, nachdem sie selbst durch Krieg und Okkupation das Absolute im Schoße der Relativität erfahren haben, das metaphysische Absolute und die Relativität der geschichtlichen Tatsache (,l'absolu métaphysique et la relativité du fait historique“281) in ihren Texten vereinen. Für Sartre fungiert Literatur als kritischer Spiegel, der zeigt, beweist und darstellt, woraus die RezipientInnen anschließend machen würden, was sie wünschen (,[m]ontrer, démontrer, représenter. C'est cela l'engagement. Après ça, les gens se regardent et font ce qu'ils veulent““282). Trotz dieser sehr weiten Definition scheint die von der Kritik vorgenommene Verkürzung des Existentialismus auf sein aktivistisches Moment zuletzt gar auf „den Willen eine individualistische, liberalistische, kapitalistische Gesellschaftsform in eine universalistische, sozialistische, totalitäre umzuändern“"283, wie Peter Handke kundtun wird - Anfang der fünfziger Jahre wie bestätigt durch Sartres eigene politische Interventionen (cf. Kap. 8.2). Der Auffassung von littérature engagée als Indienstnahme der Literatur zu literaturfremden Zwecken fehlt es insoweit an Differenzierung zwischen politischem und parteipolitischem Schreiben, als Sartre die Auffassung vertritt, jedes Schreiben sei politisch (,que tout écrit est politique“), da jede literarische Äußerung von einem Standpunkt aus geschehe. Es gebe kein rein literarisches Schreiben (,écrits purement littéraires“284), vielmehr sei Literatur wesensge-

278 Herbert Eisenreich: Literatur und Politik? (1959). In: Reaktionen, S. 105-114, hier S. 105. Cf. zu diesem Themenkomplex auch Walter Thaler: Der Heimat treue Hasser. Schriftsteller und Politik in Österreich. Ein politisches Lesebuch, Vorwort: Karl Müller, Anton Pelinka. Wien 2013.

279 Eisenreich: Literatur und Politik?, S. 106.

280 Sartre: Qu'est-ce que la littérature?, S. 215.

281 Sartre: Qu'est-ce que la littérature?, S. 223.

282 Jean-Paul Sartre: Les Écrivains en personne. [Interview mit Madeleine Chapsal.] In: Sartre: Situations, IX. Mélanges. Paris 1972, S. 9-39, hier S. 31. [Zuerst in: Madeleine Chapsal: Les Écrivains en personne, 1960.]

283 Peter Handke: Die Literatur ist romantisch (1967). In: Handke: Meine Ortstafeln. Meine Zeittafeln. 1967-2007. Frankfurt am Main 2007, S. 53-63, hier S. 53.

284 Sartre: Sartre, S. 82, 81. Mit dieser Meinung steht Sartre nicht allein. Ein engagierter Autor, so Günter Grass' bekanntes Diktum, ist „wie ein weisser Schimmel“. Cf. Wolf Scheller: 
mäß Stellungnahme (,par essence prise de position““285) und politisch, ohne notwendigerweise politischen Inhalts zu sein:

Und ich glaube wirklich, daß eine eigentliche Politisierung für ein Engagement nicht notwendig ist; das ist nur die letzte Form des Engagements. Engagement, das ist zunächst die Anfechtung der Situation durch ein literarisches Werk oder deren Annahme, gleichviel; jedenfalls heißt es anerkennen, daß die Literatur ganz allgemein sehr viel mehr ist, als was sie sagt. Sie schließt notwendig die Infragestellung des Ganzen ein. ${ }^{286}$

(Et en effet, je pense que la politisation proprement dite n'est pas nécessaire à l'engagement; c'est la forme aboutie de l'engagement. Mais l'engagement, c'est d'abord la contestation par une œuvre littéraire de la situation, ou son acceptation, peu importe; mais en tout cas c'est le fait de reconnaître que la littérature d'une manière générale, est beaucoup plus vaste que ce qu'elle dit. Elle implique nécessairement la remise en question de l'ensemble.) $)^{287}$

Unter den bis in die Gegenwart reichenden Diskussionen in Österreich argumentiert zuletzt Gerhard Scheit in Kritik des politischen Engagements (2016), Sartre sei „gegen das landläufige Missverständnis zu verteidigen, er fordere die Politisierung der Kunst. [...] Der Künstler hat sich im Grunde nur für seine Kunst zu engagieren, es ist bloß die Frage, welche und worin sie besteht. “288 Idealerweise machten es sich die SchriftstellerInnen, wie Sartre schreibt, zur Pflicht, gegen das Unrecht, woher es auch stamme, anzugehen (,de prendre parti contre toutes les injustices, d'où qu'elles viennent““289), indem sie es literarisch sichtbar werden ließen. Wesentlich ist allerdings zunächst die Bewusstwerdung über die eigene Verantwortung speziell dafür, was den LeserInnen enthüllt wird; darüber, ob man, wie Sartre zuspitzt, von „Schmetterlingen oder über die Situation der Juden“ 290 („des papillons ou de la condition des Juifs““291) schreibt. Anders als in

Der Bekenner. Ein Gespräch mit Günter Grass zu seinem 70. Geburtstag. In: Schweizer Monatshefte 77 (1997), Nr. 10, S. 16-18, hier S. 16.

285 Sartre: Qu'est-ce que la littérature?, S. 276.

286 Jean-Paul Sartre: Sartre. Ein Film. Von Alexandre Astruc und Michel Contat, unter Mitwirkung von Simone de Beauvoir, Jacques-Laurent Bost, André Gorz und Jean Pouillon. Deutsch von Linde Birk. (Gesammelte Werke. Autobiographische Schriften, Briefe, Tagebücher 2.) Reinbek 1988, S. 55.

287 Sartre: Sartre, S. 83.

288 Gerhard Scheit: Kritik des politischen Engagements. Freiburg, Wien 2016, S. 558.

289 Sartre: Qu'est-ce que la littérature?, S. 283. Albert Camus äußert sich ähnlich in seinem Discours de Suède (Paris 1958, S. 14, 15), anlässlich der Entgegennahme des Literaturnobelpreises 1957: Die SchriftstellerInnen stünden nicht im Dienste derer, die Geschichte schreiben (,au service de ceux qui font l'histoire“), sondern derer, die sie erleiden würden (,au service de ceux qui la subissent“), was die Weigerung zu lügen und den Widerstand gegen Unterdrückung beinhalte (,le refus de mentir sur ce que l'on sait et la résistance à l'oppression“).

290 Sartre: Was ist Literatur?, S. 29.

291 Sartre: Qu'est-ce que la littérature?, S. 31. 
der französischen Zwischenkriegszeit, in der laut Sperber „die Frage: ,Wie?‘ hundertmal häufiger gestellt und in zahllosen Varianten beantwortet wurde als die Frage ,Wozu?' und [...] man über das ,Was` scheinbar leichtfertig hinwegging““292, wendet sich der Existentialismus gegen die Prioritäten der Kunst um der Kunst willen; nicht, weil das ,Wie?` irrelevant wäre, sondern weil das ästhetische Gefallen nur als Hinzukommendes seine Wirkung voll entfalten könne, so Sartre in Qu'est-ce que la littérature? (,l'art pur et l'art vide sont une même chose“‘293). Diese Haltung ist nach 1945 auch in Österreich verbreitet, wie Maurice Besset schildert:

Jetzt, wo der Krieg vorbei ist, kommt die Literatur, wenn nicht als Selbstzweck - die „L'art pour l'art“-Ära ist ja vorbei - , so doch als selbstständiger Wert wieder zu ihrem Recht. Von ihr verlangt man nicht mehr, daß sie unmittelbar Stellung nimmt; bei der Jugend ist sogar eine ziemlich deutliche Bewegung gegen die allzu auf Politik bezogene Literatur festzustellen. Das bedeutet aber keine Rückkehr zum verantwortungslosen Ästhetizismus der Zwischenkriegszeit: man fordert im Gegenteil von der Literatur, daß sie „engagiert“ sei. Der Begriff des „Engagements“, der vom Heideggerschen „Geworfensein“ abgeleitet ist, weist mehr als dieses auf die Pflicht des Menschen und vor allem des Dichters hin, sich seiner Verantwortung der Mitwelt gegenüber bewußt zu werden. Er ist zum Schlagwort der jungen Literatur geworden..$^{294}$

Sartres Behauptung, niemand glaube mehr an die Verantwortungslosigkeit der Kunst um der Kunst willen (,,personne ne croit plus à l'irresponsabilité ni à l'art pour l'art“295), bestätigt sich nach 1945 besonders deutlich an Zeitschriften, einer Gattung, die Alphons Silbermann allein aufgrund ihres Verhältnisses zur Aktualität schon als „engagierte Literatur“ bezeichnet, da sie stets ein „Hauch von Erneuerung, ein Bemühen um Fortschritt“296 umgibt, der üblicherweise schon aus den im ersten Heft vorgestellten Grundsätzen hervorgeht (cf. Kap. 4.3). Hohe Ansprüche hat vor allem der gerade auch für l'art pour l'art-Li-

292 Sperber: Bis man mir Scherben auf die Augen legt, S. 161.

293 Sartre: Qu'est-ce que la littérature?, S. 32.

294 Besset: Jugend und Literatur in Frankreich, S. 923. Was Besset hier schon als allgemein bekanntes Schlagwort präsentiert, sorgt zehn Jahre später bei Lilly von Sauter noch für Unsicherheit: Beauftragt, Francis Jeansons Sartre par lui-même (Paris 1955) zu übersetzen, wählt sie laut Unterweger (L’Être ou le Néant?, S. 287 f.) für den Begriff „engagement“, der nicht ausreichend verbreitet sei, wie ihr Kurt Kusenberg vom Rowohlt Verlag mitteilt, das Wort „Bindung“. Dabei handle es sich, wie Feindt (Engagement, empathie, distanciation, S. 72) herausstreicht, um ein emphatisch verwendetes Schlüsselwort in konservativen Kulturkreisen der Nachkriegsrestauration (,un mot-clé utilisé de manière emphatique par les cercles culturels conservateurs de la restauration d'après-guerre“).

295 Jean-Paul Sartre: La Responsabilité de l'écrivain. Lagrasse 1998 [1946], S. 39.

296 Silbermann: Die Kulturzeitschrift als Literatur, S. 102, 104. 
teratur offene Plan: statt der „echt österreichischen Oblomowerei“ sei die Parole nun „Arbeit, Aktivität, positive Leistung!“297

Auch die konservativ(er)en Periodika erachten es als notwendig, die SchriftstellerInnen auf die mit ihrem Beruf einhergehende Verantwortung hinzuweisen. In der Zeitschrift Die Drau stellt der Herausgeber Rudolf Felmayer im Artikel „Der Dichter und die Zeit“ Forderungen, die durchaus mit jenen Sartres im Einklang stehen: Literatur habe nicht mehr nur „,[o]berflächlich ablenkender Unterhaltung zu dienen“, vielmehr müsse sie „ein unbestechlicher Gradmesser der wahren Gesittung einer Epoche“ sein: „Jede echte Kunstleistung ist ein Barometer, das mit erschreckender Genauigkeit die jeweilig drohende Wetterlage des Menschlichen anzeigt.“298

Auch Blätter, die dem Existentialismus ausdrücklich ablehnend gegenüberstehen, verlangen nach einem ähnlichen literarischen Engagement, etwa das kommunistische Österreichische Tagebuch, demzufolge Kunst „immer auch Politik zu sein“ habe: „irgend etwas wird im Werk des Künstlers mitschwingen, das als Stellungnahme, als geistige Verantwortung und Mitverantwortung gewertet werden muß.“299 Der dort ab 1948 als Redakteur tätige Ernst Fischer hält 1945, noch als Unterrichtsminister, vor SchriftstellerInnen und JournalistInnen eine Ansprache „zu der großen gemeinsamen und für jeden einzelnen bestehenden Verantwortung“ und betont, „daß sie als Kämpfer im gesellschaftlichen Leben stehen müssen, daß sie Stellung nehmen müssen zu den großen Fragen unserer Zeit.“300

Zeitlos zu schreiben, posthume Bücher („des livres posthumes“301) zu verfassen, sich nach „der überzeitlichen Geltung“ zu richten, könne nicht mehr Maßstab sein, so der mit einer Arbeit zu Gerhart Hauptmann promovierte Redakteur

297 Herausgeber, Verlag und Redaktion: Zum Wiederbeginn. In: Plan 1 (1945), Nr. 1, S. 1-2, hier S. 2. In dieser Hinsicht ist der Plan „das ebenso legendäre Gegenstück“ zu Alfred Anderschs und Hans Werner Richters Zeitschrift Der Ruf, die „mit einem dezidiert jungen Profil“ auf „eingreifenden Zeitkommentar“ zielt. Fischer: Zur Geschichte der deutschsprachigen Literaturzeitschriften 1945-1970, S. 15, 11. Zugleich enthält der Plan Mahnungen zur Vorsicht vor Übereifer, vor allem Ilse Aichingers berühmten „Aufruf zum Misstrauen“ im Plan 1 (1946), Nr. 7, S. 588: „Und [wir] sind doch schon wieder bereit, selbstsicher und überlegen zu werden, zu liebäugeln mit unseren Tugenden. Kaum haben wir gelernt, den Blick zu heben, haben wir auch schon wieder gelernt zu verachten und zu verneinen.“

298 Rudolf Felmayer: Der Dichter und die Zeit. In: Die Drau 1 (1950), Nr. 3, S. 6-7, hier S. 6. 299 Otto Basil, mit K. H. Waggerl, Viktor Matejka und Edwin Rollet: Der Schriftsteller und seine Verantwortung. Eine Diskussion. In: Österreichisches Tagebuch 3 (1948), Nr. 12, S. 13-15, hier S. 15.

300 Ernst Fischer: Im Kampf um ein geistiges Österreich. Aus einer Ansprache vor den Schriftstellern und Journalisten. In: Fischer: Das Jahr der Befreiung, S. 93-97, hier S. 96, 93 f. [Zuerst in: Neues Österreich, 13.06.1945.]

301 Sartre: Qu'est-ce que la littérature?, S. 34. 
Hermann Schreiber im Plan: Er sekundiert Sartre („dessen hohe Qualitäten als Dichter und Schriftsteller hier nicht zur Debatte stehen“), dass man ,sein Schicksal in seiner Epoche zu erblicken habe“302. Dies gilt nach Ansicht des aus dem Schweizer Exil zurückgekehrten Hans Weigel besonders für die ÖsterreicherInnen in ihrer ,seltsamen, vielleicht glückhaften und verpflichtenden Zwischenstation zwischen Siegern und Besiegten“; gerade sie stünden in der „Pflicht, das Gebot der Zeit richtig zu erkennen“303. Einige BeiträgerInnen aus Weigels Stimmen der Gegenwart wie etwa Jeannie Ebner richten sich gegen das Diktat, sie mögen aus ihrer Zeit schöpfen und ihre Literatur möge der Gesellschaft dienen; sie wehren sich zugleich gegen den mitschwingenden Vorwurf, die „Verfechter der reinen Kunst“ würden sich „den Aufgaben ihrer Zeit entziehen und aus der Realität zu flüchten suchen“304. Unwohl fühlt sich auch der überwiegend journalistisch tätige Hans Heinz Hahnl damit, dass sich die jungen DichterInnen zu ihrer Zeit „bekennen müssen“305, wenngleich Andreas Weber ihn - und Herbert Eisenreich - als auffallend existentialistisch geprägt ausweist: Generell werde in der Anthologie „eine geradezu orthodox-existentialistische Ambition deutlich“, eine „Art ,Austro-Existentialismus` auf der Basis eines eher inkonsequenten Sartre/Camus Halbverständnisses“, dessen Ziel, so deutet Weber an, eine beschreibende Literatur sei, die „Darstellungsformen für das ,Wesen(tliche) s sucht und Fragen stellt, ohne sich Antworten anzumaßen“306. Der Nutzen eines solchen Schreibens erschließt sich Hahnl nach eigenen Aussagen nur bedingt, zumal gegenüber einer desinvolvierten LeserInnenschaft:

Man fordert von ihm [dem jungen Autor], daß er eine soziale Funktion erfülle und ist enttäuscht, wenn er, in diesem gesellschaftlichen Chaos und mit einem ungeistigen Kino- und Fußballpublikum, das jede Regung, die über die Bequemlichkeit geht, ignoriert, ein Einzelgänger wird. Man stellt ihm öffentliche Aufträge (oder tut so), die von der Ignoranz der schöpferischen Entwicklung und dem Geist des Journalismus und der Propaganda diktiert sind, und ist enttäuscht, wenn diese Aufträge oder vielmehr Aufrufe keinen Widerhall finden. ${ }^{307}$

Mag das SchriftstellerInnen-Dasein auch „eine seltsame, absonderliche Art zu existieren, asozial, einsam, verdammt ${ }^{\text {“308 }}$ sein und ungehört bleiben, ist es für

302 Hermann Schreiber: Der Bruch mit dem Intellektualismus. In: Plan 1 (1946/47), Nr. 12, S. 929-937, hier S. 933.

303 Weigel: Das verhängte Fenster, S. 397.

304 Ebner: Der Künstler und die Welt, S. 148.

305 Hahnl: Zur Situation der Literatur, S. 21.

306 Weber: Stimmen der Gegenwart, eine Anthologie, S. 24.

307 Hahnl: Zur Situation der Literatur, S. $23 \mathrm{f}$.

308 Ingeborg Bachmann: [Rede zur Verleihung des Anton-Wildgans-Preises]. In: Bachmann: Werke, Bd. 4, S. 294-297, hier S. 294. 
Ingeborg Bachmann dennoch ganz „auf ein Du gerichtet“ in seinem Willen, „der Gestalt der Welt, [...] den Zügen des Menschen in dieser Zeit“309 Ausdruck zu verleihen. Die konkrete Aufgabe der Literatur sei es, so Bachmann in ihrer Rede „Die Wahrheit ist dem Menschen zumutbar“ (1959), den „großen geheimen Schmerz“ der conditio humana abzubilden; sie müsse ihn

wahrhaben und noch einmal, damit wir sehen können, wahrmachen. Denn wir wollen alle sehend werden. [...] Wir sagen sehr einfach und richtig, wenn wir in diesen Zustand kommen, den hellen, wehen, in dem der Schmerz fruchtbar wird: Mir sind die Augen aufgegangen. [...] Und das sollte die Kunst zuwege bringen: daß uns, in diesem Sinne, die Augen aufgehen. ${ }^{310}$

Literatur soll auf genau diese Weise sehen machen, geht es nach Sartre, der bei der ersten UNESCO-Generalkonferenz im November 1946 in Paris zur Veranschaulichung seiner Überlegungen ein Glas heranzieht:

Wenn ich „das Glas“ sage, so ändere ich zwar scheinbar nichts. Aber wenn ich es benenne, lasse ich es für mich und für meinen Nebenmann, der es vielleicht nicht gesehen, vielleicht eine allgemeine Wahrnehmung hatte, in der das Glas in allem übrigen unterging, aus dem Schatten hervortreten. Folglich existiert es von diesem Moment an für ihn, und so bescheiden diese Veränderung auch sein mag, seine Welt hat sich dadurch verändert. Es gibt für ihn jetzt einen Gegenstand, der existiert und der vorher nicht existierte. ${ }^{311}$

(Il est vrai que si je dis: le verre, en apparence je ne change rien. En fait, si je le nomme, je le fais sortir de l'ombre pour moi et pour mon voisin, qui peut-être ne l'avait pas vu, qui peut-être avait une perception globale dans laquelle le verre était perdu au milieu du reste. Par conséquent, dès ce moment, il existe pour lui, et de ce fait, si humble que soit le changement, son univers est changé. Il y a maintenant pour lui un objet qui existe et qui, auparavant, n'existait pas. $)^{312}$

Diese Art des Aufdeckens ist konsensfähig für viele AutorInnen mit oder ohne Beziehung zum Existentialismus. Noch 1989 plädiert Christoph Ransmayr anlässlich der Verleihung des Anton-Wildgans-Preises dafür, „daß auch ein einziges Buch alles leisten sollte, was der Literatur insgesamt zugetraut wird“, ein

309 Ingeborg Bachmann: Die Wahrheit ist dem Menschen zumutbar. Rede zur Verleihung des Hörspielpreises der Kriegsblinden. In: Bachmann: Werke, Bd. 4, S. 275-277, hier S. 276. [Zuerst in: Der Kriegsblinde 10 (1959), Nr. 8.]

310 Bachmann: Die Wahrheit ist dem Menschen zumutbar, S. 275.

311 Jean-Paul Sartre: Die Verantwortlichkeit des Schriftstellers. Vortrag zur Gründung der UNESCO am 1. November 1946 an der Sorbonne. In: Sartre: Schwarze und weiße Literatur. Aufsätze zur Literatur 1946-1960. Hg. und mit einem Nachwort von Traugott König. Übersetzt von Traugott König, Gilbert Strasmann und Elmar Tophoven. (Gesammelte Werke in Einzelausgaben, Schriften zur Literatur 5.) Reinbek 1984, S. 17-38, hier S. 20.

312 Sartre: La Responsabilité de l'écrivain, S. $16 \mathrm{f}$. 
aus Qu'est-ce que la littérature? bekannter Gedanke, der auch bei ihm in die Erwartung mündet, die Literatur solle „enthüllen““313. Die LeserInnen haben für Sartre wesentlich daran Anteil: Das zu Enthüllende offenbare sich ihnen nicht als etwas Evidentes, sondern als verworrenes und widersprüchliches Gewebe („tissu embrouillé et contradictoire“314), sie sollten Szenen voll von Zweifeln, Erwartungen, Unfertigem ausgeliefert werden, denen gegenüber sie sich in weiterer Folge nicht mehr unbeteiligt geben könnten. Die Absicht sei,

\begin{abstract}
daß jede Figur eine Falle ist, daß der Leser darin gefangen und von einem Bewußtsein in ein andres geworfen wird [...], daß er noch die Ungewißheit der Helden, ihre Unruhe teilt, von ihrer Gegenwart überwältigt, unter dem Gewicht ihrer Zukunft niedergebeugt, von den Wahrnehmungen und von ihren Gefühlen eingeschlossen wie von unübersteigbaren hohen Felswänden ${ }^{315}$.

([...] que chaque personnage soit un piège, que le lecteur y soit attrapé [...] qu'il soit incertain de l'incertitude même des héros, inquiet de leur inquiétude, débordé par leur présent, pliant sous le poids de leur avenir, investi par leurs perceptions et par leurs sentiments comme par de hautes falaises insurmontables) ${ }^{316}$.
\end{abstract}

Der Rezeptionsseite misst der Existentialismus höchste Bedeutung bei: Werke hätten nur Wert in dem Maß, in dem andere sie aufnähmen („n'ont de valeur que dans la mesure où les autres les reprennent“،317), die LeserInnen konstituieren sie dabei ebenso wie die VerfasserInnen. Dieser Schritt lässt sich laut Ingeborg Bachmann, deren eigenes engagiertes Schreiben sich einer klaren Oppositionsbildung von autonomer und politischer Literatur entgegenstellt, ${ }^{318}$ nur schwerlich steuern: Zwar legt sie als erste Poetik-Gastdozentin der Universität Frankfurt in ihrer Vorlesung (1959/1960) die Weltveränderung als Aufgabe der Dichtung nahe, doch ein Anspruch, „zumindest die Welt zu

313 Christoph Ransmayr: Hiergeblieben. Sehr geehrte Damen und Herren! In: Ransmayr: Die Verbeugung des Riesen, S. 84-89, hier S. 86 (Hervorhebung im Original).

314 Sartre: Qu'est-ce que la littérature?, S. 224.

315 Sartre: Was ist Literatur?, S. 174.

316 Sartre: Qu'est-ce que la littérature?, S. 226.

317 Sartre: Sartre, S. 61. In der Bundesrepublik Deutschland wird diese Aufwertung der LeserInnen-Rolle durch Sartres Was ist Literatur? besonders im Umfeld der Konstanzer Schule registriert, wobei sich in der Rezeptionsästhetik „das gesellschaftskritische Element nur in verdünnter Form als gesellschaftsbildende Kraft der Literatur“ erhält. Cf. Peter Uwe Hohendahl: Einleitung. In: Hohendahl (Hg.): Sozialgeschichte und Wirkungsästhetik. Dokumente zur empirischen und marxistischen Rezeptionsforschung. Frankfurt am Main 1974, S. 9-48, hier S. 44.

318 Cf. dazu Christine Lubkoll, Manuel Illi und Anna Hampel: Politische Literatur. Begriffe, Debatten, Aktualität. Einleitung. In: Lubkoll, Illi und Hampel (Hg.): Politische Literatur. Begriffe, Debatten, Aktualität. Stuttgart 2018, S. 1-10, hier S. 6. 
verändern“, sei „völlig sinnlos“319, da die Wirkung des eigenen Schreibens wenig beeinflussbar sei.

Bachmann, die Sartre und Beauvoir beim Kongress der europäischen AutorInnenvereinigung „Comunità europea degli scrittori“ (COMES) in Leningrad im August 1963 hätte begegnen sollen, aber kurzfristig absagt, ${ }^{320}$ kommt mit der engagierten Literatur bei den Treffen der „Gruppe 47“ in Deutschland vertiefend in Kontakt. Dieser Literatur-Transfer aus zweiter Hand erreicht auch andere österreichische AutorInnen wie Milo Dor und Herbert Eisenreich, besonders aus Weigels Kreis, den man durch die personellen Überschneidungen mit der „Gruppe 47“ bald „im Wiener Literatenjargon die ,Gruppe 4 Komma sieben“،321 nennt. Die „Gruppe 47“ verleiht 1952 ihren Preis an Ilse Aichinger, 1953 an Ingeborg Bachmann. Auch wenn viele der österreichischen AutorInnen, die „keinen gebührenden Platz“ im literarischen Feld ihres eigenen Landes finden, Anerkennung in Deutschland suchten und auch fanden, ${ }^{322}$ war doch „,nie [...] ein Land exotischer als dieses Deutschland, und nie waren Leute wunderlicher als diese ,Gruppe 47““, so Bachmann, die die seinerzeitigen literarischen Felder deutlich voneinander abgrenzt:

Im Jahr 1952 wußte man in Österreich so gut wie nichts über neue deutsche Schriftsteller. Hin und wieder fuhr jemand, der Paß und Visum hatte, nach Deutschland, das ferner schien als jedes andre Land, einige wenige ,Pioniere‘, die dann erzählten, es wäre zuviel gesagt, daß man [aus] jenen Erzählungen klug hätte werden können. ${ }^{323}$

Das Engagement ist ein wichtiger Faktor für die „Gruppe 47“, deren Name vom Sartre- und Camus-Übersetzer Hans Georg Brenner erdacht wurde. Auch landen Texte von den Tagungen der Gruppe in den Temps modernes, so vom deutschen Autor Hans Erich Nossack (worüber auch das Besatzungs-Bulletin Kulturelles am 4. April 1949 berichtet), der damit ohne Verzug in der öffentlichen Wahrnehmung zum Existentialisten wird. Gefragt, ob er diese Klassifi-

319 Bachmann: [Rede zur Verleihung des Anton-Wildgans-Preises], S. 296f. Cf. das Kapitel „Fragen und Scheinfragen“ in Ingeborg Bachmann: Frankfurter Vorlesungen. Probleme zeitgenössischer Dichtung. München 1980, S. 6-23.

320 Cf. Hans Magnus Enzensberger: Tumult. Berlin 2014, S. 11.

321 Beer: Immer noch Kafka ... In: Die Zeit, 13.08.1953.

322 Cf. Kriegleder: Die Literatur der fünfziger Jahre in Österreich, S. 39. Dies gilt besonders für experimentelle Künstler, für die die Lage in Österreich bis in die sechziger Jahre hinein denkbar schlecht ist: Der Traditionalismus des kulturellen Feldes, der alle öffentlichen Subventionen „ausschliesslich in konservative kanäle“ leitet, treibt sie laut Rühm (das phänomen „wiener gruppe“, S. 29) vor allem nach Deutschland, „wo damals das kulturelle klima für kunst, wie wir sie vertraten, sehr viel günstiger war.“

323 Bachmann: [Gruppe 47] Entwurf, S. 325, 323. 
zierung annehmen würde, antwortet Nossack, er sei „zu unphilosophisch“, um dies zu ermessen:

Das ist, historisch gesehen, ganz einfach, weil Sartre den ,Untergang‘ schon 47 in die ,Temps Modernes' übernahm. Als die Leute das hörten, sagten sie: Aha, ein Existentialist. Da hatten sie einen Aufhänger. Ich wußte noch nicht einmal, was das ist: Existentialismus. Das ist genau die historische Entwicklung, dadurch, daß Sartre das gemacht hat. Ich meine, vielleicht bin ich in seinem Sinne Existentialist, aber ich selbst weiß das nicht genau. Und wenn Leute mich fragen: Was ist das eigentlich, Existentialismus? Dann sage ich: Ja, ich weiß das auch nicht genau. Das können Sie mir glauben: so ist das gekommen. ${ }^{324}$

Zwar spielt Sartre als engagierter Intellektueller für den Literaturbetrieb Nachkriegsdeutschlands eine wesentliche Rolle ${ }^{325}$ und wird vielen „zum Leitbild ihres Selbstverständnisses“, doch nimmt laut Rahner eigentlich nur die „Gruppe 47“ das existentialistische Deutungsangebot „einhellig positiv“326 auf. Großes Gewicht kommt in diesem Zusammenhang Alfred Andersch zu, der in der an sich programmlosen Gruppe „das einzige erfrischende Widerstandszentrum der reichlich angejahrten Literaturjugend“327 sieht, antretend gegen „gewisse Snobs der älteren ästhetischen Schule“, die „dem Verfasser von Was ist Literatur? mangels Argumenten nur noch mit einem larmoyanten Lächeln“ begegnen. Hans Werner Richter, dessen Lebenswerk die Gruppe ist, setzt ebenfalls auf Literatur „als gesellschaftspolitisches Instrument“328, so dass die Texte

324 Manfred Durzak: Gespräche über den Roman, mit Joseph Breitbach, Elias Canetti, Heinrich Böll, Siegfried Lenz, Hermann Lenz, Wolfgang Hildesheimer, Peter Handke, Hans Erich Nossack, Uwe Johnson, Walter Höllerer. Formbestimmungen und Analysen. Frankfurt am Main 1976, S. 375.

325 Cf. Thomas Ernst: Literatur und Subversion. Politisches Schreiben in der Gegenwart. Bielefeld 2013, S. 26.

326 Rahner: Selbst- und Fremdwahrnehmungsmuster, S. $131 \mathrm{f}$.

327 Andersch: Jugend am Schmelzpott einer Kultur, S. 286f. Anderschs intensive Auseinandersetzung mit dem Existentialismus ist inzwischen weitgehend untersucht; cf. Norman Ächtler: Zwischen Existenzialismus und Strukturalismus, Engagement und Degagement - Alfred Anderschs Poetik des Beschreibens. In: Ächtler (Hg.): Alfred Andersch. Engagierte Autorschaft im Literatursystem der Bundesrepublik. Stuttgart 2016, S. 111-131. Cf. auch Anja Koberstein: „Gott oder das Nichts“. Sartre-Rezeption im frühen Nachkriegswerk von Alfred Andersch im Kontext der zeitgenössischen Existentialismusdiskussion. (Beiträge zur Literatur und Literaturwissenschaft des 20. Jahrhunderts 15.) Frankfurt am Main et al. 1996. Cf. weiters Jörg Döring: Westdeutscher Nachkriegsexistentialismus im Frühwerk von Alfred Andersch. In: Braese und Vogel-Klein (Hg.): Zwischen Kahlschlag und Rive Gauche, S. 125-152.

328 Sabine Cofalla: Die Gruppe 47: Dominante soziale Praktiken im literarischen Feld der Bundesrepublik Deutschland. In: Joch und Wolf (Hg.): Text und Feld. Bourdieu in der literaturwissenschaftlichen Praxis. (Studien und Texte zur Sozialgeschichte der Literatur 108.) Tübingen 2005, S. 353-369, hier S. 367. 
der Mitglieder bisweilen „mit einer Literatur des Engagements“ gleichgesetzt werden, konkret mit dem „Begriff von Engagement, Involviert-Sein und Pflicht zur Stellungnahme, den Sartre in Was ist Literatur? entwickelt hatte“3329, so Helmut Peitsch. Mag es diesbezüglich auch „,an begrifflicher Prägnanz “330 mangeln, lassen die literaturtheoretischen Äußerungen der „Gruppe 47“ doch „bis in die Diktion hinein die Adaptation der Sartre’schen Begrifflichkeit“331 erkennen.

Es ist schließlich Peter Handke, ein diese Art von literarischem Engagement missbilligender und am Gruppengeschehen bis dato recht unbeteiligter Teilnehmer, der das Ende der Institution vorantreibt. Bei der ansonsten eher matten Tagung 1966 in Princeton erregt er Aufsehen, indem er die „Beschreibungsimpotenz ${ }^{\text {“332 }}$ der deutschen Gegenwartsliteratur moniert, also das reine Beschreiben beanstandet, das vielmehr ein Mittel sein müsse, „über das Verhältnis von Ding und Bezeichnung, von Sprache und Wirklichkeit nachzudenken“‘333. Seinem Verleger Siegfried Unseld prophezeit Handke 1967, der „Rückschlag in einen trivialen Realismus“ ende bald: „Die Zeit der engagierten Literatur ist vorbei, es kommt eine Zeit der Reflexion, hoffe ich, eine Zeit des Nachdenkens über Denkschablonen, vielleicht ein sprachlicher Realismus statt eines beschreibenden. “334 In der Zeitschrift Akzente äu-

329 Helmut Peitsch: Zur Vorgeschichte des Hamburger Streitgesprächs deutscher Autoren aus Ost und West: Die Rezeption des Konzepts „Engagement“ in der BRD und in der DDR. In: Hanuschek, Hörnigk und Malende (Hg.): Schriftsteller als Intellektuelle. Politik und Literatur im Kalten Krieg. (Studien und Texte zur Sozialgeschichte der Literatur 73.) Tübingen 2000, S. 307-330, hier S. 308.

330 Christian Sieg: Die „engagierte Literatur“ und die Religion. Politische Autorschaft im literarischen Feld zwischen 1945 und 1990. (Studien und Texte zur Sozialgeschichte der Literatur 146.) Berlin, Boston 2017, S. 11.

331 Rahner: Jean-Paul Sartre als Modell des Intellektuellen, S. 335.

332 Peter Handke: Zur Tagung der Gruppe 47 in den USA. In: Handke: Meine Ortstafeln. Meine Zeittafeln, S. 47-52, hier S. 47. [Zuerst in: konkret, Juni 1966.]

333 Jörg Magenau: Princeton 66. Die abenteuerliche Reise der Gruppe 47. Stuttgart 2015, S. 184; cf. S. 142: Berührungspunkte mit Sartres Enthüllungspoetik bietet Handkes Faszination „bei jedem Satz darüber, dass man etwas sagen konnte und das Gesagte damit tatsächlich existierte." Ein weiterer Aspekt, der ihm aus Sartres Frühwerk imponiert, ist der La NauséeHeld „Roquentin, in der Fleischlichkeit und in der Aggressivität und Auswucherung der Dinge, die er wahrnimmt. “ Peter Handke: Aber ich lebe nur von den Zwischenräumen. Ein Gespräch, geführt von Herbert Gamper [1987]. Frankfurt am Main 1999, S. 232. Hans Mayer (Die umerzogene Literatur, S. 54 [Hervorhebung im Original]) hebt Camus' Einfluss auf Handke hervor: „Die frühen Erzählungen Peter Handkes sind undenkbar ohne Camus, also ohne den ,Fremden', ohne die ,Pest', ohne die sonderbare Privatphilosophie eines modernen Sisyphus.“ 334 Peter Handke: Brief vom 27.01.1967. In: Handke und Unseld: Peter Handke und Siegfried Unseld. Der Briefwechsel. Hg. von Raimund Fellinger und Katharina Pektor. Berlin 2012, S. 59. 
ßert sich Handke dann unmissverständlich gegen AutorInnen, die „kritiklos die literarischen Formen jener Gesellschaft verwenden werden, die sie zu kritisieren glauben“:

Ich selber bin nicht engagiert, wenn ich schreibe. Ich interessiere mich für die sogenannte Wirklichkeit nicht, wenn ich schreibe. Sie stört mich. Wenn ich schreibe, interessiere ich mich nur für die Sprache [...]. Es wäre mir widerlich, meine Kritik an einer Gesellschaftsordnung in eine Geschichte zu verdrehen oder in ein Gedicht zu ästhetisieren. Das finde ich die scheußlichste Verlogenheit: sein Engagement zu einem Gedicht zu verarbeiten, Literatur daraus zu machen, statt es gerade heraus zu sagen. ${ }^{335}$

Engagement zu Gedichten zu verarbeiten, sieht auch Sartre nicht vor, allerdings weil die Gattung der Lyrik seiner Ansicht nach Worte als Dinge und nicht als Zeichen behandelt, womit sie der Möglichkeit, auf etwas ihr Äußerliches zu verweisen, und damit einer enthüllenden Qualität entbehre. ${ }^{336}$ Behaupten auch manche DichterInnen nicht ohne Provokation, unter ihnen Bachmann, das Gedicht habe „keine Funktion und kümmert mit Recht niemand“337, gießen andere entsprechende poetologische Überlegungen zum Engagement in Gedichtform, so die an sich eher anti-existentialistisch eingestellte Jeannie Ebner in „Entscheidung“:

Tot zu sein ist ein Zustand,

lebendig zu sein ist ein Werk, das unsere Entschließung beansprucht.

Hier nur ist es uns möglich, das Unsre zu tun,

dort nur - zu sein. ${ }^{338}$

Dass Lyrik sich nicht auf den, wie Sartre formuliert, Moment des Durchatmens und der Rückkehr zu sich (,le moment de respiration où l'on revient sur soi““339) beschränkt und durchaus über kommunikative Eigenschaften verfügt, lässt Alfred Andersch im Gedicht „Andererseits“ wissen, einer Hommage an Sartre, in deren dreigeteilter Struktur man laut Feindt den Aufbau von Sartres Qu'est-ce que la littérature? (,[q]u'est-ce qu'écrire?“, „,[p]ourquoi écrire?“, „[p]our

335 Peter Handke: Wenn ich schreibe. In: Akzente 13 (1966), Nr. 5, S. 467.

336 Cf. Sartre: Qu'est-ce que la littérature?, S. 13-44.

337 Ingeborg Bachmann: [Wozu Gedichte?]. In: Bachmann: Werke, Bd. 4, S. 303-304, hier S. 303. Hermann Korte sieht gerade in Bachmanns erstem Gedichtband Die gestundete Zeit (1953) „Spuren der Auseinandersetzung mit Jean-Paul Sartre und Albert Camus“, konkret in ihrer „Poetik der Erinnerung an Gewalterfahrungen“, verbunden „mit appellativer Zeitkritik und einem existenzialistisch gefärbten Gestus des Widerstands gegen restaurative Entwicklungen“. Korte: Österreichische Literatur der Gegenwart. Stuttgart 2016, S. 36.

338 Jeannie Ebner: Entscheidung. In: Tür an Tür. Die neue Folge, 1951, S. 153.

339 Jean-Paul Sartre: L'Écrivain et sa langue. [Interview mit Pierre Verstraeten.] In: Sartre: Situations IX, S. 40-82, hier S. 61. [Zuerst in: Revue d'Esthétique 3/4, 1965.] 
qui écrit-on?“) wiedererkennen kann. ${ }^{340}$ Auf Überlegungen zur littérature engagée folgt zuletzt eine Liebeserklärung an ihren berühmtesten Verfechter:

andererseits
schreibe ich schon lange
nicht mehr nur
für mich [...]
seit einiger zeit
weiß ich
daß ich
schreibend
für andere
schreibe
literatur ist
mitteilung
[...]
die anderen
seien die hölle
hat sartre gemeint
von allen schriftstellern
meiner zeit
derjenige der mich
am stärksten
bewegt hat
ich liebe sartre
ich bewundere viele schriftsteller
einige liebe ich

Auffällig ist die Anzahl der am Existentialismus interessierten AutorInnen, die unbekümmert von Sartres Gattungstrennung Lyrik verfassen, teils traditionelle, teils experimentell-avantgardistische, teils selbst eine poésie engagée, ${ }^{342}$ wie zum

340 Cf. Feindt: Engagement, empathie, distanciation, S. 75.

341 Alfred Andersch: Andererseits. In: Andersch: empört euch der himmel ist blau. Zürich 1977, S. 103-108, hier S. 103, 105. Eine theoretische Existentialismus-Betrachtung liefert Andersch vor allem in „Deutsche Literatur in der Entscheidung. Ein Beitrag zur Analyse der literarischen Situation (1948)“. In: Haffmans (Hg.): Das Alfred Andersch Lesebuch. Zürich 1979, S. 111-134.

342 Die junge Generation, so René Ferriot, hat teils erfahren, wie sich Lyrik in Kriegszeiten durch Form und Sprache „manches erlauben [konnte], was der Prosa längst verboten war. So wurde die Dichtung oft ein Mittel zum Zweck, den geknechteten Menschen die Freiheit zu verkünden." Ferriot: Junge Dichtung in Frankreich. In: Plan 1 (1946), Nr. 4, S. 329-331, hier S. 331. Für eine Diskussion der Zwecke engagierter Lyrik cf. auch Andreas Okopenko: Engagement. In: Okopenko: Erinnerung an die Hoffnung, S. 207-226, insbesondere S. 224. 
Beispiel Walter Buchebner, dessen Gedicht „die revolte“ wiederholt aufruft, „eine revolte [zu] entfesseln“ und „den schutt / der literatur“ beiseitezuschieben:

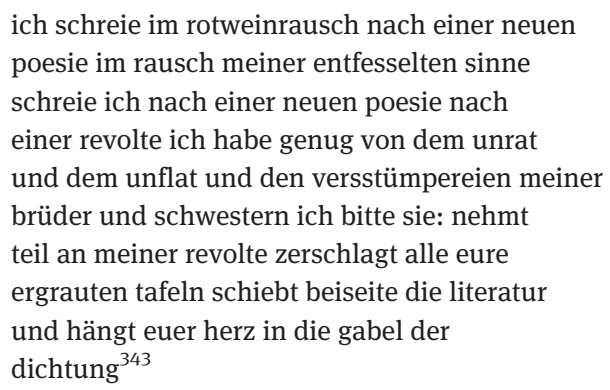

$\mathrm{Zu}$ dieser Zeit, in den späten fünfziger und frühen sechziger Jahren, verwendet auch Ernst Jandl experimentelle Verfahren für gesellschaftskritische Gedichte wie „wien: heldenplatz“ oder „schtzngrmm“. Seine Intention ist unmissverständlich:

Ich versuche, meinen Gedichten gesellschaftliche Aufgaben zu stellen. [...] Immer ist, was einer schreibt, wenn es überhaupt Bedeutung hat, ein Eingriff in die Vorstellungen des Lesers, so wie der Autor selbst mit jedem neuen Text, wenn dieser überhaupt Bedeutung hat, seine eigenen Vorstellungen nicht nur von Kunst, sondern von der Welt erweitert, ändert. Das ist, glaube ich, politisch. [...] Was wir brauchen, sind Worte, die in eine Richtung weisen; ob wir sie einschlagen, oder eine andre wählen, in jedem Fall sind wir herausgefordert, aktiv zu sein. ${ }^{344}$

Unter den in der restaurativen Nachkriegssituation marginalisierten modernen KünstlerInnen lässt sich nicht nur eine ,teils sprachkritische, teils politisch engagierte Richtung“345 erkennen, sondern in vielen Fällen eine Überschneidung der Bereiche. Zurückzuführen dürfte dies unter anderem auf das parallele Kennenlernen von voneinander abweichenden literarischen Strömungen sein, bedingt durch die Präferenzen einzelner VermittlerInnen. Dies erwähnt Okopenko, der etwa von H. C. Artmann Sartres Der Ekel erhält, wie er am 23. August 1950 in sein Tagebuch notiert: ${ }^{346}$ „Besonders Artmann und Eisenreich schleppten riesige Bestände an

343 Buchebner: die revolte, S. 162, 165 (Hervorhebung im Original).

344 Ernst Jandl: Aufgaben. In: Autor in Gesellschaft. Aufsätze und Reden. Hg. von Klaus Siblewski. (poetische werke 11.) München 1999, S. 61.

345 Kriegleder: Die Literatur der fünfziger Jahre in Österreich, S. 37.

346 Andreas Okopenko: Tagebücher 1949-1954. Digitale Edition. Hg. von Roland Innerhofer et al., Österreichische Nationalbibliothek und Universität Wien. https://edition.onb.ac.at/oko penko (einges. 15.02.2019). Okopenko, der Sartres Schreiben und Tun kritisch, aber mit großem Interesse verfolgt, macht dieser Roman „sehr optimistisch“ (20.08.1950). Spätere Sartre-Prosa leiht sich Okopenko dann laut seinen Aufzeichnungen auch von Gerhard Fritsch (cf. 19.04.1953). Die Tagebücher erwähnen darüber hinaus Diskussionen zu Sartre in der Redaktion der viele 
wichtigen Büchern und Informationen herbei. “347 Für die Mitglieder der später so genannten „Wiener Gruppe“, die „im selbststudium mühsam kenntnisse über die avantgardistischen bewegungen europas (und auch österreichs) vor dem kriege erworben“348 haben, kann von einem systematischen Nachholen nach 1945 keine Rede sein, berichtet Rühm: „man musste zunächst einmal die wichtigsten namen und titel herausfinden, um überhaupt zu wissen, wonach man suchen sollte. “349 Die „bruchstückhaften informationen“ zu allem, was sich zwischenzeitlich international ereignet hat, wurden „gierig aufgenommen, weitergereicht, mühsam zu einem bild zusammengefügt“ ${ }^{\star 350}$, das weniger ein Nebeneinander als eine Durchdringung von verschiedenen Stilrichtungen darstellt. Diese beim Kulturtransfer typischen Formen von Vermischung und Hybridität (,formes de métissage et d'hybridité، ${ }^{351}$ ) betreffen nach 1945 hauptsächlich den Existentialismus und den Surrealismus, für Andreas Okopenko keineswegs ein Nachteil:

Den Eklektizismus, der sich aus dem Ansturm vieler literarischer Eindrücke zugleich ergab, habe ich nie als schimpflich, sondern immer als ganz natürlich empfunden. Wie abwegig wäre doch der Gedanke, daß ein einziger Philosoph oder Dichter den Stein der Weisen gefunden haben sollte, und wie unnatürlich die Forderung, nichts Vorhandenes aufzugreifen oder aber gerade einen einzigen nachzuahmen. ${ }^{352}$

Avantgarde-AutorInnen lancierenden Zeitschrift neue wege (28.11.1950) sowie spätere LektüreErfahrungen, die Okopenko in (diesen abwertende) Verbindung zu Sartre bringt, etwa André Gides Die Falschmünzer (05.07.1953: „Kein Vergleich auch mit dem tendentiösen, armen Sartre“) und Viktor Frankl (02.09.1950): „,Objektives Korrelat‘ zu allem Subjektiven beruhigt unendlich. Frankl ist weiter als Sartre.“ Frankls Studie Ärztliche Seelsorge. Von der Psychoanalyse zur Existenzanalyse (1946) wird selten in Relation zum Existentialismus besprochen, etwa im Wiener Kurier (-n: Zwei Bücher aus Österreich, 28.03.1946), der Frankls Werk als „die Lehre von der Freiheit der Entscheidung, von der Verantwortung jedes einzelnen seinem Schicksal gegenüber“ präsentiert. Von offensichtlichen Berührungspunkten zeugen Sätze Frankls wie: „Das menschliche Dasein ist Verantwortlich-sein, weil es Frei-sein ist“ im Kapitel „Allgemeine Existenzanalyse“ (Unterkapitel „Freiheit und Verantwortlichkeit“), oder: „Dem Zwang zur Wahl unter den Möglichkeiten entgeht der Mensch in keinem Augenblick seines Lebens.“ Viktor E. Frankl: Ärztliche Seelsorge. Grundlagen der Logotherapie und Existenzanalyse. Mit den „Zehn Thesen über die Person“. München 2009, S. 130, 131.

347 Okopenko: Meine Wege zum Schriftsteller, S. 114.

348 Peter Weibel: die wiener gruppe im internationalen kontext. In: Weibel (Hg.): die wiener gruppe, S. 763-784, hier S. 775.

349 Rühm: das phänomen „wiener gruppe“, S. 17.

350 Rühm: das phänomen „wiener gruppe“, S. 17.

351 Espagne: La Notion de transfert culturel, S. 2.

352 Okopenko: Meine Wege zum Schriftsteller, S. 114. 
Die Liste dessen, was Okopenko und seine MitstreiterInnen bei neue wege, der kulturzeitschrift junger menschen (von 1945-1948 Theater der Jugend), als modern auffassen, ist entsprechend lang:

Im Weltanschaulichen waren es linksgeneigte Sozialkritik, Kahlschlag-Nüchternheit, Existentialismus, humanistisches Anständigkeits-Ideal, zugleich Freiheit der Phantasie, Antiphilistertum; im Ästhetischen bewegte es sich vor allem zwischen der Sprachfaszination elliptischer, präziser, kondensierter Stile (Brechts, Hölderlins, Jüngers, Kafkas, Rilkes), der Eloquenz Eliots, Eluards, Whitmans, dem Bildzauber protokollierten Momentes und dem Reiz surrealen Erlebens und Ausdrucks. ${ }^{353}$

Ähnlich Okopenko, als vom Surrealismus beeinflusstem Avantgardisten, dem „die Etikette des existentialistischen Autors aufgeklebt““354 worden ist, befasst sich die junge Dichterin Hertha Kräftner nicht nur mit Sartre (cf. Kap. 5.1), sondern ebenfalls mit der Planung einer Dissertation mit dem Titel „Die Stilprinzipien des Surrealismus nachgewiesen an Franz Kafka““355. Selbst bei Konrad Bayer, den der Surrealismus „ungeheuer beeindruckt ${ }^{\star 356}$, trifft der Existentialismus auf „starkes interesse“ ${ }^{357}$, ohne dass sich dies in seinen (oder Kräftners und Okopenkos) literarischen Werken sonderlich spiegelt. ${ }^{358}$

Die Verschränkung von Surrealismus und Existentialismus illustriert auch, was die Transfertheorie unter Resemantisierung versteht, der Anverwandlung eines Kulturguts nach eigenen Bedürfnissen und Maßstäben. So urteilt Alfred Schmeller, die „surrealistische Gruppe“ in Österreich existiert, „ohne genau zu wissen, was Surrealismus wirklich ist““359, Albert Paris Gütersloh sagt aus, „daß der wienerische Surrealismus nur aus Mangel eines betreffenden Namens so heißt, also fast keine Ähnlichkeit mit dem anderswo noch geübten oder schon

353 Okopenko: Die schwierigen Anfänge österreichischer Progressivliteratur nach 1945, S. 2 f.

354 Okopenko: Engagement, S. 214.

355 Scholl: Sex, Gott und Alkohol - Hertha Kräftners „Pariser Tagebuch“, S. 130.

356 Konrad Bayer: autobiografische skizze. In: Weibel (Hg.): die wiener gruppe, S. 721.

357 Konrad Bayer. Zit. n. Englerth, Gausterer und Kaukoreit: Österreichs Literaturzeitschriften 1945-1990 im Überblick, S. 19. Bayer bietet in seinem am 03.09.1964 im Times Literary Supplement erschienenen Artikel „the vienna group“ eine weitere, quantitative Erklärung für die zeitgleiche Rezeption von im Ausland teils schon überholten Strömungen: „in those days we had to master these movements of the past in order to ward off the pre-past that was threatening to engulf us.“ Konrad Bayer. In: Weibel (Hg.): die wiener gruppe, S. 31.

358 So macht sich etwa Okopenko, der Sartres Was ist Literatur? als Jugendlektüre empfiehlt, „Mitteilung, treuherzig geglaubte, über Eindrücke und Verhalte aus einer treuherzig geglaubten Wirklichkeit“ zum sehr experimentell umgesetzten literarischen Gebot. Okopenko: Meine Wege zum Schriftsteller, S. 117.

359 Schmeller: Ein Sammelsurium, S. 33. 
abgestorbenen hat“360, und Max Blaeulich schätzt ihn schließlich als „ein ziemliches Mißverständnis“ ein: In den fünfziger Jahren wurde „viel probiert“ und „verschiedentlich surrealistisch, absurd, existentialistisch“ gearbeitet, was „nicht wirklich überliefert“" ${ }^{361}$ ist. Eines der diesbezüglichen Experimente lässt an Vians parodistische Surrealisierung existentialistischer Elemente denken, an die Figur Chick in L'Écume des jours, die zwei Vortragsmitschnitte Sartres gleichzeitig hört, um neue Ideen aus dem Zusammenprall alter Ideen hervorzubrigen (,pour faire jaillir des idées nouvelles du choc de deux idées anciennes“362):

Wir wohnen einer Nachzündung von Dada und Surrealismus bei. Es ist kein Zufall, daß so viele Maler anwesend sind. Vieles läßt sich primär von der Form her verstehen. Ein philosophischer Text von Sartre wird mit einem Bericht über indische Freudenmädchen zwei Sprecher - Satz für Satz ineinandergeschnitten. ${ }^{363}$

Verkettungen lassen sich vor allem im Bereich der Malerei und Bildhauerei beobachten, die „das sinnlos grausam existentialistische Hinausgeworfensein“364 des Menschen vergegenständlichen. Sartre selbst wundert sich angesichts der Ausdehnung seiner ,Lehre‘ bis hin zur Grafik und zur Musik über seine eigene Rolle in diesem Geschehen (,[p]uisqu'on connaît des peintres et des dessinateurs existentialistes. Et même des musiciens. Il paraît - je m'excuse de parler de moi - que j’ai quelque chose à faire là-dedans““365). Bildende Kunst und Malerei - die das Innsbrucker Institut Français als nonverbale und daher Sprachbarrieren umgehende Kunstformen besonders fördert, da sich so „eine größere Anzahl von Interessierten“366 erreichen lässt - befinden sich in Österreich nicht am Rand des existentialistischen Milieus, sondern in dessen Kern (nichts-

360 Albert Paris Gütersloh: Der unterirdische Art Club. In: Breicha (Hg.): Der Art Club in Österreich, S. 22-24, hier S. 22. [Zuerst in: Weltpresse, 11.01.1952.]

361 Max Blaeulich, Klaus Demus, Wieland Schmied, Wendelin Schmidt-Dengler (Moderation): Wie’s „wirklich“ war, oder was passiert, wenn sich die erinnern, die nicht definiert haben, wie unser Blick auf die fünfziger Jahre sein soll. In: Polt-Heinzl und Strigl (Hg.): Im Keller, S. 177196, hier S. 182, 178.

362 Vian: L'Écume des jours, S. 259.

363 Karl Maria Grimme: Dada plus Surrealismus, wienerisch akzentuiert. In: Österreichische Neue Tageszeitung, 17.04.1959.

364 Gütersloh: Der unterirdische Art Club, S. 24.

365 Sartre: La Nationalisation de la littérature, S. 37.

366 Verena Zankl und Sandra Unterweger: Frankreichs Feste im Freundesland und was darüber berichtet wurde. Die Aktivitäten der französischen Kulturverantwortlichen in Tirol 19461960. In: Klettenhammer (Hg.): Kulturraum Tirol. Literatur - Sprache - Medien. (Innsbrucker Beiträge zur Kulturwissenschaft, Germanistische Reihe 75.) Innsbruck 2009, S. 313-333, hier S. 323. 
destoweniger „blankes Unverständnis und Ablehnung،367 von der Öffentlichkeit erntend). Der „Art Club“ ist die Existentialismus-Hochburg (cf. Kap. 5.1) und zugleich „Zentrum des damaligen Surrealismus“368 mit den KünstlerInnen der Wiener Schule des Phantastischen Realismus wie Ernst Fuchs, Rudolf Hausner und Wolfgang Hutter. Hervorzuheben ist weiters die Gruppe um den aus dem Saarland stammenden Edgar Jené, mit Max Hölzer Herausgeber von Surrealistische Publikationen (1950), eine Gruppe, die „die künstlerische Freiheit“369 als gemeinsamer Nenner vereine, die aber nicht aus PhilosophInnen bestehe: „Sie versuchen nichts zu beweisen, sondern zu verändern, sie tun das nicht mit Sentenzen, sondern mit Kunstwerken.“370 In Anbetracht der Art, wie sich die meisten SurrealistInnen von der äußeren Realität abwenden hin zu „unbewußten Seelenvorgänge[n]“371, betont Jené, dass die Strömung weder Illustration noch Anwendung der Psychoanalyse sei; wohl aber ziehe man nach dem Krieg die „Kompetenz des Verstandes“372 als Trieb-Unterdrücker in Zweifel. In diesem Kontext nennt Jené die Vorzüge, die die SurrealistInnen gegenüber den ExistentialistInnen hätten:

Sie hegen die Hoffnung, die Struktur der menschlichen Seele zu verändern, den Widerspruch in ihrem Wesen zu überbrücken, unausgeschöpfte Fähigkeiten zu heben, zu einer totaleren Vision der Welt zu gelangen und dem Leben einen neuen Sinn zu geben, der nach Breton in der Liebe, der Dichtung, der Freiheit, der Revolte gefunden werden kann. Man ersieht daraus, wodurch sie sich von den Existenzialisten, den Aposteln der Verzweiflung unterscheiden. Heute, nach dem zweiten Weltkrieg, da die Situation, in die der Mensch gestellt, noch hoffnungsloser und auswegloser ist als nach dem ersten, den Menschen das Gefühl der Ohnmacht und Verlassenheit befallen hat, er sich - um mit den Existenzialisten zu sprechen - als Fremder in einer fremden Welt fühlt und aus der tragi-

367 Englerth, Gausterer und Kaukoreit: Österreichs Literaturzeitschriften 1945-1990 im Überblick, S. 19. Die vorderste Aufgabe der SurrealistInnen sei es, Skandale zu provozieren, moniert Sartre, und die österreichische Presse (die auch den Existentialismus für ein Skandalon hält) stimmt zu, dass es sich um eine „skandalöse Kunstrichtung“ handelt (Okopenko: Meine Wege zum Schriftsteller, S. 114). Der Surrealismus sorgt in den Redaktionen der ihn vermittelnden Periodika für erhebliche Spannungen, beim Plan, dessen Vorkriegsausgabe (1938, Nr. 3) ein Surrealismus-Sonderheft ist, und insbesondere bei den sich als Avantgarde-Zeitschrift verstehenden neue wege.

368 F. Hundertwasser: Ich hatte wenig mitzureden (1980). In: Breicha (Hg.): Der Art Club in Österreich, S. 41-44, hier S. 44.

369 Arnulf Neuwirth: Auf einen Nenner gebracht (1980). In: Breicha (Hg.): Der Art Club in Österreich, S. 34-45, hier S. 34.

370 Edgar Jené: Über den Surrealismus. In: Europäische Rundschau 2 (1947), Nr. 15, S. 709711, hier S. 711.

371 Walter Hollitscher: Ueber Surrealismus. In: Österreichisches Tagebuch, 12.04.1947.

372 Jené: Über den Surrealismus, S. 710. 
schen condition humaine keinen anderen Ausweg sieht als das Nichts, bedeutet der Surrealismus eine Hoffnung. ${ }^{373}$

Sartre, dessen eigene „rationalist philosophy of consciousness“374 diesem „Kampf gegen die Uebermacht von Ratio und Logik“375 ferner nicht stehen könnte, bescheinigt dem Surrealismus einen Geist der Negativität („esprit de Négativité‘(376). Problematisch aus Sicht des von der Subjektivität ausgehenden Existentialismus ist der Angriff auf alles Freiwillige und die Auflösung der Gegensätze von Wachheit und Traum, Leben und Tod, Phantasie und Wirklichkeit sowie Zukunft und Vergangenheit, auf dass sich die Welt als radikaler Widerspruch zu erkennen gebe. Aus diesem Grund kann die der Parti Communiste zwischenzeitlich nahestehende Strömung für Sartre nicht wirklich revolutionär sein: „Denn das im Kampf engagierte Proletariat muß in jedem Augenblick, um sein Unternehmen verfolgen zu können, die Vergangenheit von der Zukunft, das Reale vom Imaginären und das Leben vom Tod unterscheiden.“377 („Car le prolétariat engagé dans la lutte a besoin de distinguer à chaque instant, pour mener à bien son entreprise, le passé du futur, le réel de l'imaginaire et la vie de la mort.“378) Eine solche „Anti-littérature“379, die die Literatur selbst infrage stelle, sei nach dem Zweiten Weltkrieg unbrauchbar und zeitfeindlich, wie auch der österreichische Kritiker Herbert Eisenreich beklagt, „pure Vergangenheit“, die „an unseren Problemen kilometerweit vorbeischielt“380.

Ein tatsächliches Wiederaufleben des Surrealismus - weil sich, befördert durch Maurice Nadeaus 1945 publiziertes Standardwerk Histoire du surréalisme, vermehrt AutorInnen aus dem surrealistischen Umfeld (wie Jacques Prévert, André Breton, Michel Leiris) ${ }^{381}$ in die existentialistische Szene von Saint-Germain-des-Prés mischen - hält Sartre für ein Fehlurteil. Für ein noch größeres, dass manche ihn selbst als Chef des Neo-Surrealismus ausrufen, dem Eluard und Picasso unterstünden (,je leur en demande bien pardon et n'ai pas encore oublié, Dieu merci, que je portais encore des culottes courtes quand ils avaient

373 Jené: Über den Surrealismus, S. $710 \mathrm{f}$.

374 Sartre: Itinerary of a Thought, S. 50.

375 Jené: Über den Surrealismus, S. 709.

376 Sartre: Qu'est-ce que la littérature?, S. 182.

377 Sartre: Was ist Literatur?, S. 138.

378 Sartre: Qu'est-ce que la littérature?, S. 189.

379 Sartre: Qu'est-ce que la littérature?, S. 138.

380 Herbert Eisenreich: Surrealismus und so. In: neue wege 5 (1950), Nr. 54, S. 502-504, hier S. 503.

381 Cf. Dugast: La Situation culturelle de la France après 1945, S. 311. 
déjà la maîtrise d'eux-mêmes“382). In den Besatzungsorganen Kulturelles und Geistiges Frankreich ist der Surrealismus kaum Thema, durch den engen Kontakt zu Frankreich erscheint er als im Rückgang befindlich („en période de repli“383), während seine Präsenz in unabhängigen österreichischen Periodika jener des Existentialismus nicht nachsteht. Auch wenn er „eine Auslaufsache“384 und „in Paris schon längst in die Jahre gekommen“ sei, eine „Sackgasse[]“ unter den künstlerischen Entwicklungen, diene er AutorInnen wie Artmann, Rühm und Okopenko ,als Spielwiese ihrer ersten literarischen Versuche“, ungeachtet der von Blaeulich angeführten Tatsache, dass „schon längst andere Richtungen dominierten. Ich denke da an Camus, Beckett, Ionescu, Sartre oder die ,Gruppe 47، ،385.

Die zeitversetzte Aufnahme des Surrealismus in Österreich ist auch insofern hervorhebenswert, als die Strömung in den Zwischenkriegsjahren schon auf Sartre - wenngleich „à distance“386 gehalten - einen gewissen Einfluss hatte, wie etwa die bildlichen Traumszenen in La Nausée (1938) verdeutlichen. Die Erzählung L'Enfance d'un chef von 1939 macht einen psychoanalytisch versierten Surrealisten („qui était très versé dans la psychanalyse“387) ebenso verächtlich wie einen Jugendlichen, der écriture automatique-Gedichte kreiert - erschaffen, nach Breton, ohne jede Kontrolle durch die Vernunft und frei von ästhetischen oder moralischen Anliegen (,en l'absence de tout contrôle exercé par la raison, en dehors de toute préoccupation esthétique ou morale“388). Indem sich SchriftstellerInnen hinter der écriture automatique und der Vernichtung ihrer Subjektivität versteckten, stützten sie sich auf ein Prinzip totaler Verantwortungslosigkeit, wertet Sartre in seiner ausführlichen Analyse in Qu'est-ce que la littérature?. ${ }^{389} \mathrm{Er}$ hingegen setzt als konstruktive Methode auf die Entmystifizierung von Begriffen, um die kommunikative Funktion der Sprache zurückzugewinnen:

Die Funktion eines Schriftstellers besteht darin, die Dinge beim Namen zu nennen. Wenn die Wörter krank sind, dann ist es an uns, sie zu heilen. Statt dessen leben viele von dieser Krankheit. Die moderne Literatur ist in vielen Fällen ein Krebsgeschwür der Wörter. [...] Ich weiß: mancher Autor hat die Wörter zerstören wollen, so wie die Surrealisten Sub-

382 Sartre: La Nationalisation de la littérature, S. 37.

383 Sartre: Qu'est-ce que la littérature?, S. 304.

384 Blaeulich et al.: Wie’s ,wirklich“ war, S. 182.

385 Blaeulich: Zirkel, Kreise, Treffpunkte der österreichischen Literatur nach 1945, S. 151.

386 Sartre: Sartre, S. 37.

387 Sartre: L'Enfance d'un chef, S. 52.

388 André Breton: Manifeste du Surréalisme (1924). In: Breton: Manifestes du Surréalisme, S. 40 .

389 Sartre: Qu'est-ce que la littérature?, S. 183f., 140. 
jekt und Objekt gemeinsam zerstören wollten: das war der äußerste Punkt der Konsumtionsliteratur. Aber heute muß man, wie ich gezeigt habe, konstruktiv sein. Wenn man nicht anfängt, [...] die Unangemessenheit der Sprache gegenüber der Realität zu beklagen, macht man sich zum Komplizen des Feindes, das heißt der Propaganda. Unsere erste Aufgabe als Schriftsteller besteht also darin, die Sprache in ihrer Würde wiederherzustellen. Schließlich denken wir mit Wörtern. Wir müßten sehr dünkelhaft sein, um zu glauben, daß wir unaussprechliche Schönheiten bergen, die die Sprache auszudrücken nicht würdig ist. [...] Wenn wir den Wörtern ihre Fähigkeiten wiedergeben wollen, müssen wir eine doppelte Operation durchführen: einerseits eine analytische Reinigung, die sie von ihrem hinzugetretenen Sinn befreit, andrerseits eine synthetische Erweiterung, die sie der historischen Situation anpaßt. ${ }^{390}$

(La fonction d'un écrivain est d'appeler un chat un chat. Si les mots sont malades, c'est à nous de les guérir. Au lieu de cela, beaucoup vivent de cette maladie. La littérature moderne, en beaucoup de cas, est un cancer des mots. [...] Je sais: le propos de maint auteur a été de détruire les mots, comme celui des surréalistes fut de détruire conjointement le sujet et l'objet: c'était l'extrême pointe de la littérature de consommation. Mais aujourd'hui, je l'ai montré, il faut construire. Si l'on ne se met à déplorer [...] l'inadéquation du langage à la réalité, on se fait complice de l'ennemi, c'est-à-dire de la propagande. Notre premier devoir d'écrivain est donc de rétablir le langage dans sa dignité. Après tout nous pensons avec des mots. Il faudrait que nous fussions bien fats pour croire que nous recélons des beautés ineffables que la parole n'est pas digne d'exprimer. [...] Si nous voulons restituer aux mots leurs vertus il faut mener une double opération: d'une part un nettoyage analytique qui les débarrasse de leurs sens adventices, d'autre part un élargissement synthétique qui les adapte à la situation historique.) $)^{391}$

Diesen Weg, der beispielsweise auch in Wolfgang Borcherts „Manifest“ anklingt, demzufolge es DichterInnen braucht, die „zu Baum Baum und zu Weib Weib sagen und ja sagen und nein sagen: laut und deutlich und dreifach und ohne Konjunktiv“392, schlägt auch die Kahlschlagliteratur der „Gruppe 47“ ein. Sie verfolgt die Reinigung der Sprache mit einem knappen, harten, asketischen Stil, so Fischer, und „richtet sich gegen die ,Kalligraphie‘ der Inneren Emigration“ und „die verbrauchte, von der Realität denunzierte Sprache und die überkommenen Ideen der literarischen Tradition.“"393 Das Neue in der Literatur, formuliert ähnlich Bachmann, sei „kein Buchstabenexperiment, nicht kalligraphische Mutproben, sondern eine Radikalität, die im Denken liegt und bis zum

390 Sartre: Was ist Literatur?, S. $216 \mathrm{f}$.

391 Sartre: Qu'est-ce que la littérature?, S. 281f.

392 Wolfgang Borchert: Das ist unser Manifest. In: Borchert: Das Gesamtwerk. Hg. von Michael Töteberg unter Mitarbeit von Irmgard Schindler. Reinbek 2007, S. 517-524, hier S. 519. [Zuerst in: Der Phönix 1948. Ein Almanach für junge Menschen.]

393 Fischer: Zur Geschichte der deutschsprachigen Literaturzeitschriften 1945-1970, S. 13. 
Äußersten [geht].“394 Zweifel gegenüber der Realisierbarkeit der von Sartre propagierten Reinigung („,nettoyage“) der Sprache finden sich in Bachmanns Prosa dennoch fortwährend. Sprache, für Sartre Basis des Für-Andere-Seins (,l'êtrepour-autrui““395), bleibt hier ein Ort von Missverständnissen: „Zwischentöne“, „Halbheiten“ und „Zweideutigkeiten“396 erschweren die Kommunikation mit dem Anderen, sie werden der Realität nicht gerecht, begehen gar einen „Mordversuch an der Wirklichkeit“397. Die Zustände ließen sich nicht verändern ohne Mitveränderung der einzig verfügbaren „Gaunersprache“: „Keine neue Welt ohne neue Sprache.“398 In Bachmanns Erzählung „Das dreißigste Jahr“ heißt es erklärend:

Die Abschaffung von Unrecht, von Unterdrückung, jede Milderung von Härten, jede Verbesserung eines Zustandes hält doch noch die Schimpflichkeit von einst fest. Die Schändlichkeit, durch das Fortbestehen der Worte festgehalten, wird dadurch jederzeit wieder möglich gemacht. ${ }^{399}$

Wie zum Beweis beschreibt die Erzählung „Unter Mördern und Irren“ aus der Sammlung Das dreißigste Jahr eine in einem Mord endende Herrenrunde von Weltkriegsopfern und -tätern, unter denen Letztere mehrheitlich „leugneten und verschleierten“ und sich die Sprache zum Komplizen machten: „da knäuelt er in seinem Mund Humanität, bietet Zitate aus den Klassikern auf, bietet die Kirchenväter auf und die neuesten metaphysischen Platitüden.“400 Dass sich „das fortschwelende Unheil“ äußert, als wäre es „das Heil“, dass also dem Faschismus sprachlich weiterhin „Asyl“ gewährt wird, ruft Adornos „Jargon der Eigentlichkeit“ wach, mit dem die Ausdrucksweise von Jaspers, Heidegger, Otto Friedrich Bollnow, aber auch der französischen NachkriegsexistentialistInnen gemeint ist, die über „eine bescheidene Anzahl signalhaft einschnappender Wörter“ wie „existentiell, ,in der Entscheidung‘, Auftrag, Anruf, Begegnung, echtes Gespräch,

394 Bachmann: [Thomas Bernhard:] Ein Versuch. Entwurf, S. $361 \mathrm{f}$.

395 Der Mensch stehe „mit dem Andern durch die Sprache in direkter Verbindung“ (,en liaison directe avec autrui par le langage“), er sei Sprache: „Die Sprache ist kein dem Für-Anderesein hinzugefügtes Phänomen: sie ist ursprünglich das Für-Andere-sein, das heißt das Faktum, daß eine Subjektivität sich als Objekt für die andere erfährt.“ („Le langage n’est pas un phénomène surajouté à l'être-pour-autrui: il est originellement l'être-pour-autrui, c'est-à-dire le fait qu'une subjectivité s'éprouve comme objet pour l'autre.") Sartre: Das Sein und das Nichts, S. 477, 652 (Hervorhebung im Original). (Sartre: L’Être et le Néant, S. 304, 412.)

396 Bachmann: Das dreißigste Jahr, S. 124.

397 Ingeborg Bachmann: Ein Schritt nach Gomorrha. In: Bachmann: Sämtliche Erzählungen, S. 187-213, hier S. 208.

398 Bachmann: Das dreißigste Jahr, S. 112, 132.

399 Bachmann: Das dreißigste Jahr, S. 132.

400 Bachmann: Unter Mördern und Irren, S. 176, 177 f. 
Aussage, Anliegen, Bindung،“401 verfüge. Eine Nähe besteht Fischer zufolge zur Vorstellungswelt des Mythos und der Theologie, die sich begrifflich in Zeitschriften-Titeln wie Sammlung, Wandlung, Begegnung, Aufbau oder Der Ruf manifestiert und die als Erneuerungsrhetorik zum Teil schon den Expressionismus und das nationalsozialistische Sprechen gefärbt hat, nun allerdings dabei helfen soll, der begriffslosen Wirklichkeit „der Trümmerlandschaften, der Flüchtlingsströme und der geöffneten KZs“402 sprachlich beizukommen. Dass „antifaschistische Thesen in bester faschistischer Diktion“403 vorgetragen werden, beanstandet schon im Jahr 1946 Otto Basil; manche AutorInnen benützten „wahrscheinlich unbewußt - die ,zackige‘ Ausdrucksweise des Dritten Reiches [...], die Sätze sind betont hart und karg im Ausdruck: eine Sprache, die der Kaserne und dem Rüstungskontor eignet. “404 Es sei notwendig, so Oscar Pollak im Oktober 1945 in der Arbeiter-Zeitung, „die deutsche Sprache von der fremdenfeindlichen Verspießerung, Verkrampfung und Verballhornung zu befreien, die die Nazi ihr angetan haben. “405 Dass Sartres Sprachreinigung sich dazu nicht eignet, will Adornos Rundfunkvortrag „Engagement“ (1962) vermitteln: Anders als die engagierte Literatur, die sich der Massengesellschaft als botschaftsschweres „Geblök“ andiene, zu gefällig, um etwas umzustürzen, sollte Kunst autonom sein und durch ihre Ästhetik infrage stellen, sollte „im Schock der Unverständlichkeit“ sich mitteilen, durch ihre Sprache an der Bedeutung rütteln und „durch ihre Sinnferne vorweg gegen die positive Unterstellung von Sinn“406 rebellieren. Solche Werke, die, „durch nichts anderes als ihre Gestalt, dem Weltlauf widerstehen“ ${ }^{407}$, verfassten etwa Kafka und Beckett. Bei Kafka, auch in Herbert Marcuses Augen der „ganzen Struktur nach Rebellion“ gegen die unversöhnliche Welt, würden „die Verbindungen zur gegebenen Wirklichkeit dadurch zerschnitten, daß die Dinge bei ihren Namen genannt werden, die sich als

401 Theodor W. Adorno: Jargon der Eigentlichkeit. Zur deutschen Ideologie. Frankfurt am Main 1997, S. 4 f.

402 Fischer: Zur Geschichte der deutschsprachigen Literaturzeitschriften 1945-1970, S. 9. Cf. Müller: Die Bannung der Unordnung, S. 189, 196: So ist der Grund, warum sich die in Kapitel 6.3 beschriebene „Heimatsucher-Literatur“ derart leicht in den Literaturbetrieb der Zweiten Republik integrieren lässt, „die fast mühelose Adaptierbarkeit bestimmter Anteile ihrer Sprache und ihrer Anliegen“: „Religiös getöntes Sprechen wurde nach dem Zweiten Weltkrieg im Rahmen eines konservativen kulturellen Klimas geschätzt, auch wenn dieses Sprechen ein paar Jahre vorher für aktuelle faschistische Zwecke eingesetzt worden war.“

403 Mayer: Die umerzogene Literatur, S. 19.

404 Basil: Stimme der Jugend, S. 307.

405 Oscar Pollak: Entfaschisierung der Sprache. In: Arbeiter-Zeitung, 17.10.1945.

406 Theodor W. Adorno: Engagement. In: Adorno: Noten zur Literatur. Hg. von Rolf Tiedemann. (Gesammelte Schriften, 11.) Frankfurt am Main ${ }^{4} 1996$, S. 409-430, hier S. 413, 411.

407 Adorno: Engagement, S. 411. 
falsche Namen erweisen. Der Widerspruch zwischen dem, was der Name sagt, und dem, was ist, wird unüberwindlich.“ ${ }^{408}$

Eine Reihe von SchriftstellerInnen, unter ihnen Ilse Aichinger, leisten ab den späten 1940er Jahren mit einer „Tendenz zum Sprachexperiment“ einen Beitrag „zur skeptischen Infragestellung der Sprache selbst“ (in Aichingers Prosa kommen durch die „grotesken Elemente und die existenzialistischen Motive“ sowie „die Anklänge an Kafka“ zusätzlich noch die anderen „literarischen Parallelphänomene der Nachkriegszeit“409 zusammen). Bachmann fordert als Pionierin mit radikal poetischen Mitteln (,par des moyens radicalement poétiques“410) ebenfalls die Schattenseiten des sprachlichen Status quo heraus, wobei sich auch ihre Bemühungen innerhalb des Systems bewegen:

Denn wer die Regeln gutheißt und in das Spiel eintritt, wirft den Ball nicht übers Spielfeld hinaus. Das Spielfeld ist die Sprache, und seine Grenzen sind die Grenzen der fraglos geschauten, der enthüllt und genau gedachten, der im Schmerz erfahrenen und im Glück gelobten und gerühmten Welt.. ${ }^{411}$

Sich an die Sprache klammernd und Sartres Aufbauwillen (,il faut construire“412) folgend, übt in Jean Amérys Essay-Roman Lefeu oder Der Abbruch (1974) die Hauptfigur, der Maler Lefeu, Kritik an der als destruktiv empfundenen avantgardistischen Praxis der Gegenwartsliteratur. Diese repräsentiert das Gedicht „Pappelallee“ seiner Geliebten Irene, die damit „in gewaltsam zerhämmerten Sprachtrümmern blind herumtastet“: „Sie dichtet: Pappelalle, Pappelallee, alle Pappeln, Pappelnalle, Plapperpappel, Geplapper, Geplapper. Es kann nichts gedeihen auf diese Weise.“ ${ }^{413}$ Lefeu, auf Wittgensteinschen Pfaden, hängt ,an der Realität und ihrer Aussagbarkeit“, man müsse „streng am Sinn des Satzes haften

408 Herbert Marcuse: Konterrevolution und Revolte. Frankfurt am Main 1972, S. 120 (Hervorhebung im Original).

409 Walter Erhart: Erzählen zu keiner Stunde. Ilse Aichingers Experimente mit kalten und heißen Gesellschaften. In: Text + Kritik 2007, Nr. 175 („Ilse Aichinger“), S. 29-41, hier S. 30. Aichinger gelingt mit Die größere Hoffnung (1948) ein „Neuentwurf von Sprache, Bildern und Begriffsbestimmungen“, um nicht nur das Erleben jüdischer Kinder vor der Deportation „beschreibbar“ zu machen, sondern auch „der vom Nationalsozialismus geschändeten Sprache die Qualität als Verständigungsmittel zurückzuerobern beziehungsweise neu zu erfinden“. Evelyne Polt-Heinzl: Der Kalte Krieg schreibt Literaturgeschichte oder der Mythos vom langen Schweigen der Literatur zum Nationalsozialismus. In: Hansel und Rohrwasser (Hg.): Kalter Krieg in Österreich, S. 123-137, hier S. 135.

410 Elfriede Jelinek: La Guerre par d'autres moyens. Französisch von Yasmin Hoffmann und Maryvonne Litaize. In: europe 81 (2003), Nr. 892-893, S. 190-198, hier S. 191.

411 Bachmann: [Wozu Gedichte?], S. 304.

412 Sartre: Qu'est-ce que la littérature?, S. 281.

413 Améry: Lefeu oder Der Abbruch, S. 8. 
bleiben, im Vertrauen, daß es ihn gibt“, jenem Sinn nämlich, der sich „am Ganzen der Erfahrung verifiziert“ und der „seine Brauchbarkeit im Felde der gesellschaftlichen Kommunikation erweist“414. Weder sinnhaft noch in unmittelbarer Weise auf die Wirklichkeit bezogen, haben Irenes „Wortaufhäufungen“ ihre Zeichenfunktion eingebüßt, wodurch sich jeder „Wort- und Denkwechsel“415 mit ihr verunmöglicht. In Qu'est-ce que la littérature? antizipiert Sartre diese Gefahr: „Und dann mißtraue ich dem Unkommunizierbaren, das ist die Quelle jeder Gewalt. Wenn die Gewißheiten, deren wir uns erfreuen, uns unmöglich mitteilbar erscheinen, dann bleibt nur noch zu schlagen, zu verbrennen oder aufzuhängen.“416 („,J]e me méfie des incommunicables, c'est la source de toute violence. Quand les certitudes dont nous jouissons nous semblent impossibles à faire partager, il ne reste plus qu'à se battre, à brûler ou à pendre. “417) Doch erfährt Lefeu bald selbst, wie dem Kommunizierbaren Grenzen gesetzt sind, dass es den Worten bisweilen nicht gelingen kann, die gewissen Erlebnissen angemessenen Emotionen zu evozieren. Zum Versagen der sprachlichen Mittel vor der Wirklichkeit, welche, angewiesen auf das Wort, zugleich von ihm zerstört zu werden droht, heißt es:

Wenn selbst in crucialen Momenten einer Existenz nur Wörter sich darbieten, die durch den dokumentarischen oder auch dichterischen Verbrauch (,ein Grab in den Lüften') vollkommen ausgelaugt, also zwar sachlich durchaus be-deutend, aber dem Erlebnisfaktum nicht gemäß sind, wird der wortohnmächtige Betroffene eine Tendenz haben, auf die Aussage zu verzichten und die sich einstellenden Wortgemächte von sich zu schieben: mit Ekel. ${ }^{418}$

Mit der Einsicht, dass es keine „sachgerechte[n] Worte“ geben kann und jeder Ausdruck „zur Entwertung des Tatbestandes selber verurteilt“ ist, entwickelt Lefeu ein gewisses Verständnis „für die Demolitions-Poeten“ und sagt zuletzt wie Irene sogar „ja zur literarischen Selbsttäuschung“419. Auf mehreren Ebenen verhandelt der Roman die Debatte um Adornos Ausspruch, „nach Ausschwitz ein Gedicht zu schreiben, ist barbarisch“ ${ }^{420}$, ebenso wie die Überlegung, dass „ein konkretes Gedicht heute genauso eine Kampfansage gegen das Establishment ist wie ein ästhetisches Maoabzeichen“421. Der von Sartre und Camus be-

414 Améry: Lefeu oder Der Abbruch, S. 37, 8, 56, 71.

415 Améry: Lefeu oder Der Abbruch, S. 153.

416 Sartre: Was ist Literatur?, S. 217.

417 Sartre: Qu'est-ce que la littérature?, S. 282.

418 Améry: Lefeu oder Der Abbruch, S. 125, 122.

419 Améry: Lefeu oder Der Abbruch, S. 122, 123, 103, 127.

420 Theodor W. Adorno: Kulturkritik und Gesellschaft. In: Adorno: Kulturkritik und Gesellschaft 1, S. 11-30, hier S. 30.

421 A. K.: marginalie. In: manuskripte (1969), Nr. 25, o. S. 
einflusste Autor Alfred Kolleritsch ${ }^{422}$, von dem letzterer Ausspruch stammt, führt als Beweis das von ihm gegründete avantgardistische Blatt manuskripte an, dessen Texte durchaus „,verärgerten, demaskierten“ und den Stand der Dinge entlarvten, „,besser als eine lange Analyse der politischen Verhältnisse“423.

Die im Lichte Fritz Mauthners und Ludwig Wittgensteins wirkenden sprachskeptischen KünstlerInnen treibt das Problem, das „der alte sinn“ in „den versuchen, eine ,neue“ sinnhaftigkeit zu mobilisieren“424 überlebt, insgesamt zu neuen Lösungen. Bahnbrechend an der Herangehensweise der österreichischen Avantgarde ist laut Rühm, dass sie „mit und nicht wie die surrealisten bloss in der sprache arbeiteten“425. Oswald Wiener resümiert in Die Verbesserung von Mitteleuropa (1969), in dessen Bibliographie Sartres Das Sein und das Nichts aufscheint: „den surrealisten hat eben die kühnheit gefehlt die sprache wie einen fetzen $\mathrm{zu}$ behandeln“426. Sie hätten, erläutert Paul Kont, „nunmehr die alten Wortfetzen im Widersinne zueinandergefügt““427. Mit ihren Wortentgrenzungen und der Loslösung des Sprachmaterials von Vernunft und Willen behaupteten sie sich als ZerstörerInnen der Sprache und des Sinns, gingen dabei allerdings nie weit genug, meint auch Sartre. In seinem Diskussionsbeitrag bei der „Comunità europea degli scrittori“ am 6. Oktober 1965 in Rom äußert er, die VertreterInnen des Surrealismus wie des nouveau roman definierten sich mehr durch das, was sie ablehnen, als durch das, was sie schaffen, während eine

422 Valérie de Daran: „Traduit de l’allemand (Autriche)“. Étude d’un transfert littéraire. (Travaux Interdisciplinaires et Plurilingues 14.) Bern et al., S. 350. Neben Kolleritsch wären als weitere SprachkünstlerInnen dieser Generation, die einen (sich literarisch kaum niederschlagenden) existentialistischen Einfluss kundtun, unter anderem der Jaspers-Experte Heimrad Bäcker und Elfriede Gerstl zu nennen.

423 A. K.: marginalie, o. S. Pragmatische Gründe für die kurze Form führt Jandl an (Jandl: Aufgaben, S. 61): „Lyrik, denke ich, ist die beste Art, heute Literatur zu machen; richtig angewandt, erlaubt sie, mehr als jede andre Gattung, Schärfe, Präzision, Intensität. Langes Lesen macht müde, oder schwammig.“

424 Oswald Wiener: einiges über konrad bayer. In: Weibel (Hg.): die wiener gruppe, S. 43-49, hier S. 43. Cf. auch Weibels Bemerkung zu Wiener (Weibel: die wiener gruppe im internationalen kontext, S. 779): „während die anderen konzeptkünstler der sprache als möglichkeit der analyse und kritik noch vertrauten, mißtraute wiener gerade jenem medium, in dem er seine kritik ausdrückte, der sprache. kritik an der gesellschaft, an der wirklichkeit im medium sprache ist deshalb zweifelhaft, weil eben die sprache diese wirklichkeit, diese gesellschaft mitkonstruiert hat.“

425 Rühm: das phänomen ,wiener gruppe“, S. 19.

426 Oswald Wiener: Die Verbesserung von Mitteleuropa. Hg. und mit einem Nachwort von Thomas Eder. Salzburg und Wien 2013, S. XLIII.

427 Paul Kont: Fragen, vor die sich ein Neuer Komponist gestellt sieht. In: Stimmen der Gegenwart, 1952, S. 148-155, hier S. 155. 
wirkliche Avantgarde nicht nur Sprache benützen, sondern sie schreibend hervorbringen sollte („une avant-garde réelle suppose que l'écrivain ne se borne pas à user du langage, mais qu’il le crée en écrivant““428). Mit Sprache solle nicht gespielt werden, sie müsse eine neue Wirklichkeit konstruieren, eine neue Sicht des Realen ausdrücken, für die den Menschen noch die Worte fehlen.

Die jungen experimentellen KünstlerInnen wissen: „mit einer umwertung der begriffe, der werte, ist es niemals getan, ganz abgesehen davon, dass eine solche je schon wieder organisation voraussetzt, mindestens aber hervorruft“429, weshalb sie eine neue Wirklichkeit „mit der neuen grammatik einschmuggeln“ möchten, so Wiener:

mit der geschichte lehne ich auch die mit ihr kompromittierte sprache ab. ich schaffe die nicht ab doch dekretiere ich verrottung mittels der gesamtkunstwerke meiner gespräche. das einzelne wort ist nicht inhaltslos, nicht mehr- oder vieldeutig, es arbeitet nicht im handelsüblichen sinn der kommunikation; noch mehr, es geht da um das herauselementieren des begriffs, abtötung durch anatomie der lage. ${ }^{430}$

Als österreichische Besonderheit erfolgt die gesellschaftliche Hinterfragung „im Duktus einer akribisch-aggressiven Sprachkritik“431 und ist nicht im engeren Sinne politisch, sondern „kritik an staat und wirklichkeit durch kritik an der sprache“; sowohl das Sartresche Engagement als auch surrealistische Methoden fließen ein in diese originär ,anti-etatistische und anti-autoritäre haltung, die überschreitung der gattungsgrenzen und der grenzen von kunst und leben“ ${ }^{432}$ vorsieht. Während die Einschätzungen zur Bedeutung des Surrealismus für die österreichische Literatur weit auseinandergehen - keine Kunstrichtung habe „so tiefe Spuren in Österreich hinterlassen wie der Surrealismus“ “433,

428 Jean-Paul Sartre: Avant-garde? de quoi et de qui? In: Contat und Rybalka (Hg.): Les Écrits de Sartre, S. 421. [Zuerst in: Le Nouvel Observateur, 20.-26.10.1965.]

429 Wiener: Die Verbesserung von Mitteleuropa, S. CXLIV.

430 Wiener: Die Verbesserung von Mitteleuropa, S. XXXVII, XXXVI.

431 Rabenstein-Michel: Bewältigungsinstrument Anti-Heimatliteratur, S. 1. Cf. Friedbert Aspetsberger: Sprachkritik als Gesellschaftskritik. Von der Wiener Gruppe zu O. Wieners „die verbesserung von mitteleuropa, roman. In: Zeit- und Gesellschaftskritik in der österreichischen Literatur des 19. und 20. Jahrhunderts. Hg. vom Institut für Österreichkunde. Wien 1973, S. $145-170$.

432 Peter Weibel: vorwort. In: Weibel (Hg.): die wiener gruppe, S. 15.

433 Rüdiger Wischenbart: Zur Auseinandersetzung um die Moderne. Literarischer „Nachholbedarf“ - Auflösung der Literatur. In: Aspetsberger, Frei und Lengauer (Hg.): Literatur der Nachkriegszeit, S. 351-366, hier S. 353. 
meint Wischenbart; 1948 war sie „kurzfristig Tagesthema““434, sagt Kriegleder -, erscheint er zumindest als wichtiger Ausgangspunkt der Avantgarde, ${ }^{435}$ die von der „Wiener Gruppe“ bis zu AktionistInnen wie Hermann Nitsch, Otto Muehl, Günter Brus und Rudolf Schwarzkogler reicht, die vor allem in den sechziger Jahren mit „Sprachexperiment und politischem Engagement“436 auf sich aufmerksam machen.

Von der Chiffre ,1968“ ist Österreich dennoch „nur wenig bewegt““437, so Anton Pelinka, während diese in Frankreich und auch Deutschland sichtbar mit Sartre verbunden ist, der sein Image als eine „der einflußreichsten Identifikationspersonen der Linken, aller Protest-, Widerstands- und Befreiungsbewegungen seit dem Ende des Zweiten Weltkriegs“438 weiter festigt, nun als aufmerksamer Wegbegleiter der nächsten Generation (,le compagnon réfléchi et curieux d'une génération qui n'était pas la sienne“439). Herrscht Hoffmeister zufolge im Vergleich „eine unheimliche Friedhofstille“440 in Österreich, entsteht indes eine „neue linke, sozialkritische Literatur im Gefolge der 68er“441 mit beispielsweise Michael Scharang, der schon 1967 Camus’ Erzählung „Der Gast“ und 1968 Sartres Erzählung „Die Mauer“ dramatisiert, ${ }^{442}$ sowie Helmut Eisendle, der sich als „vom Existentialismus beeinflusst[ ]“443 erklärt. Eisendle glaubt seinerzeit an die „bewußtseins- und damit gesellschaftsverändernde

434 Kriegleder: Die Literatur der fünfziger Jahre in Österreich, S. 38. Cf. Ernst Schönwiese: Die oesterreichische Lyrik der Gegenwart. In: Études Germaniques 13 (1958), Nr. 4, S. 333-347, hier S. 340 .

435 Fischer: Zur Geschichte der deutschsprachigen Literaturzeitschriften 1945-1970, S. 16.

436 Sigrid Schmid-Bortenschlager: Die Etablierung eines literarischen Paradigmas. Hans Weigels „Stimmen der Gegenwart“. In: Walter Buchebner Gesellschaft (Hg.): Literatur in Österreich von 1950 bis 1965, S. 38-51, hier S. 38.

437 Anton Pelinka: Die Paulus Gesellschaft in Österreich. In: Benedikt et al. (Hg.): Verdrängter Humanismus, S. 852-859, hier S. 857.

438 Traugott König: Sartre, Jean-Paul. In: Jacoby (Hg.): Lexikon linker Leitfiguren. Frankfurt am Main, Olten und Wien 1988, S. 331-334, hier S. 331.

439 Badiou: L’Aventure de la philosophie française, S. 103.

440 Hoffmeister: Access Routes into Postmodernism, S. 122.

441 Englerth, Gausterer und Kaukoreit: Österreichs Literaturzeitschriften 1945-1990 im Überblick, S. 26.

442 Cf. Vorlass Michael Scharang. Literaturarchiv der Österreichischen Nationalbibliothek, Wien (LIT), Sign.: 290/W265 und 290/W270.

443 Helmut Eisendle: Dreißig Jahre danach. http://www.ejournal.at/Essay/edanach.html (einges. 09.01.2019). 
Wirkung“ der Literatur, „das engagierte Schreiben war die unerbittliche Forderung und das Kriterium was gut oder schlecht sei.“444 In seinen Kreisen wurde nach Eisendles Angaben Literatur klassenkämpferisch ,in eine politische und gesellschaftliche Schlüsselrolle gezwängt“, bloß, so musste man wie auch Sartre schließlich einsehen, „interessierte es kaum die Arbeiter, sondern bestätigte sich in einer Gesinnungsgebärde für einige wenige“:

Der Kampf der Arbeiter muss bewaffnet werden, sagten wir gerne und schlürften am Bier. Die Arbeiter wussten nichts von unserer Sympathie zu ihnen. Diese Art zu denken, zu schreiben und Literatur herzustellen, wurde bald als Kopfliteratur, Intellektuellenonanie und Hirnprosa, Reflexionsterror diffamiert. ${ }^{445}$

Auch Okopenko, der sich im Hinblick auf die enthüllende Aufgabe von Literatur als „immer engagiert“ empfindet und Engagement allgemein definiert als „Einsatz künstlerischer Mittel für Anliegen außerhalb der Kunst“, blickt ernüchtert auf die Beschränkungen dieser Jahre: „Die späten sechziger Jahre blendeten uns, indem sie nur den Einsatz für die Emanzipation der Arbeiterklasse [...] als Engagement gelten ließen.“446 Dass das österreichische 1968erEngagement insgesamt „weit weniger politisiert und radikal“ ausfällt als in Frankreich oder Deutschland, ${ }^{447}$ hat seine Ursache Braunsperger zufolge zum einen ,in der verzögerten Vergangenheitsbewältigung, zum anderen im noch nicht abgeschlossenen Prozess der österreichischen Identitätsfindung, vor die die Zweite Republik nach Kriegsende gestellt war.“448 Vor diesem Hintergrund erschließt sich das vermehrte Aufrufen Sartres und das Aufblühen einer engagierten Literatur knapp zwanzig Jahre später mit dem öffentlichen Diskurs über die nationalsozialistische Vergangenheit des Landes im Zuge der „WaldheimAffäre“ (um die Involvierung des Wehrmachtsoffiziers und späteren Bundespräsidenten Kurt Waldheim in nationalsozialistische Kriegsverbrechen) und der Wahlerfolge der RechtspopulistInnen. Wesentlich beteiligt durch ihre literarische

444 Eisendle: Dreißig Jahre danach.

445 Eisendle: Dreißig Jahre danach.

446 Okopenko: Engagement, S. 226, 228 (Hervorhebung im Original).

447 Ins Zentrum der bundesdeutschen Aufmerksamkeit gerät Sartre erneut, als er Andreas Baader am 4. Dezember 1974 in Stammheim besucht, um sich ein Bild von den als unmenschlich beschriebenen und von Hungerstreiks begleiteten Haftbedingungen zu machen, woraufhin er in den Medien, die erst 2013 volle Einsicht in die von Uneinigkeit und Distanz zeugenden Gesprächsakten erhalten, als Sympathisant der RAF stark angegriffen wurde.

448 Gudrun Braunsperger: Studentenbewegung in Österreich. In: Benedikt et al. (Hg.): Verdrängter Humanismus, S. 860-863, hier S. 861. 
Aufdeckaktionen (als „action par dévoilement“449) sind daran AutorInnen wie Thomas Bernhard (1931-1989) und die fünfzehn Jahre jüngere und seit den siebziger Jahren aktive Elfriede Jelinek, deren Werk ebenfalls „die Dinge beim Namen nennt “450. In einem weiteren Transferschritt wird Sartre schließlich als symbolischer Rückvermittler genau dieser LiteratInnen nach Frankreich dienen, deutet Valérie De Daran:

Bis in die 1980er Jahre diente Sartre weiterhin als unsichtbares Medium für den Import ausländischer Schriftsteller oder Intellektueller nach Frankreich, die sich, wie er, um den Rang des „totalen Intellektuellen“ bewarben (ohne notwendigerweise ganz dahin zu gelangen), die das Engagement (der Linken) verkörperten oder als Gründungsgewissen (der Kommunistischen Partei) auftraten. Wäre die Jelinek-Rezeption in Frankreich nicht anders ausgefallen, wenn Sartre nicht einen solchen Einfluss ausgeübt hätte? ${ }^{451}$

(Jusque dans les années 1980, Sartre continue de servir de vecteur invisible à l'importation en France des écrivains ou intellectuels étrangers qui, comme lui, postulent au rang d',intellectuel total“ (sans nécessairement y accéder pleinement), incarnent l'engagement (de gauche) ou se posent en conscience fondatrice (du parti communiste). Qu'en aurait-il été de la réception de Jelinek en France si Sartre n'avait exercé une telle influence? $)^{452}$

Prägend sind die Geschehnisse der achtziger Jahre auch für die Generation österreichischer Intellektueller, die seinerzeit erstmals in Erscheinung tritt, so für den 1954 geborenen Schriftsteller und Essayisten Robert Menasse, der sich direkt auf

449 Sartre: Qu'est-ce que la littérature?, S. 28. In der 1969 von Peter Henisch und Helmut Zenker gegründeten Zeitschrift wespennest finden sich zahlreiche sozialkritisch-engagierte Beiträge, insbesondere auch in den 1980er Jahren (cf. etwa in der Juni-Nummer 1984, Nr. 55: Jochen C. Schütze: Schreiben, Lesen als imaginäre Politik. Anmerkungen zu Sartres engagierter Literaturtheorie). Dass die Beschäftigung mit Sartres Literaturtheorie bis in die Gegenwart reicht, zeigt etwa Ruth Aspöcks 2016 in Wien erschienener autofiktionaler Text Die alte Dichterin, die Literatur und die Kunst. Ein Diskurs mit Poesie. Vor dem Hintergrund einer ersten Lektüre von Was ist Literatur? 1971 wird 45 Jahre später darin gefragt: „Wie schnell veralten Texte? Jean-Paul Sartre, der so aktuell und erfolgreich war und weltweit gelesen wurde, macht Vergleiche und Anspielungen, die Elizabeths Generation, jene, die nach dem Zweiten Weltkrieg geboren wurde, nicht, und noch weniger deren Kinder und Enkel verstehen.“ (S. 118) Die Erzählerin erbringt mit knapp 80 sich meist über mehrere Sätze erstreckenden, größtenteils unkommentiert Zitaten aus Was ist Literatur? selbst den Gegenbeweis und kommt zu dem Schluss: Sartre hat in Österreich „eine ganze Generation von Schriftstellern und Intellektuellen beeinflusst“ (S. 230).

450 Thomas Bernhard: Monologe auf Mallorca (1981). [Interview mit Krista Fleischmann.] In: Bernhard: Thomas Bernhard. Eine Begegnung. Gespräche mit Krista Fleischmann. Frankfurt am Main 2007, S. 11-89, hier S. 79.

451 De Daran: Étude d'un transfert littéraire, S. 308. [Übers. d. Verf.]

452 De Daran: Étude d'un transfert littéraire, S. 308. 


\section{Sartre als Vorbild beruft und sich so einen Ruf als „Jean-Paul Sartre-Mimikry“453 aufbaut:}

Es gibt verschiedene literarische Temperamente und Typen von Autoren; und jeder ist auf seine Art und Weise berechtigt oder notwendig. Aber ich hab für mich selbst ein ganz bestimmtes Bild von Autor. Ich möchte auch gesellschaftlich wirksam werden. Mir ist also typologisch gesehen, nicht literarisch - Sartre näher als Joyce. Mein Selbstverständnis als Autor ist der Versuch, in meiner Zeit, mit meinen Mitteln und mit möglichst großer literarischer und intellektueller Qualität ein Sartre zu werden. Und ich hab diesen Typus Autor auch immer am meisten bewundert. Es war naheliegend, dem nachzueifern. ${ }^{454}$

453 Günter Traxler: Zwischen Menasse und Sartre. In: Der Standard, 02.08.2005 (Hervorhebung im Original). Cf. Paul Jandl: Weltgeist und Waldviertel. In: Neue Zürcher Zeitung, 26.05.2004: „Spricht man von Sartre als letztem Universaltheoretiker, dann verbessert Robert Menasse: der vorletzte! Und der letzte? Ich! So ist es mit ihm. Es gibt eine naive Lust an der Provokation, die jederzeit in den Wunsch umschlagen kann, das Behauptete möge stimmen." 454 Ernst Grohotolsky: Gespräch Robert Menasse. In: Bartsch und Holler (Hg.): Robert Menasse. (Dossier 22.) Graz, Wien 2004, S. 9-23, hier S. 19. 